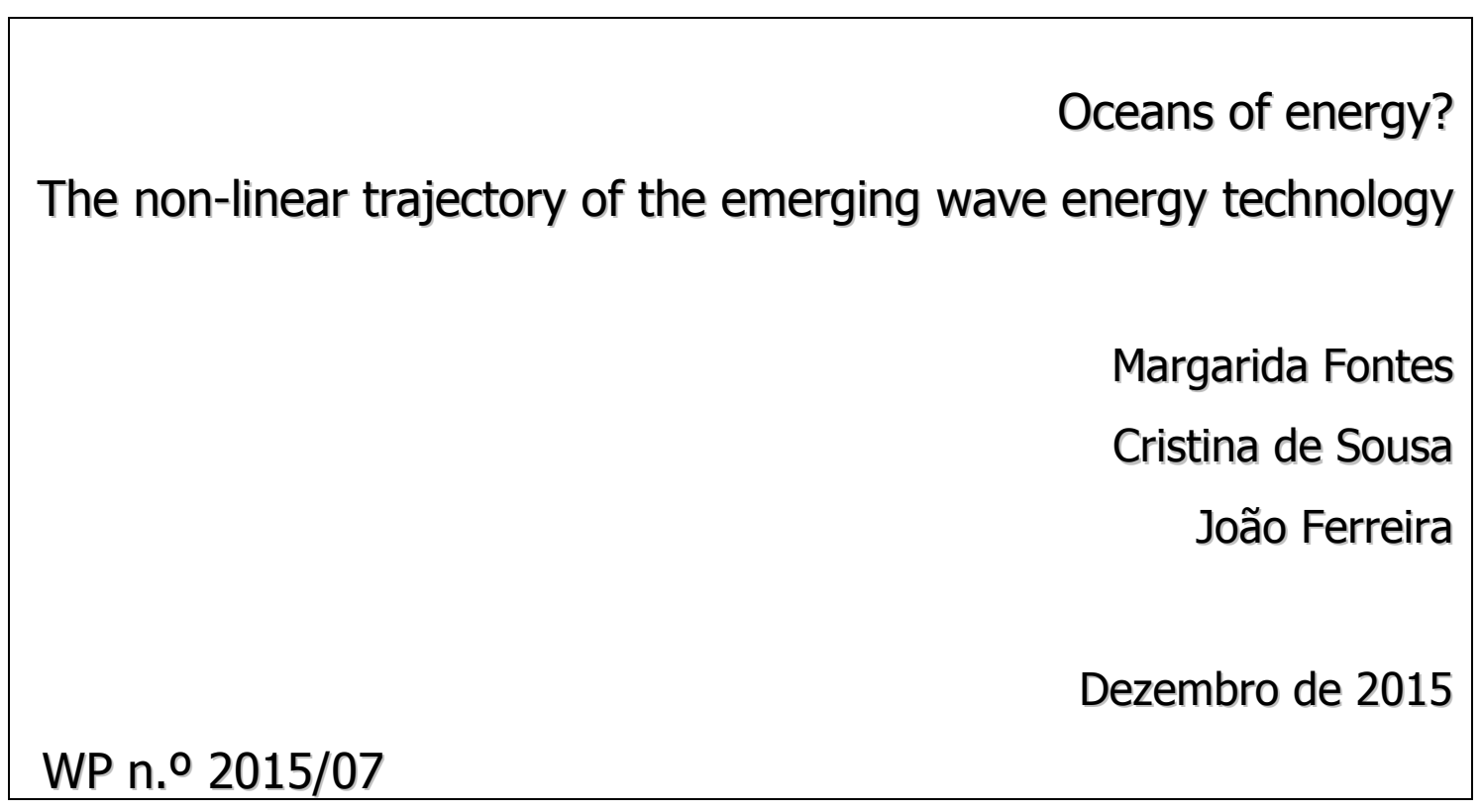

DOCUMENTO DE TRABALHO WORKING PAPER

DINAMIP'CET IBCTE-ax 


\title{
The non-linear trajectory of the emerging wave energy technology
}

\author{
Margarida Fontes * \\ Cristina de Sousa ** \\ João Ferreira *** \\ WP n. ${ }^{\circ} 2015 / 07$
}

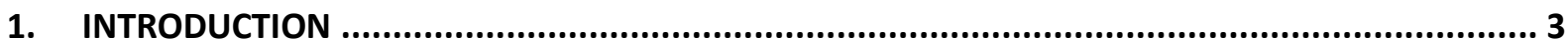

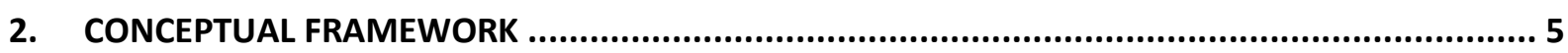

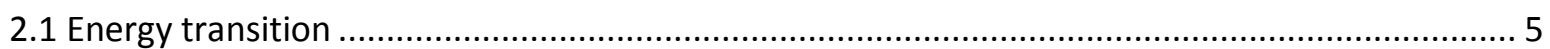

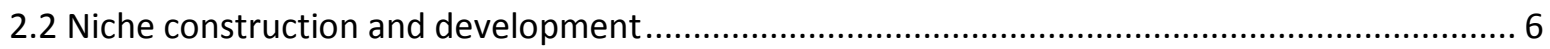

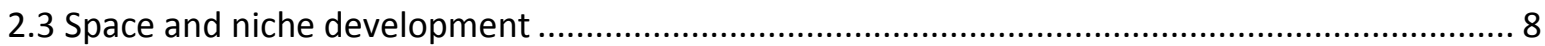

2.4 The multi-spatial dynamics of niche development .................................................................. 10

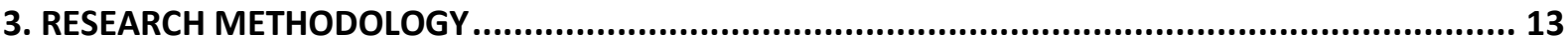

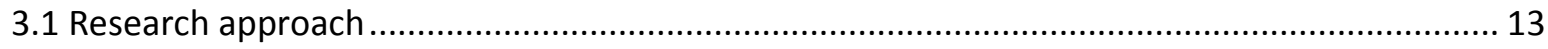

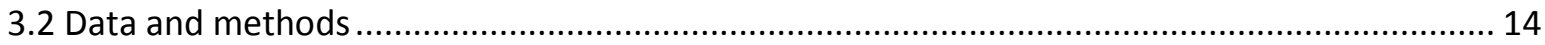

4. THE WAVE ENERGY TECHNOLOGICAL NICHE: THE OVERALL NICHE SPACE............................... 17

4.1 Network formation around research and experimental activities - spatial dynamics ................ 17

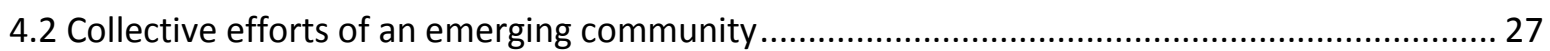

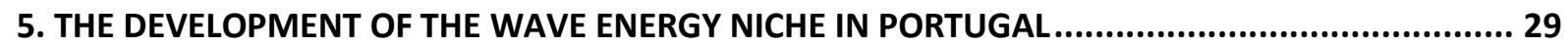

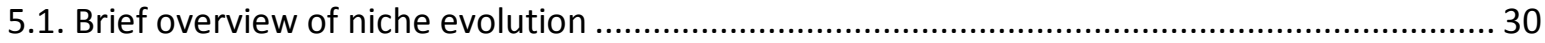

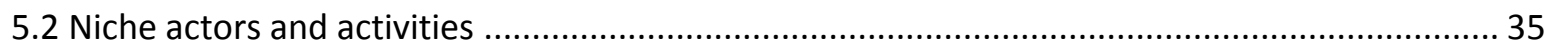

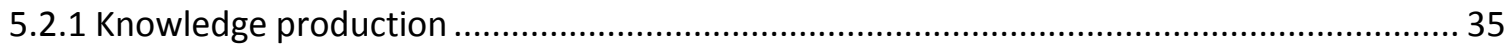

5.2.2 Technology development \& experimental activities............................................................. 43

$5.3 \mathrm{An}$ in-depth analysis of niche formation and evolution from a Portuguese perspective ........... 50

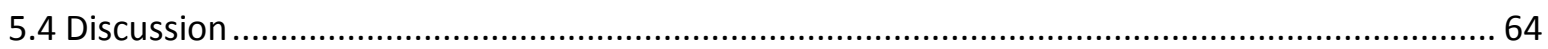

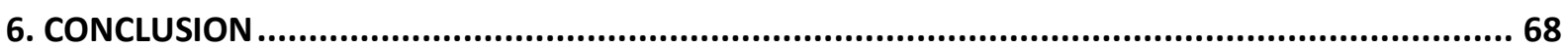

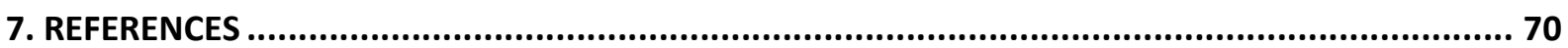

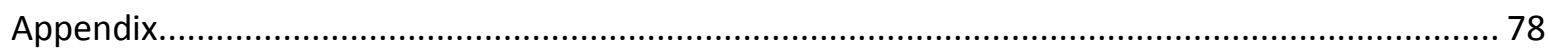

* LNEG - Laboratório Nacional de Energia e Geologia - Campus do Lumiar e DINÂMIA'CET - IUL.

** DINÂMIA'CET - IUL e ISCTE - IUL.

*** LNEG - Laboratório Nacional de Energia e Geologia - Campus do Lumiar. 


\title{
Oceans of energy? \\ The non-linear trajectory of the emerging wave energy technology ${ }^{1}$
}

\begin{abstract}
This paper addresses the construction and structuring of a technological niche - i.e. a protected space where promising but still underperforming technologies are stabilized and articulated with societal needs - and discusses the processes that influence niche development and may enable niche breakout.

In theoretical terms the paper is grounded on the multi-level approach to sustainability transitions, and particularly on the niche literature. But it also attempts to address the limitations of this literature in what concerns the spatial dimension of niche development. It is argued that technological niches can transcend the narrow territorial boundaries to which they are often confined, and encompass communities and actions that span several spatial levels, without losing some territorial embeddedness. It is further proposed that these features shape the niche trajectory and, therefore, need to be explicitly considered by the niche theoretical framework. To address this problem the paper builds on and extends the socio-cognitive perspective to technology development, introducing a further dimension - space - which broadens the concept of technological niche and permits to better capture the complexity of niche behaviour.
\end{abstract}

This extended framework is applied to the case of an emerging renewable energy technology - wave energy - which exhibits a particularly slow and non-linear development trajectory. The empirical analysis starts by examining how an "overall niche space" in wave energy was spatially constructed over time. Then it investigates in greater detail the niche development processes that took place in Portugal, a country that was among the pioneers in the field, and whose actors have been, from very early stages, engaged in the activities conducted at various spatial levels. Through this combined analysis, the paper seeks to understand whether and how niche development is shaped by processes taking place at different spatial levels. More specifically it investigates the interplay between territorial and relational elements in niche development, and how these different dynamics influence the performance of the niche processes and impact on the overall niche trajectory.

The results confirm the niche multi-spatial dynamics, showing that it is shaped by the interplay between a niche relational space constructed by actors' actions and interactions on/across levels, and the territorial effects introduced by these actors' embeddedness in particular geographical and institutional settings. They contribute to a more precise understanding of the processes that can accelerate or slow down the trajectory of a technological niche. In addition, the results shed some light into the niche activities conducted in/originating from a specific territorial setting - Portugal - offering some insights into the behaviour of key actors and its implications for the positioning of the country in the emerging field, which can be relevant for the formulation of strategies and policies for this area.

\section{KEYWORDS:}

Technological niches; sustainability transitions; spatial dynamics; wave energy technology; Portugal.

\footnotetext{
${ }^{1}$ This paper draws on research carried out within Project TESS - Transition to an environmentally sustainable energy system - The role of technology-intensive firms in the commercialization of emerging energy technologies, funded by FCT - Fundação para a Ciência e a Tecnologia (PTDC/CS-ECS/113568/2009), DINÂMIA'CET-IUL, Lisbon, Portugal.
} 


\section{INTRODUCTION}

The wave energy conversion technology is one of the less mature renewable energy technologies, exhibiting a very slow development when compared with other renewables (Falcão, 2010, IRENA, 2014). However, wave energy advocates have managed to convey a vision of future benefits, creating and expanding a community that is prepared to commit attention and resources and to engage in learning processes (OES, 2002-2014). In other words, they have been able to set-up a technological niche (Schott and Geels, 2007) and maintain its activity, despite the somewhat disappointment results that remained much below expectations.

Thus, the wave energy niche offers a relevant setting for investigating the (non-linear) processes along which a technological niche is constructed and sustained over relatively long periods of time (Geels and Raven, 2006; Verhees et al , 2013). In fact, the niche presents a number of features that configure a particularly complex context and whose investigation can contribute to a better understanding of the conditions that influence (positive and negatively) niche trajectory. First, while wave energy technology is being developed in a protected environment that somewhat shields it from the pressures of the dominant regime, this process also takes place in a context of growing involvement of established energy companies and other regime actors in renewable energy technologies (Berget et al, 2013), which is clearly visible in this field (EU-OEA, 2013). Second, wave energy technologies evolve in interaction with other renewable technologies, in the context of a "shared" regime (Sandén and Hillman, 2011), resulting in complementarities but also competition between them. Finally, the historical evolution has shown that the wave energy technological niche encompasses activities and networks that span territorial boundaries and display, from start, a strong multi-spatial dynamics (Falcão, 2010). The impact of these features on niche development is still under discussion in the transitions literature and, therefore, their investigation will also provide a contribution to this debate. The niche-regime interplay has already been addressed by the niche literature (Raven, 2006; Smith, 2007) but there is still limited empirical evidence upon its implications for niche trajectory. The potential impact of the presence of competing technologies upon the development of less mature ones is rarely taken in consideration (Flyn, 2015). The spatial aspects of niche development are a particularly under-explored line of research (Coenen, 2012). In fact, the literature still frequently associates the niche to (narrow) territorial boundaries and localised networks. As a result, the complex multi-spatial behaviour displayed by the wave energy technological niche is still imprecisely captured (Spath and Rohracher, 2012). Thus, in order to fully understand the processes underway in this type of niche, it is first of all necessary to introduce space more decisively in niche research (Raven et al, 2012). This paper contributes to this goal by proposing a conceptual framework which provides a more explicit treatment of the role of space in niche development. 
The process of niche development and breakout has been addressed by the strategic niche management literature (Kemp et al, 1998; Schot and Geels, 2007; Verbong et al, 2008). Recent advances led to a conceptualisation of niche development as a non-linear trajectory along which the emerging field is structured through a socio-cognitive process (Geels and Raven, 2006; Raven and Geels, 2010). This approach has provided significant contributions to an understanding of the complex processes that occur in the niche space, by moving the focus beyond individual experiments and introducing the notion of a socially and cognitively constructed "global niche level". From a social perspective, the global niche consists of the global network that encompasses the emerging community. From a cognitive perspective the global niche consists of increasingly articulated and stable global rules and expectations, which are created through dedicated efforts aiming at the formalisation and aggregation of contextual knowledge generated in local experiments, transforming it into abstract, generic knowledge and lessons that can be shared by the community and base an agenda for the field (Geels and Deuten, 2006). But, although spatial issues are often implicit in the discussion of the processes that occur in/between local experiments and the more abstract global niche level, space is not explicitly assumed as a relevant dimension, and its implications for the conduction of the niche processes are not considered. This absence is criticised as reducing the explanatory power of the sociocognitive framework (Coenen et al, 2012).

The objective of the paper is to provide a more encompassing approach to niche formation, development and breakout, thus contributing to a better understanding of the processes taking place along the trajectory of technological niches. Thus, we adopt the socio-cognitive perspective to niche development, which supports the broader view of the niche as a space that transcends individual experiments and territorial boundaries. But we also acknowledge the need to spatially ground this still relatively abstract concept. Thus we add the spatial dimension, by introducing in the analysis the "places" where the different processes occur and the "spatial scope" of the relations that are enacted between actors involved in them. Following this approach we define an "overall niche space" that encompasses and "spatializes" the processes described in the socio-cognitive framework as taking place at both "local" and "global" levels. This approach contributes to strengthen the socio-cognitive perspective, by grounding it on the actions being developed by niche actors in and across different spatial levels.

This extended framework is applied to the case of the wave energy technological niche. For this purpose we start by examining how an "overall niche space" in wave energy was constructed over time. Then we look in greater detail into the processes that took place in a country - Portugal - that was among the pioneers in this field (Falcão, 2010), and whose actors have been, from very early stages, engaged in the activities conducted at various spatial levels (OES 2002-2014). This analysis is set in the context of the "overall niche space", of which the activities conducted in Portugal are seen as

DINÂMIA'CET - IUL, Centro de Estudos sobre a Mudança Socioeconómica e o Território ISCTE-IUL - Av. das Forças Armadas, 1649-026 Lisboa, PORTUGAL 
an element. It enables us to examine in greater depth the niche internal processes and its interactions with the dominant energy regime, in order to start answering to the following question: how is niche trajectory shaped by processes taking place at different spatial levels. More specifically we investigate: i) which is the interplay between territorial and relational elements in niche development; ii) how these different dynamics influence the performance of the niche processes and impact on the overall niche trajectory.

The paper is organised as follows. In section 2 we review the relevant literature and develop a conceptual framework. Section 3 details the approach and methodology for the empirical research on the wave energy technological niche. The results are presented and discussed in sections 4 and 5, where we start by providing a brief characterisation of the overall niche space (section 4) and subsequently analyse in greater detail the Portuguese case (section5). This is followed by a discussion of key findings. The paper ends with a conclusion on the multiple dimensions that shape the trajectory of technological niches.

\section{CONCEPTUAL FRAMEWORK}

\subsection{Energy transition}

The research on the roles played by new renewable energy technologies in the transition to a sustainable energy regime has recently gained some momentum, due to the changes underway in the energy system (Verbong and Geels, 2010). Transformations in a major socio-technical system as energy - or socio-technical transitions - have been conceptualised by Multi-Level Perspective (MLP) scholars as the product of interrelated processes at three levels: niche, regime and landscape (Geels, 2002, 2005). Radical innovations that may come to play a role in regime transformation are developed in niches that act as protected spaces, temporarily shielding them from the selection pressures exerted by the dominant socio-technical regime. Changes at the landscape level may introduce tensions in the prevailing regime, challenging it and eventually destabilising it, creating opportunities for niche innovations, which may break out and profoundly transform or even overthrow the dominant regime. The way these transformation processes unfold may vary (Geels and Schot, 2007; Haan and Rotmans, 2011; Smith et al, 2005; Foxon et al, 2010). In the case of energy, a process that involves interaction and integration between regime and niche actors and their technologies and practices, potentially resulting in some basic reconfigurations in the regime architecture, appears to be more probable (Verbong and Geels, 2010). The energy system has already undergone profound changes, which introduced some tensions in the established socio-technical regime, leading some actors to doubt the long term viability of the "fossil-fuel based" regime configuration. This created a growing space for a

DINÂMIA'CET - IUL, Centro de Estudos sobre a Mudança Socioeconómica e o Território ISCTE-IUL - Av. das Forças Armadas, 1649-026 Lisboa, PORTUGAL 
variety of substantially different technological options - the renewable energies - that were being developed in niches.

These technologies had reached diverse levels of maturity, and the respective niches also displayed differences in terms of internal stability and level of articulation, thus their development process was dissimilar (Verbong et al, 2008). Some of them have achieved considerable market diffusion (e.g. wind energy), supported by favourable policies and also attracting the interest of regime actors (Bergek et al, 2013), while others are at a more incipient stage. However, even more "laggard" technologies have benefited from the creation of a space for the alternative sustainable path that renewable energies collectively entail (Geels, 2005; Bergek et al, 2008). This is namely the case of wave energy conversion, where the technology is far from being stabilised, but that despite a slow development and frequently unfulfilled expectations (Jeffrey et al, 2013), has benefited from supportive policies and a positive public attitude (particularly in some countries) and has recently started to attract some private investment (REN, 2014; OES, 2014; EC, 2014). Nevertheless, its "laggard" position means wave energy technology has to withstand competition from other faster developing renewable technologies (Flyn, 2015), with impact on the level of resources available and thus on the conditions for niche development.

\subsection{Niche construction and development}

In this paper we are interested in the formation and development of technological niches, that is, spaces where promising but still underperforming technologies are protected against the selection pressures of the dominant regime (Kemp et al, 1988). These spaces are expected to provide an environment that not only shelters the technology but also nurtures it. That is, they allow for experimentation in a societal context that permits improvements in technological performance and enables the alignment of the technology with user needs and institutional structures (Geels, 2002; Kemp et al, 1998; Smith and Raven, 2012). Thus technological niches can be defined as protected spaces where technologies and user specifications are still unstable and where the technology-specific structures (actors, networks, and institutions) are still in the process of being created and aligned (Schot and Geels, 2007). According to these authors, "technological niches act as 'proto-markets' for new technologies, allowing for interaction between users and producers in protected spaces" (Schott and Geels, 2007: 616). The final goal of these processes is enabling the technologies to become competitive, break out of the niche and trigger changes in dominant regimes. Such outcome, and the ways in which it may be achieved, depend both on processes internal to the niche and on the way niche developments link-up with developments taking place in the regime and also at landscape level (Raven, 2006; Schot and Geels, 2007). 
The types of internal processes that are critical for the formation and development of technological niches have been put forward by the early proponents of the Strategic Niche Management (SNM) approach (Hoogma et al, 2002; Kemp et al, 1988). These authors identify socio-technical experiments as the locus for niche formation and development and outline three main processes whose interplay might lead to niche upscale and eventual break out: i) voicing and articulation of expectations, i.e. of visions of future functionalities and benefits that provide directions for development and permit to attract resources and enrol new actors; ii) formation of networks of supportive actors, thus creating a constituency behind the technology and enabling the interaction between technology developers and a variety of other actors prepared to invest attention and resources in the technology; iii) enactment of learning processes, about both technical and non-technical aspects, that permit to adjust or reconfigure subsequent work. Consistent policies are an important sheltering element in technological niches and stability of support has been pointed out as critical for achieving long-term results (Jacobsson and Lauber, 2006; Verbong et al, 2008).

Subsequent developments have attempted to address some limitations of this early approach (Schot and Geels, 2008). One of these limitations concerns the excessive focus on niche internal processes. Thus, research has addressed the implications for niche development of the interaction between niche and regime actors and institutions (Raven, 2006; 2007; Smith and Raven, 2012). The presence of powerful regime actors can be important for niche development, since they convey resources and legitimacy and can make it attractive to other key actors, such as capital providers (Schot and Geels, 2007). Niche innovators may namely opt for engaging in processes of "hybridization", whereby niche technologies are partly adapted to match incumbents' competences and interests (Raven, 2007). While the involvement of regime actors can be a strategy through which niche actors profit from regime tensions to "infiltrate" their novel technologies and practices, translating them into ways acceptable by regime actors and thus gaining their support (Smith, 2007), it also has risks, inevitably leading to a "niche reconfiguration closer to the regime" (Smith, 2007: 447). In fact, novel developments and approaches may end-up being captured by powerful actors, that use their insider intervention to prevent radical transformations or to steer the processes towards their interests (Kern and Smith, 2008; Smink et al, 2013). In any circumstance the involvement of regime actors is always likely to influence the development trajectory of technologies (Geels and Schot, 2007).

In the case of the energy system, the ongoing transformations put increasing pressure on established companies to take into account new technologies that can threaten their assets and competitive position (Hekkert and Negro, 2009). Even in the case of more immature technologies, regime actors may wish to keep an eye on new developments, in order to follow-up their evolution and/or to guarantee an early position, once a dominant design starts to emerge (Sine and David, 2003).

DINÂMIA'CET - IUL, Centro de Estudos sobre a Mudança Socioeconómica e o Território ISCTE-IUL - Av. das Forças Armadas, 1649-026 Lisboa, PORTUGAL 
Thus, regime actors are increasingly involved in niche activities (Bergek et al, 2013; Richter, 2013; Fontes et al, 2012). However, there is still limited empirical evidence of the actual impact of their active presence in the niche trajectory (Berggren et al, 2015).

Another limitation concerns the learning processes and the way they can contribute to strengthening the niche trajectory. New contributions came from the application of a socio-cognitive evolutionary perspective on technology emergence to niche development (Geels and Raven, 2006; Raven and Geels, 2010). This resulted in the distinction between local experiments (individual projects enacted by local networks) that generate contextualised knowledge, and a global niche level where abstract, generic knowledge is generated, taking the form of shared cognitive rules (problem agendas, heuristics, abstract theories and technical models). The transformation of contextualised knowledge from individual projects into generic lessons and cognitive rules is not straightforward. It requires dedicated aggregation activities that bring together lessons from multiple projects, codifying them and articulating field-level agendas. These agendas need to be subsequently translated to local projects, in a process that also requires dedicated efforts (Raven et al, 2011).

This approach also clarifies the relation between learning and expectations and contributes to explain the non-linearity of niche processes (Verbong et al, 2008). In fact, outcomes from experiments give rise to learning processes that are confronted with expectations. If expectations are confirmed, new developments are pursued along a trajectory that shows increasing stability, making it easier to extend the supportive network and obtain additional resources. If results fail to meet expectations, support declines and it is necessary to conduct some "repair work", which eventually results in redirection of the trajectory and new promises being made (Geels and Raven, 2006). This non-linearity in niche development has been addressed in detail by scholars who studied the role of expectations and discussed the presence of cycles of "hype" followed by disappointment (Bakker and Budde, 2012; Borup et al, 2006; Konrad et al, 2012; Van Lente et al, 2013; Verbong et al, 2008).

\subsection{Space and niche development}

These theoretical developments permitted to advance our understanding of the process of niche formation and development. But one further limitation - the treatment of space in niche processes - is still unsatisfactorily addressed, a problem that is transversal to the socio-technical transitions literature (Coenen et al, 2012; Spath and Rohracher, 2012).

A new research stream on the "geography of sustainability transitions" (Hansen and Coenen, 2015) provided some contributions in this direction. One concerns the need to contextualise transitions, that is, to put greater emphasis on the territorial and institutional embeddedness of the processes taking place (Coenen et al, 2012). This perspective was applied to the SNM approach (Coenen et al, 2010). Particular emphasis was put on the role of proximity in local niche experimentation, conceptualising

DINÂMIA'CET - IUL, Centro de Estudos sobre a Mudança Socioeconómica e o Território ISCTE-IUL - Av. das Forças Armadas, 1649-026 Lisboa, PORTUGAL 
proximity as encompassing social, cognitive or institutional aspects (Boschma, 2005) and stressing their importance in the conduction of niche internal processes. This had the advantage of highlighting the critical role played by specific local circumstances - institutional environments, policies, actors and agglomeration effects. But it also implicitly associated niche to local experimentation and, therefore, tended to confine the niche to a territorially bounded place and the network formed around it.

Other contributions came from research that explicitly considered that transitions take place at different spatial levels - assuming space in territorial and relational terms - and that "localised" activities are in fact subject to local and non-local influences through the position of actors in networks operating at (or spanning) diverse levels (Markard and Truffer, 2008; Binz et al, 2014; Spath and Rohracher, 2012). This approach was namely developed by the technological innovation systems (TIS) literature, which has introduced the notion of "global TIS" (Binz et al, 2012). Although the focus of this research is frequently on how new regions/countries adopt maturing technologies that are already diffusing (Binz et al, 2012; Gosens et al, 2015), the notion of a system that transcends territorial boundaries is also useful in the case of emerging technologies (Binz et al, 2014). In particular, the role attributed to networks in linking actors across spatial levels (Binz et al, 2014; Wieczorek et al, 2015) is especially pertinent in the case of less structured systems such as technological niches, whose development is supported by the efforts of an evolving community (Geels and Raven, 2006).

This view is also present in recent attempts to incorporate a spatial scale in the multi-level perspective (MLP) to socio-technical transitions (Raven et al, 2012), which recognise that "there is no reason to conflate the MLP levels with specific territorial boundaries" (Raven et al, 2012: 64). This is namely the case for niches: even if "social networks are less extensive, less stable, expectations more fragile and learning processes are less institutionalized" (idem), it is recognised that they are not necessarily only local. Similarly regimes, with which niches link-up and interact, are not necessarily homogeneous and may incorporate local variations.

In spite of this, the niche literature has not yet managed to fully linking niche processes to this spatial behaviour. One important advance concerns the notion that different local niches can "become (inter)nationally connected through existing or new networks" (Raven et al, 2012: 71). But the emphasis is on how separated niches connect, not being assuming (at least explicitly) that, in some cases, the niche itself can be a space where internal processes and niche-regime interaction take place simultaneously at different spatial levels. 


\subsection{The multi-spatial dynamics of niche development}

In order to address this issue we draw on the advancements to SNM provided by the socio-cognitive perspective (Geels and Raven, 2006). This approach introduces two notions that support a broader definition of "niche space": one is the presence of sequences of local projects that may occur simultaneously or build on each other over time, adding-up to the technological trajectory; the other is the concept of a "global niche level" that, according to these authors, effectively corresponds to the technological niche (Raven and Geels, 2010: 89). This global level is defined along a social and a cognitive dimension. In a social dimension, the global niche is defined as the network that encompasses the emerging community engaged in the development of the technology, including actors involved in local projects and actors not directly involved but providing relevant resources. In a cognitive dimension, the global niche is defined by the cognitive processes that enable the formalisation and aggregation of contextual knowledge generated in local projects, in order to turn it into abstract, generic knowledge that can be shared by the community. Moreover, the analytical distinction between different types of cognitive activities - from problem solving at local level to aggregation at a global level - is described as leading to a division of cognitive labour between actors active in local projects and actors (also or exclusively) engaged in aggregation activities.

This approach also provides some insights into the relational processes that support the construction of a "global level" (Geels and Deuten, 2006). One is the formation of networks that facilitate circulation between projects and the development of a sense of community among the actors in the field. Another is the emergence of actors that have a central role in aggregation activities: intermediary actors that speak for the field. These are often collective organisations (e.g. professional societies, industry associations), but can also be actors that travel between local projects. Finally, there is the creation of dedicated infrastructures, i.e. specific arenas that serve as setting for the circulation of ideas and their discussion across the community, such as seminars or conferences and dedicated journals.

While the main focus of these authors is on providing a conceptual explanation of how the interactions between learning processes, expectations and social networks gradually contribute to niche development trajectory (Geels and Raven, 2006), this approach equally provides a comprehensive and integrated view of the variety of actions and interactions enacted by the actors involved in these processes. These actors are regarded as a community and their activities as part of an overall effort towards niche upscale and break out, thus supporting the notion that the technological niche is, in fact, the overall space where these efforts take place.

The technological niche can thus be described, from a relational perspective, as the combined efforts of this overall community in developing individual projects that generate new local knowledge, in conducting a variety of activities to create and share generic knowledge and to (re)define and

DINÂMIA'CET - IUL, Centro de Estudos sobre a Mudança Socioeconómica e o Território ISCTE-IUL - Av. das Forças Armadas, 1649-026 Lisboa, PORTUGAL 
agendas and visions, and in the transmission of the outcomes of these efforts, both within the community to feed new individual projects and outside it, in order to attract new members and additional resources.

However, the activities and the actors/networks that enact them remain largely a-spatial. Thus, this approach has been criticised for not explicitly addressing "the interdependence of niche processes with specific institutional configurations in space" (Coenen et al, 2012: 973). In fact, while different spatial scales of operation are implicit in the distinction between networks that are formed around local projects and those that perform aggregation activities; space is not explicitly assumed as a relevant dimension and its implications for the conduction of the niche processes are not explored. Thus, a further step is required to understand the processes being conducted in this overall niche space: to explicitly introduce the spatial dimension in the niche analytical framework. This is in line with the attempts to introduce a spatial scale in the MLP, where it is assumed that "actors, institutions, beliefs and practices at all levels are embedded and entwined in broader transnational and sub-national spaces of innovation" (Raven at al., 2012: 69). These authors also call the attention to the distinction between an absolute (territorial) and a relative (relational) spatial scale, arguing that the latter, which is "socially constructed through networks of actors and cut across territories" (idem: 70), has a greater explanatory power.

In this paper we attempt to spatially ground the socio-cognitive perspective, by introducing the idea that the niche processes described, either "local" or "global", are conducted by actors:

i) that belong to, or are temporarily located in places, i.e. specific territorial settings, whose features can influence both the actors' behaviour and the outcome of the processes (Coenen et al, 2012) - thus explicitly addressing the territorial dimension of space;

ii) that are connected in a variety of ways across those territorial settings (Binz et al, 2014), in order to pool knowledge and experiences and/or share lessons; or may even operate in territorially disintegrated networks (Bulkeley, 2005) with a view to conduct (field-level) aggregation activities; and that the particular spatial distribution of these networks is not indifferent (Hansen and Coenen, 2015) - thus making more explicit the relational dimension of space.

Thus we combine an approach that addresses the niche as a relatively abstract space where technology is being developed through socio-cognitive processes, with an approach that grounds this abstract space, through the contributions of geography, i.e. by introducing in the analysis the places where the different processes take place and the spatial scope of the relations that are enacted between actors involved in them.

DINÂMIA'CET - IUL, Centro de Estudos sobre a Mudança Socioeconómica e o Território

ISCTE-IUL - Av. das Forças Armadas, 1649-026 Lisboa, PORTUGAL 
More specifically, we apply this approach to the activities taking place at the local project level and those leading to the construction of a global level. Local projects - which we prefer to label as "individual experiments" to avoid the geographical connotation of "local" - are likely to be conducted in specific locations with particular territorial characteristics (Spath and Rohracher, 2012). However, they can encompass one place or multiple, as when an experiment is physically distributed. Similarly, they are conducted in networks that may include only actors originating from the actual experiment location(s), or also involve actors from other locations, through a variety of connections with different purposes. Moreover, some actors may have moved from projects in other locations or involving other networks, thus being carriers of different knowledge and experiences (Rosenkopf and Almeida, 2003).

In what concerns the activities that configure the "global level", their nature suggests that they will be less territorially embedded. In fact, it is expected that dedicated aggregation activities will occur in transnational or supra-national networks, and that the knowledge produced will also flow across these networks. The literature on transnational networks (Coe and Bunnel, 2003; Bulkeley, 2005) provides insights into two types of networks that may be in operation at this level. Because exchanges in technological niches are largely concerned with knowledge, networks are likely to assume the form of epistemic communities, where cognitive and (temporary) social proximity led to the development of shared meanings and communication codes (Breschi and Lissoni 2001). In addition, transnational advocacy networks, where a broad range of actors with shared values and a common discourse work together to achieve specific outcomes at an international level (Bulkeley, 2005), also emerge as potentially relevant. The "intermediary actors" that integrate those networks are also likely to originate from different locations and have different types of experiences, and they may be operating simultaneously at several spatial levels.

However, the division of cognitive labour in the niche community (Geels and Deuten, 2006) will mean that some actors will have a greater role in the conduction of the global learning processes and in the definition of field-level agendas and visions. Despite the less territorialised nature of aggregation activities, aggregation networks may be more frequently composed of actors from the most active locations, which may also tend to host discussion arenas and any physical infrastructures created. These field-level activities remain partly grounded on territorial contexts, through the actions and interests of the actors that compose them (Nedeva, 2013). This can have implications for the way generic knowledge is produced and circulated and shared across the community. Moreover, the way the outcomes of these learning processes are translated into new local projects may also be influenced by local contextual conditions (Raven et al, 2011). Thus, even if the "niche space" transcends territorial boundaries, territorial level effects remain important. A full understanding of niche behaviour will, therefore, require some consideration of the interplay between territorial conditions and the global niche processes.

DINÂMIA'CET - IUL, Centro de Estudos sobre a Mudança Socioeconómica e o Território ISCTE-IUL - Av. das Forças Armadas, 1649-026 Lisboa, PORTUGAL 
The above discussion provides a more multifaceted perspective of the niche as a complex space that transcends individual experiments and territorial boundaries, and contributes to define more precisely the spatial dimensions of niche development. The technological niche can therefore be described as a (frequently reconfigured) "overall space" that encompasses a variety of actions and interactions enacted by a diversity of actors that operate at and/or span different spatial levels. This "overall niche space" is expected to have a particular spatial dynamics, which results from the interplay between: a niche relational space constructed by niche actors along their niche development efforts; and the territorial effects introduced by the embeddedness of these actors and their actions in particular geographical or institutional settings.

As pointed out above, niche development and breakout will depend on processes internal to the niche and on the way these link-up with processes taking place at regime level. The fact that niche activities are being enacted at a multiplicity of territorial and relational levels is likely to have implications for the performance of the niche internal processes identified by the SNM literature articulation of expectations, network building and learning processes, in particular learning that leads to generic lessons - as well as for the type of interactions that take place between niche and regime. Thus, territorial effects may result into these processes assuming different forms in different locations; while relational effects may result into their performance effectively extending beyond those locations and (at least) partly escaping their effects. Relational effects may also result into outcomes of more territorialised processes having an impact on the overall niche trajectory (Spath and Rohracher, 2012), contributing either to accelerate its development or to slow it down. These features are conducive to an increased complexity in the niche dynamics. The approach proposed permits to start capturing this complexity, by providing a theoretical explanation on why the niche trajectory is shaped by the conditions, actions and interactions at work at these various levels, and by providing a framework that permits to investigate how niche processes are influenced by them.

\section{RESEARCH METHODOLOGY}

\subsection{Research approach}

The explanatory potential of this extended framework is explored through the empirical case of the wave energy technological niche. The analysis is conducted at two levels. We start by addressing, in general terms, the formation of an "overall niche space", characterising its actors and dynamics in and across a variety of locations. Then we look at the process in greater detail from the standpoint of specific territorial setting, examining the case of Portugal that was one of the pioneers in the construction of a niche around wave energy conversion and its attempted breakout. The Portuguese case enables us to further explore how niche evolution is shaped by cognitive and social processes

DINÂMIA'CET - IUL, Centro de Estudos sobre a Mudança Socioeconómica e o Território ISCTE-IUL - Av. das Forças Armadas, 1649-026 Lisboa, PORTUGAL 
taking place at different spatial levels, permitting to observe in greater detail the actors' behaviour and also to uncover the non-linear nature of the niche trajectory.

The choice of the "country" as the territorial sub-unit to be considered in this case can be justified by the characteristics of both the country and the field that are object of the empirical analysis. Portugal is a small country with a centralised administrative structure and great homogeneity in terms of institutions. Policies - namely those regarding an infrastructural sector such as energy - are largely defined at country level. The characteristics of the energy regime are also pertinent, since large energy companies with national level strategies have become interested and involved in renewable energies from very early stages (Bento and Fontes, 2015). Moreover, Portugal is a country with limited resources, which is reflected in the largely national nature of the networks established in this emerging field. As will be shown below, early niche creation activities were mostly conducted by actors originating from research universities located in the major metropolitan areas (where most research is conducted), which did not necessarily coincide with the areas identified as more favourable for experimental activities. These actors - both researchers and technology developers - managed to bring into the niche network organisations with resources or competences relevant for the conduction of scientific and/or experimental activities, wherever they were located throughout the country (or even outside it). Thus niche networks were not local or regional, but national (or transnational), and while they would sometimes include organisations from the locations where the experiments took place, these were neither predominant nor central to the network and the initiative was external to them. In other contexts (or other technological fields) the regional or even local levels might assume greater importance. But in this particular case, the national level emerged as the more adequate to investigate the impact of territorial embeddedness on niche development.

\subsection{Data and methods}

The empirical analysis of the overall niche space draws on two types of sources. Data on European funded research and technology development (RTD) projects, on publications and on patents permit to trace, in generic terms, the spatial dynamics of the research and experimental activities conducted and networks formed, and to identify key actors. For this purpose, data was collected from the EUROPA CORDIS (Community Research and Development Information Service) online database for projects and from the European Patent Office Espacenet database for patents, using search strategies based on wave energy related keywords. In addition, information on the creation of supra-national networks and collective organisations, based on documents produced by them, permits to identify attempts at structuring the niche space by conducting field-level aggregation activities. This will enable a brief characterisation of the current situation in the wave energy technological niche and support a first, generic, overview of its trajectory.

DINÂMIA'CET - IUL, Centro de Estudos sobre a Mudança Socioeconómica e o Território ISCTE-IUL - Av. das Forças Armadas, 1649-026 Lisboa, PORTUGAL 
The empirical research on activities that took place in Portugal, as part of the formation and early development of a wave energy niche, was based on the analysis of the documented actions enacted over time by actors operating in the niche, including information on research projects and research outputs, experimental activities, organization creation, business investments, research or business partnerships, participation in collective activities, policy instruments. For this purpose the analysis drew on several sets of data.

Data on publications involving Portuguese authors, patents with Portuguese applicants, European funded RTD projects involving Portuguese organisations, and PhDs awarded by Portuguese universities or recognised by them (in the case of PhDs obtained abroad) was purposefully collected from online databases. These included Thomson Reuters' Web of Science for publications, Espacenet and INPI (Portuguese National Patent Office) for patents, CORDIS for projects, Portuguese DGEG (Directorate General for Education and Science) database for PhDs. Additional data was obtained from the websites of a number of international conference series dedicated to or encompassing the wave energy field. Data were also collected on projects exclusively funded at country level by public support systems targeting R\&D, demonstration, technology transfer, innovation, entrepreneurship, infrastructure building. The data was obtained from online repositories held by a variety of Portuguese funding agencies for most recent programmes; and manually searched in final reports and other official documents, for programmes launched in the 1980s, 1990s and early 2000s.

Data on business activities conducted by Portuguese firms draw on both primary and secondary sources. The former included interviews conducted with 5 out of the 6 entrepreneurial firms created to explore new technologies in the wave energy field - Kymaner, E-move and ReefPower (wave conversion systems); Hidromod and BlueEdge (complementary technologies) ${ }^{2}$ - focusing on the process of firm creation and on firms' activities, strategies and perspectives. It also included interviews with 4 of the large energy companies with greatest involvement in wave energy - EDP Inovação, Martifer, Generg and REN-Enondas (responsible for the Pilot Zone for on Wave Energy) which were specifically inquired about their participation in this field, as part of an interview on their renewable energy activities. Data on activities conducted by other Portuguese companies and by foreign firms, as well as complementary data concerning the activities of other actors - research organisations, government agencies, collective organisations - were obtained from secondary sources: websites and other organisation level information, technical reports, specialised magazines, press releases, etc. Data on energy policies was compiled from government documents. A small number of short interviews with key actors and with the wave energy association were conducted in the beginning of the research, with exploratory purposes. Participation in a number of events organised by

\footnotetext{
${ }^{2}$ It was not possible to speak with one technology developer (Sea for Life) that was not anymore in activity.

DINÂMIA'CET - IUL, Centro de Estudos sobre a Mudança Socioeconómica e o Território ISCTE-IUL - Av. das Forças Armadas, 1649-026 Lisboa, PORTUGAL 
these actors permitted to follow-up the most recent developments in the field, which were not yet documented.

This data supported a preliminary of analysis of the development of wave energy in Portugal, focusing on the identification of the actors that have been involved with the niche, on the mapping of formalized activities they have conducted in or on behalf of the niche (individually or in collaboration), and on a first assessment of the main outcomes and their implications for niche development. While we are aware that a complete understanding of the processes of niche formation and attempted breakout can only be achieved through a more in-depth appreciation of the expectations, motivations and decisions of the various actors involved (Verhees, et al, 2013), we start by focusing on some of their most visible results, i.e. documented actions these actors conducted along the process. This analysis is expected to raise some additional questions on why these actions and outcomes come to be, which will be addressed by subsequent research.

The data is analysed from both a quantitative and a qualitative standpoint. From a quantitative perspective, we assess the extent of actor participation and the intensity with which specific types of activities were conducted, and how this evolved over time. In addition, social network analysis (SNA) (Wasserman and Faust, 1994) is used to have a more precise understanding of the configuration of the networks and the position of actors.

More specifically, SNA is applied to data on collaborative projects, in order to uncover and depict relationships between organisations. Collaborative projects constitute two-mode networks that link organisations to an event - the project. From these we extract a one-mode network, considering inter-organisational networks, where a tie joins two organisations that collaborate in the same project. We build symmetric adjacency matrices, valued by the number of common projects and conduct SNA using UCINET software. Network diagrams are built using NetDraw and NodeXL software. In order to identify key actors, two centrality measures are considered: degree and betweenness. Centrality measures enable to detect more favourable network positions (Freeman, 1979). The degree centrality indicates the actors' activity level, in terms of number of ties established with other organisations, uncovering the actors who are potentially better positioned to enact more intense knowledge exchanges.

The betweenness centrality indicates whether an actor is more frequently positioned between other pairs of actors, thus playing the role of a broker in the network.

This quantitative approach provides the ground for a more in-depth analysis of the processes taking place, which adopts an historical perspective and relies mostly on qualitative, interpretative methods. The analysis at Portuguese level takes into consideration the developments taking place at the overall niche level and, whenever relevant, addresses the overlap/interplay between them. 


\section{THE WAVE ENERGY TECHNOLOGICAL NICHE: THE OVERALL}

\section{NICHE SPACE}

Wave energy conversion is one of the less mature renewable energy technologies (IRENA, 2014, Falcão, 2010). No dominant design has emerged yet, and there is a variety of competing conversion systems being developed by different actors, mostly small technology-intensive companies. The more advanced systems have been going through intense activity of test and demonstration, sometimes in real sea conditions, but none has gone beyond the pre-commercial stage. Major problems are still to be solved concerning both the efficiency of the actual conversation process and the capacity to withstanding the very harsh conditions of operation (Magagna et al., 2014; Tiron et al, 2015). The difficulties experienced meant that wave energy has been particularly slow in achieving the extensive benefits promised (Jeffrey et al, 2013; Lewis et al, 2011). But its advocates have been able to create a protective space - e.g. a technological niche - and sustain it over long periods and several drawbacks (Caratti et al, 1993; Clément et al., 2002; EU-OEA, 2013; Hamawi and Negro, 2012).

In this section we provide an overview of the evolution of the wave energy technological niche, drawing on information on activities related with knowledge production and experimental development, which give some indications on the extent of efforts developed and on the nature of actors and networks formed over time. Data on the emergence of collective organisations and activities give some indications about the formation of a (international) community and its "global level" activities.

\subsection{Network formation around research and experimental activities - spatial dynamics}

The dynamics of the research and experimental activities and the networks formed around them are first analysed on the basis of data on European funded research and technology development (RTD) projects. Data was collected from all the programmes for which information is available in the EUROPA CORDIS database. Projects included those whose activities were exclusively focused on the wave energy field (79\%) and a smaller group where wave energy was individualised as one element of a broader topic (e.g. ocean energies), or involved activities explicitly described as relevant for wave energy development (21\%).

European programmes only started supporting wave energy projects in 1992, following an EC initiative launched in 1991 targeting this field (Elliot and Caratti, 1994). Their numbers evolved very slowly over time, only registering a greater increase in the most recent Framework Programmes, which also coincided with a greater European focus on renewable energies: FP6 (2002-2006) and FP7 (2006-2013) with a total 15 and 31 projects respectively (Figure 1). About half of the projects funded have an experimental component, related with the test of a technology/system or with the assessment

DINÂMIA'CET - IUL, Centro de Estudos sobre a Mudança Socioeconómica e o Território ISCTE-IUL - Av. das Forças Armadas, 1649-026 Lisboa, PORTUGAL 
of the wave resource $(53 \%)$. Research projects have a lower weight $(22 \%)$, but it is interesting to notice that their numbers have increased in FP7, reflecting a need to reinforce the development of knowledge at a more fundamental level, in order to address persisting technical problems. Finally, a substantial number of projects $(25 \%)$ are concerned with structural activities, such as pooling information about activities being conducted in the field, drawing lessons and sharing information about "best practices" and "key obstacles" (e.g. aggregation activities); providing guidelines for European policy formulation; raising awareness about the field and inducing its development (namely through training activities). The importance assumed by experimental projects (and even its prevalence over more research-oriented ones) is consistent with the growing role of technology deployment policies in the energy field (Hoppman et al, 2013; Nemet, 2009).

Figure 1 - Evolution in the number of RTD projects funded by European programmes (1992-2014)

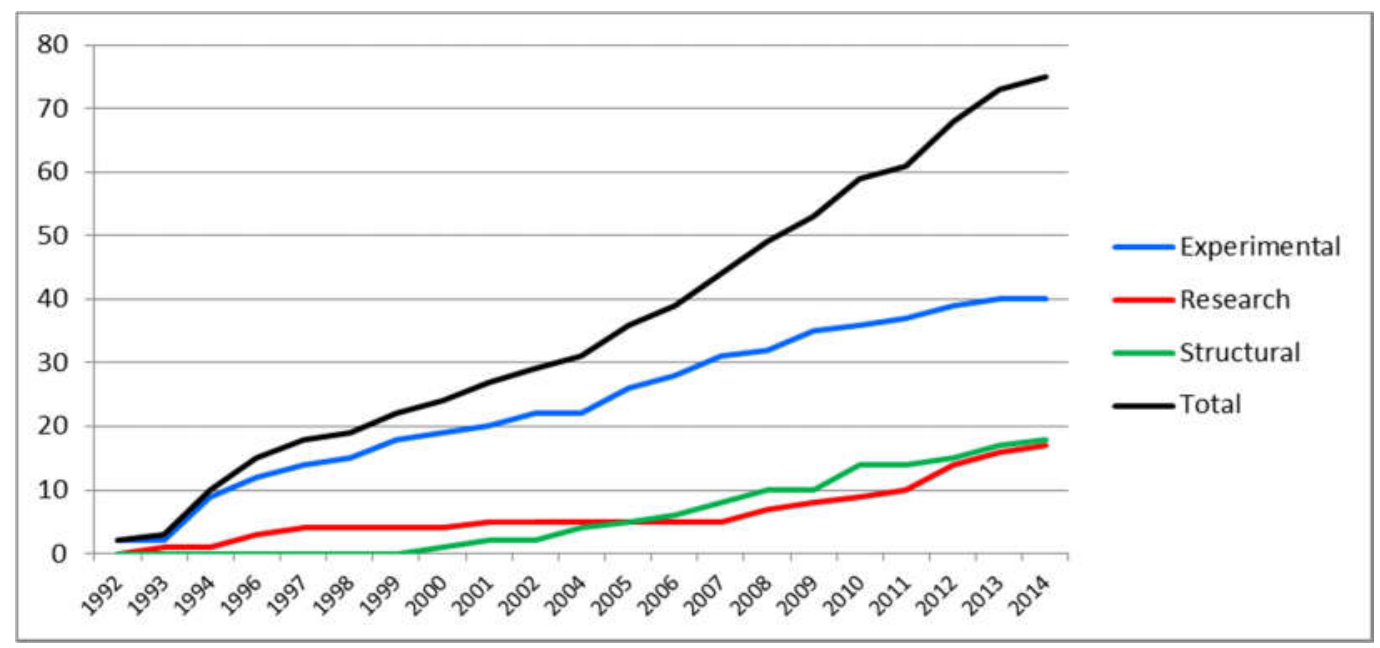

The first projects involved actors from a small number of countries, and while the range of participants have increased over time, these countries - and a core set of organisations in them - remained central actors. By the end of the period under analysis, 360 organisations from 34 countries had participated in projects, but only 13 countries had over 10 participations. Interestingly, by the early 2000s some projects started including actors from outside Europe, particularly from the US and some Asian countries (under bilateral of multilateral agreements), reflecting the growing interest of these regions in the wave energy field. A total of 10 non-European countries were involved in EU projects.

Table 1 shows the 10 countries with higher number of project participations during this period and Figure 2 shows the evolution over time of the participations of the $5+$. The UK emerges as the leading country, having participated in $2 / 3$ of the European projects funded, and coordinating almost half of them, followed by Portugal that participated in more than half and, at a certain distance, by

DINÂMIA'CET - IUL, Centro de Estudos sobre a Mudança Socioeconómica e o Território ISCTE-IUL - Av. das Forças Armadas, 1649-026 Lisboa, PORTUGAL 
Ireland, Denmark and Spain. While organisations from the first four countries pioneered the activities, Spain entered more recently but achieved a remarkable growth in a decade.

Table 1 - Participation in European projects (1992-2014) - 10+ countries

\begin{tabular}{lccccc}
\hline $\begin{array}{c}\text { Countries } \\
(\mathbf{1 0 + )}\end{array}$ & $\begin{array}{c}\text { No Projects } \\
\text { Total=75 }\end{array}$ & $\begin{array}{c}\text { \% total } \\
\text { projects }\end{array}$ & $\begin{array}{c}\text { \% projects } \\
\text { coordinated } \\
\text { (on participated) }\end{array}$ & $\begin{array}{c}\text { No participations } \\
\text { Total=681 }\end{array}$ & $\begin{array}{c}\text { No } \\
\text { organisations } \\
\text { Total=360 }\end{array}$ \\
\hline UK & 55 & $73.3 \%$ & $40.0 \%$ & 133 & 75 \\
Portugal & $\mathbf{4 3}$ & $\mathbf{5 7 . 3 \%}$ & $\mathbf{3 2 . 6 \%}$ & $\mathbf{8 6}$ & $\mathbf{2 7}$ \\
Ireland & 33 & $44.0 \%$ & $15.2 \%$ & 44 & 13 \\
Denmark & 29 & $38.7 \%$ & $37.9 \%$ & 62 & 32 \\
Spain & 25 & $33.3 \%$ & $28.0 \%$ & 53 & 36 \\
Germany & 22 & $29.3 \%$ & $9.1 \%$ & 31 & 18 \\
Norway & 21 & $28.0 \%$ & $14.3 \%$ & 41 & 29 \\
France & 19 & $25.3 \%$ & $10.5 \%$ & 30 & 15 \\
Italy & 19 & $25.3 \%$ & $15.8 \%$ & 34 & 26 \\
Sweden & 19 & $25.3 \%$ & $0.0 \%$ & 25 & 14 \\
\hline
\end{tabular}

Figure 2 - Countries with higher number of European projects over the FP (1992-2014)

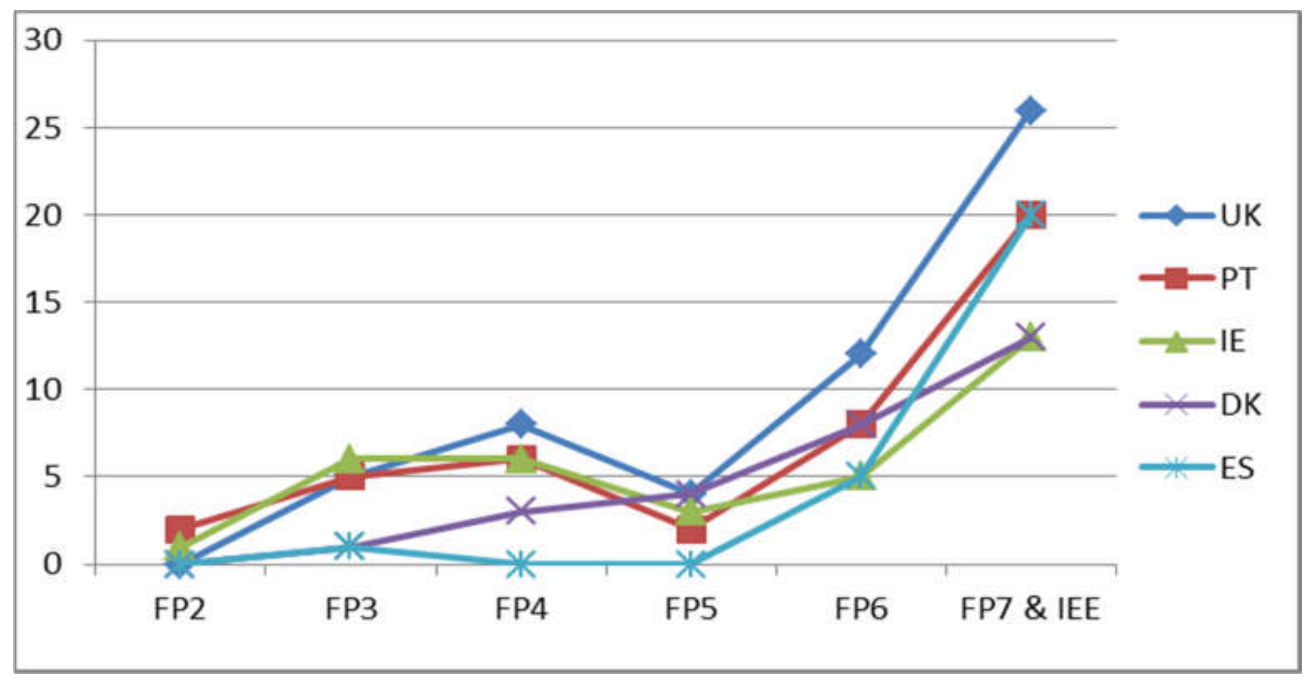

Firms represent over $50 \%$ of the participants. Around $20 \%$ are technology developers (i.e. companies involved in the development of an energy conversion system or of some of its key elements), the remaining being energy utilities, engineering companies and other firms developing activities along the value chain, that were frequently present in experimental projects. Firms have been active from the early stages, but their numbers took-off more recently. This reflects the expansion of the niche network, in particular the capacity to attract a broader set of companies the field (Figure 3). Nevertheless, most of them tend to be present in very few projects (several only in one) and, as would be expected, to prevail in experimental ones. Conversely, research organisations, which also have an important presence in quantitative terms $(37 \%)$, and a few collective organisations, often play an

DINÂMIA'CET - IUL, Centro de Estudos sobre a Mudança Socioeconómica e o Território ISCTE-IUL - Av. das Forças Armadas, 1649-026 Lisboa, PORTUGAL 
additional role as knowledge conveyers across projects and over time. This is namely the case of some organisations that have a high participation level and are frequently involved in structural projects. The most active are listed in Table 2, which also confirms the continued presence of actors from the countries highlighted above.

Figure 3 - Number of projects by type of organisation along the FPs (1992-2014)

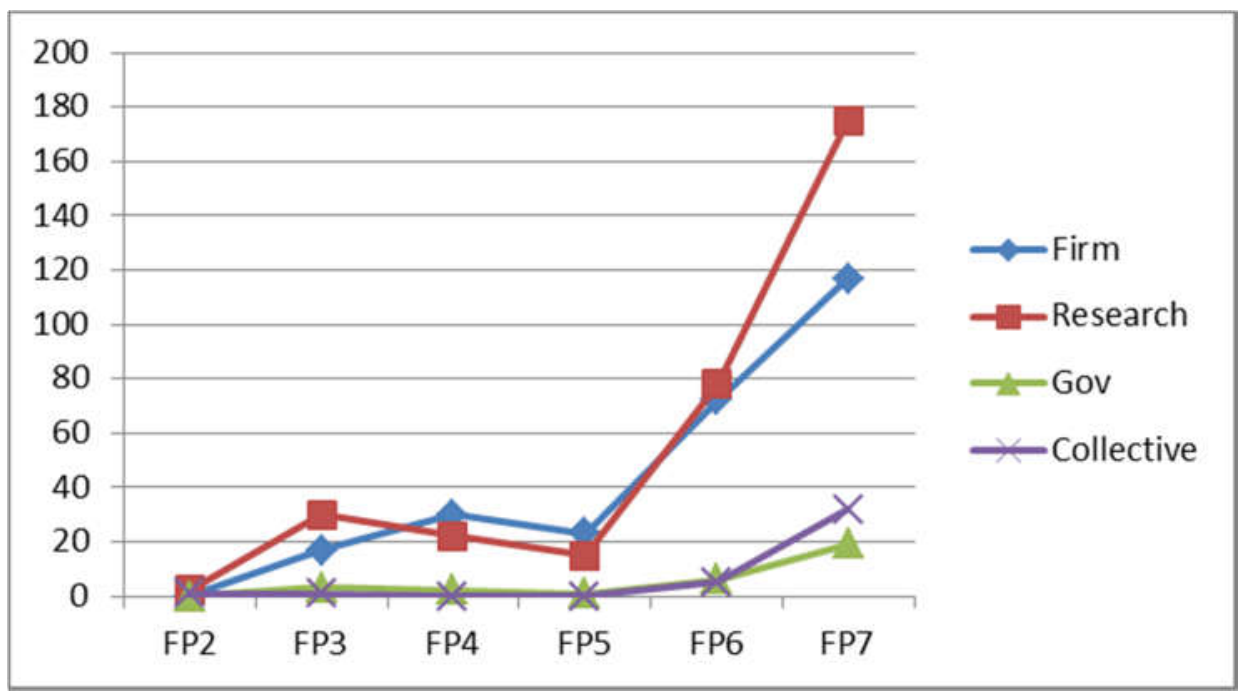

Table 2 - Individual organisations with highest participation in projects between 1992-2014

\begin{tabular}{|l|c|c|c|c|}
\hline Organization (10+) & Country & No Projects & No Coordinations & \% total projects \\
\hline University College Cork & IE & 24 & 2 & $32.0 \%$ \\
Instituto Superior Técnico (IST) & PT & $\mathbf{2 0}$ & $\mathbf{7}$ & $\mathbf{2 6 . 7 \%}$ \\
WavEC & PT & $\mathbf{1 8}$ & $\mathbf{2}$ & $\mathbf{2 4 . 0 \%}$ \\
University Of Edinburgh & UK & 17 & 3 & $22.7 \%$ \\
LNEG & PT & $\mathbf{1 3}$ & $\mathbf{2}$ & $\mathbf{1 7 . 3 \%}$ \\
Aalborg Universitet & DK & 11 & 0 & $14.7 \%$ \\
Queen's University of Belfast & UK & 11 & 2 & $14.7 \%$ \\
Fraunhofer-Gesellschaft & DE & 9 & 1 & $12.0 \%$ \\
Ecole Centrale de Nantes & FR & 9 & 0 & $12.0 \%$ \\
NTNU & NO & 9 & 0 & $12.0 \%$ \\
\hline
\end{tabular}

Finally Figure 4 presents the network of organisations that participated in European projects during the period under analysis, showing European organisations in blue and those from other regions in different colours. The size of the nodes reflects the actor betweenness centrality, highlighting actors that participated in a variety of RTD projects with diverse networks compositions, acting as brokers between other actors and contributing to the structuring of the network. Figure 4 confirms the central position of a set of organisations that acted as conveyers of knowledge. These are mainly research

DINÂMIA'CET - IUL, Centro de Estudos sobre a Mudança Socioeconómica e o Território ISCTE-IUL - Av. das Forças Armadas, 1649-026 Lisboa, PORTUGAL

Tel. 210464031 - Extensão 293100 E-mail: dinamia@iscte.pt http://dinamiacet.iscte-iul.pt/ 
organisations (squares) - which often coincide with the ones listed above as the most active - although we can also observe some collective organisations (circles) and firms (triangles). These organisations can be described as "intermediary actors", as proposed by the socio-cognitive perspective (Geels and Deuten, 2006). They participate in a sequence of individual projects, linking between them; and they further contribute to the learning processes by bringing the knowledge and experience thus gained into the performance of aggregation activities conducted in the context of European level structural projects.

Figure 4 - Network of organisations in European wave energy projects (1992-2014)

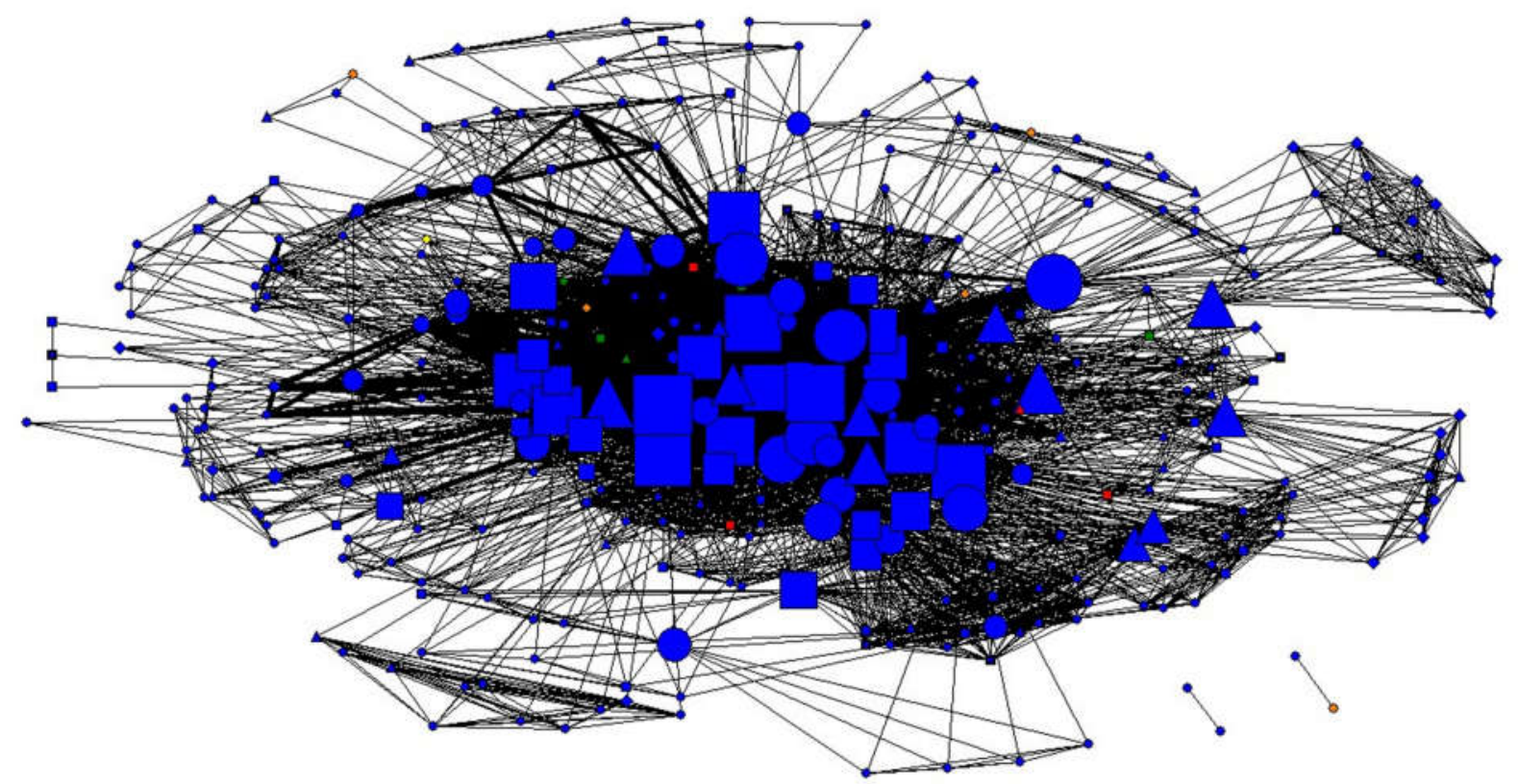

Legend: Squares - Research organisations; Triangles - Firms; Circles: Other

Actors with highest values for betweenness centrality (brokers): NTNU (NO), Fraunhofer-Gesellschaft (DE), IST (PT), LNEG (PT); University College Cork (IE); Ecole Centrale de Nantes (FR); IT Power Ltd (UK); Denmark Technical University (DK); Ente Vasco de la Energia (ES); University of Edinburgh (UK).

The strengthening of the learning processes in the wave energy field, and the role played by some key countries and organisations is confirmed by data on scientific publication. For this we draw on an analysis conducted by Corsatea and Magagna (2014) for the period 1998-2011, using two sources of data: ISI Web of Science for journal papers, and the proceedings database of the European Wave and Tidal Energy Conference for peer-reviewed conference papers. They uncovered a high growth rate in both cases, which was particularly impressive for published papers, which took off in the late 2000s. This increase was also associated with the appearance of some topic specific journals, which provided an additional arena for knowledge sharing. These authors also identified the organisations with highest scientific production. UK was the country with the highest rate of production, followed at a distance 
by organisations from Ireland, Denmark and Portugal. The most productive organisations were largely coincident with the central players in the European projects listed above.

Finally, patent data, provides additional information on the product oriented activities and also permits to move the focus beyond the European area. For this purpose we use data on "International Patent Applications", filed under the Patent Cooperation Treaty (PCT), since they are likely to reflect better the intense activity taking place in the field. In fact, although no patent is granted as a result of an international patent application, it is an indication of intention of patenting in the near future ${ }^{3}$. Data on European Patents (EP), i.e. those effectively submitted to the European Patent Office, are also presented, for comparative purposes.

Figure 5 presents the evolution of patent PCT applications distinguishing between patents that included at least one organisation among the applicants and patents exclusively filed by individual applicants. The data shows an increase in patenting in the mid-2000s ${ }^{4}$. Individual applicants prevailed in the early years and remained important throughout the period, even if their weight appears to be decreasing in recent years. Their continued presence reflects the low stability of the technology which gives margin for a wide variety of solutions proposed by individual inventors. Data on European patent applications (Figure 6), which already entail a greater commitment, namely in financial terms, shows that organisations become more decisively involved from around the mid-2000s, while the number of individual applications remained comparatively smaller (despite a slight increase).

\footnotetext{
${ }^{3}$ Following the signature of the Patent Cooperation Treaty (PCT), inventors can file an "International Patent Application" that enables them to request protection simultaneously in several countries (so far 148 countries ratified the treaty) and also to have the potential patentability of their invention examined by experts. This permits to defer for 30 months the final decision on whether (and where) to apply for a patent (thus postponing the substantially higher costs involved), and also provides inventors with an informed opinion that can lead to a more substantiated patent application.

${ }^{4}$ If we consider the priority date - which corresponds to the year when the application was first submitted instead of the publication date, it is possible to conclude that patenting activity effectively took-off in the early 2000s.
} 
Figure 5 - Number of PCT patent applications by date of publication-1979-2014

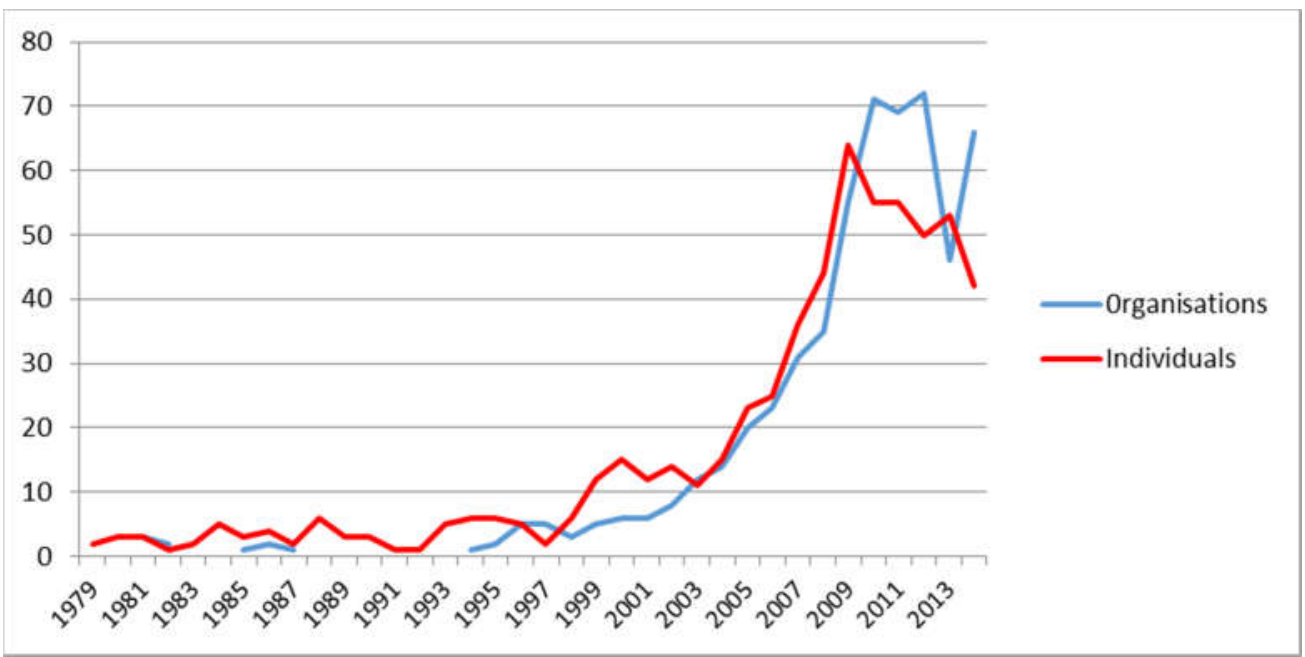

Figure 6 - Number of EP patent applications by date of publication - 1979-2014

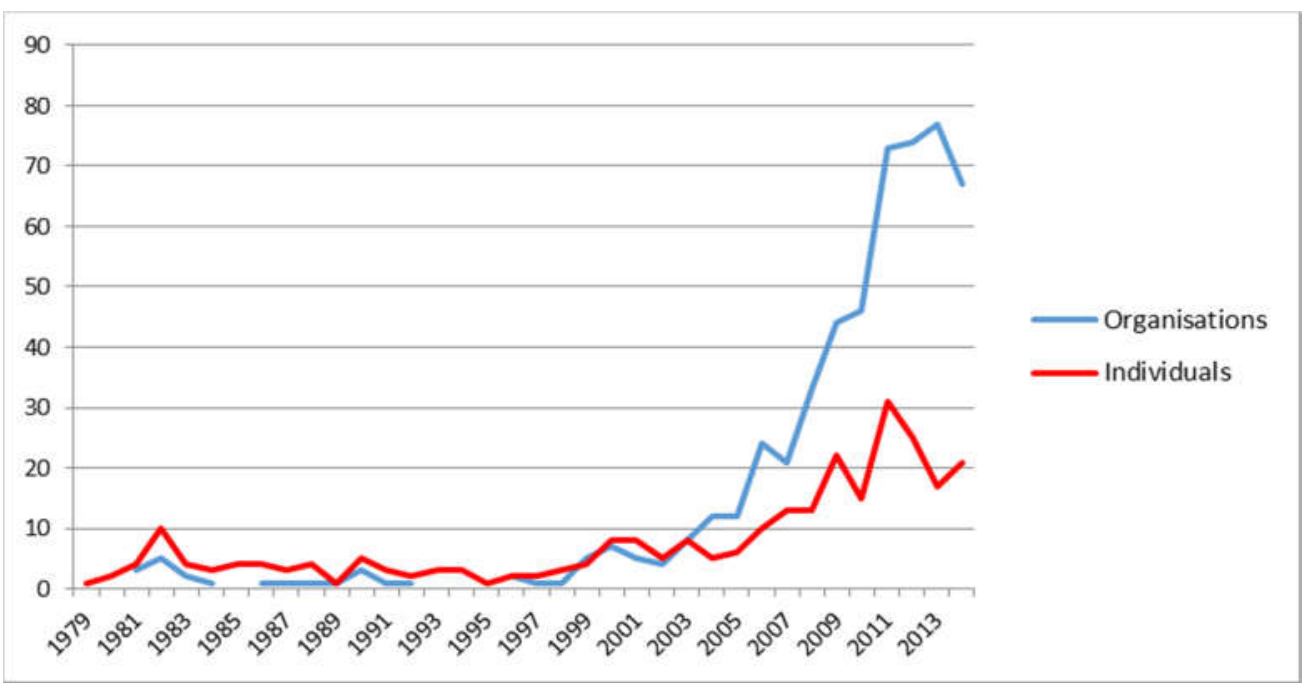

In what concerns the origin of PCT patent applicants (Figure 7) Europe dominates with about half of the patent applications in the period, followed by North America (US and Canada) with 23\% and Asia (mostly China, Korea and Japan) with 13\%. Figure 8 presents the evolution of patenting over time by world region, confirming the early involvement of European countries in wave energy technology development and showing that patenting by American and Asian nationals took-off later but gained some momentum. It is nevertheless relevant to point out that in the case of Asian countries this increase was mostly based on individual applications. 
Figure 7 - Distribution of PCT patent applications by world region (period 1979-2014)

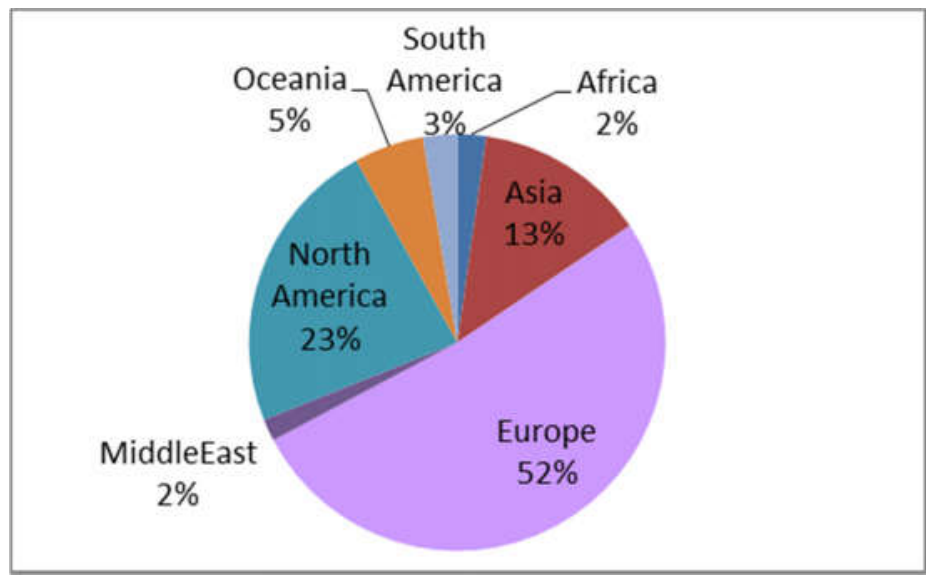

Figure 8 - Evolution of number of PCT patent applications by world region (publication date 1979-2014)

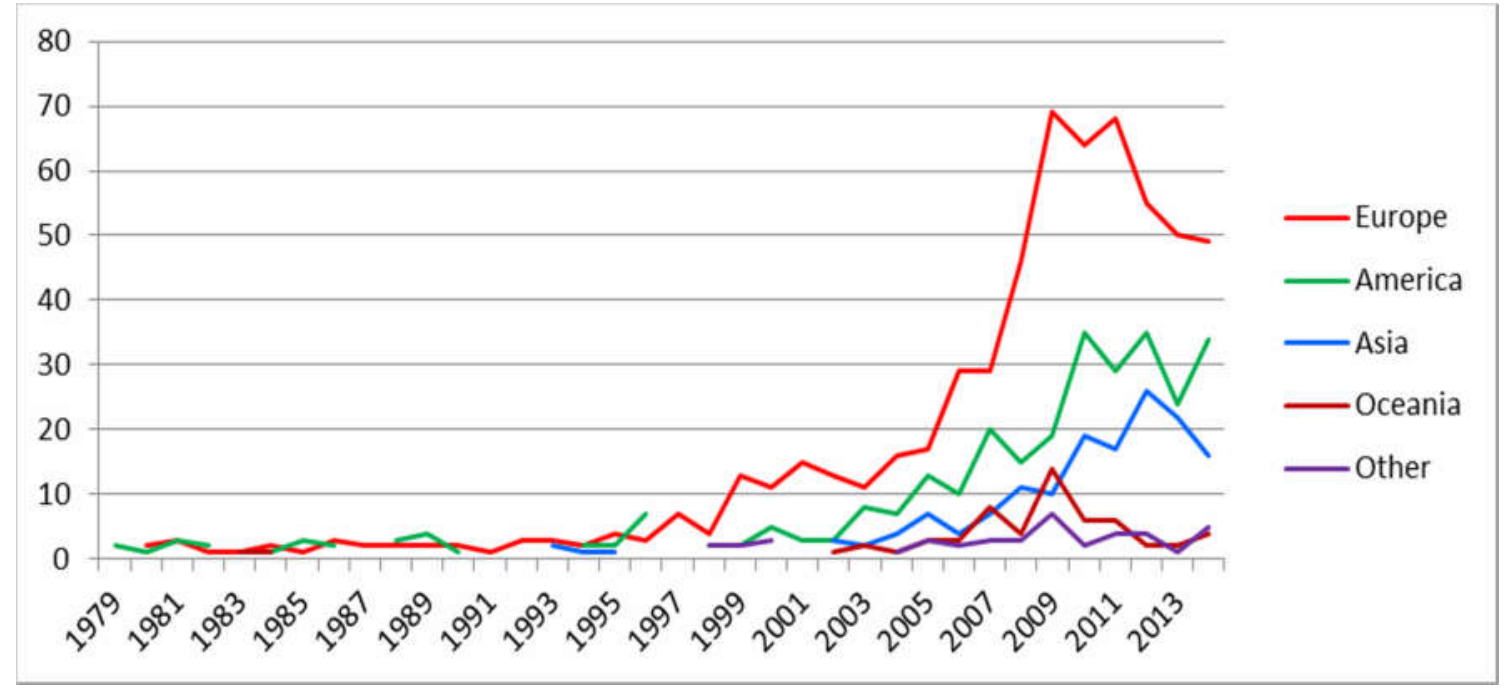

In what concerns individual countries Figure 9 shows that the US is now dominant, followed by the UK and that some of the European countries with strong positions in knowledge production (e.g. Portugal, Ireland and Denmark) are much less productive in terms of patenting. Among non-European countries Australia stands out, having gone through a fast development in recent years. The data also shows that countries display different patterns in terms of the weight of organisational vs. individual patents. 
Figure 9 - Number of PCT patent applications by countries with more than 10 applications (1979-2014)

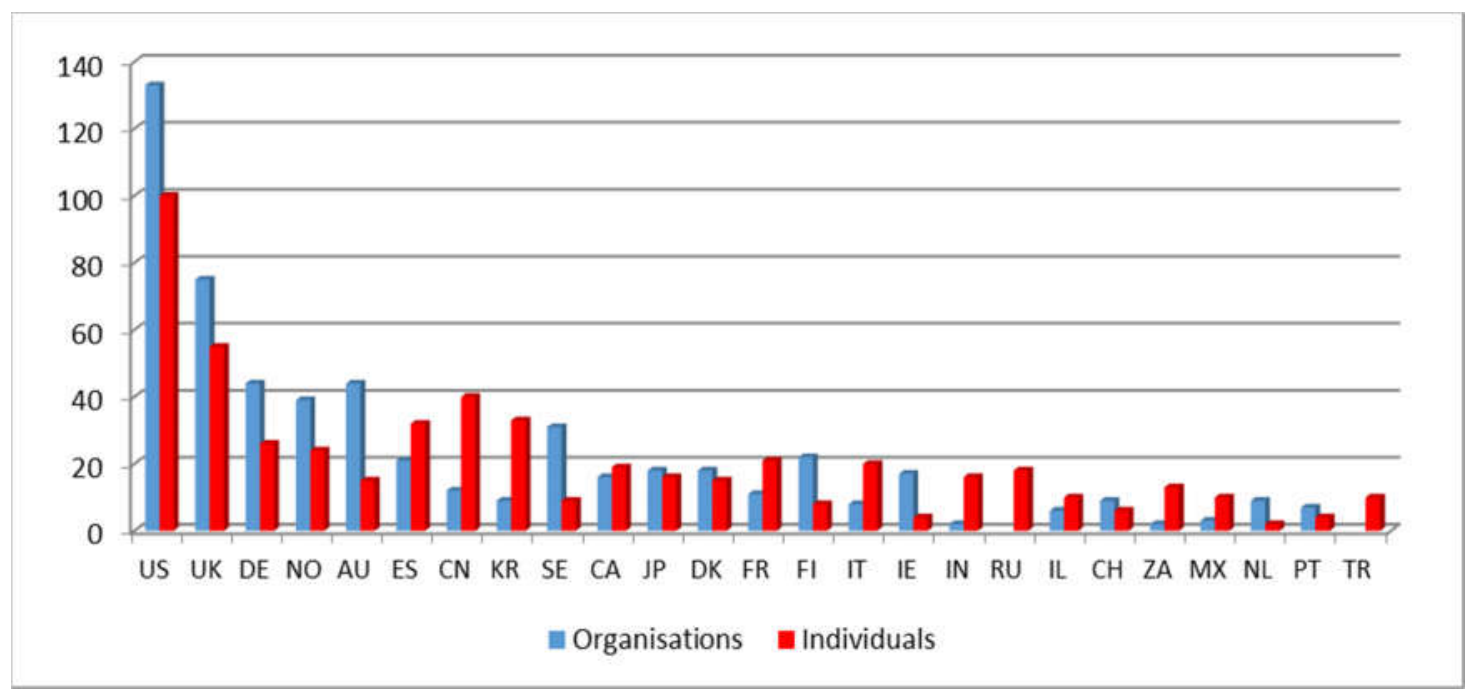

Organisational patenting is clearly dominated by firms from all around the world, as can be observed in Table 3 that lists organisations with at least 5 patent applications. Applicants tend to be new technology intensive companies, but it is also possible to find some large established companies that have become involved in the field, often through the acquisition of small companies and/or their technologies, reflecting the growing interest of some regime actors in the emerging field. Although some research organisations can also be found (alone or in collaboration), they have much less expression and do not always coincide with the main knowledge producers.

Table 3 - Organisations with at least 5 PCT patent applications (1979-2014)

\begin{tabular}{|l|c|c|}
\hline Applicant & Country & No patents \\
\hline BOSCH GMBH & DE & 29 \\
OCEAN POWER TECHNOLOGIES INC & US & 24 \\
AW ENERGY OY & $\mathrm{FI}$ & 11 \\
SEABASED AB & SE & 11 \\
VOITH PATENT GMBH & DE & 10 \\
SEAPOWER PACIFIC PTY LTD & AU & 9 \\
AQUAMARINE POWER LTD & UK & 8 \\
SINGLE BUOY MOORINGS & CH & 8 \\
FOBOX AS & NO & 6 \\
OSCILLA POWER INC & US & 6 \\
WELLO OY & FI & 6 \\
APPLIED RES \& TECHNOLOGY LTD & UK & 5 \\
RESOLUTE MARINE ENERGY INC & US & 5 \\
SWEDISH SEABASED ENERGY AB & SE & 5 \\
WAVEBOB LTD & IE & 5 \\
\hline
\end{tabular}

DINÂMIA'CET - IUL, Centro de Estudos sobre a Mudança Socioeconómica e o Território ISCTE-IUL - Av. das Forças Armadas, 1649-026 Lisboa, PORTUGAL 
The development of viable wave energy technologies always involves technology testing in real sea conditions. The activities associated with the testing of wave energy converting systems are complex, time consuming and expensive, in particular because the final step always requires buildling, installing and testing full-sized proptotypes, in open sea (Falcão, 2010). Given the nature of wave conversion, it is only at this stage it is possible to effectively test the viability of the systems and their actual performance (contrary to what happens with other renewable technologies). The costs involved are much beyond the capacity of a technology developer, requiring the involvement of external investors and a substantial financial support from governments.

This problem, that has hindered the development of the technology, and has been addressed by the creation, at European level, of shared test infrastructures. In some cases this involves the creation of consortia joining countries/organisations that have installed experimental facilities at various levels (from basin to open sea) and making them available to members or also to other organisations, sometimes under the coordination of supra-national entities. Some facilities were created at country level and are at least partly funded by governments or, in some cases, by European programmes (e.g. MARINET). A recent overview identified 13 test and demonstration sites in Europe, including those that accommodate smaller projects and those that enable full scale test and demonstration or even precommercial projects (SOWFIA, 2011). Figure 10 shows the location of some of the main European centres.

Figure 10: Main wave energy testing and demonstration sites in Europe (2011)

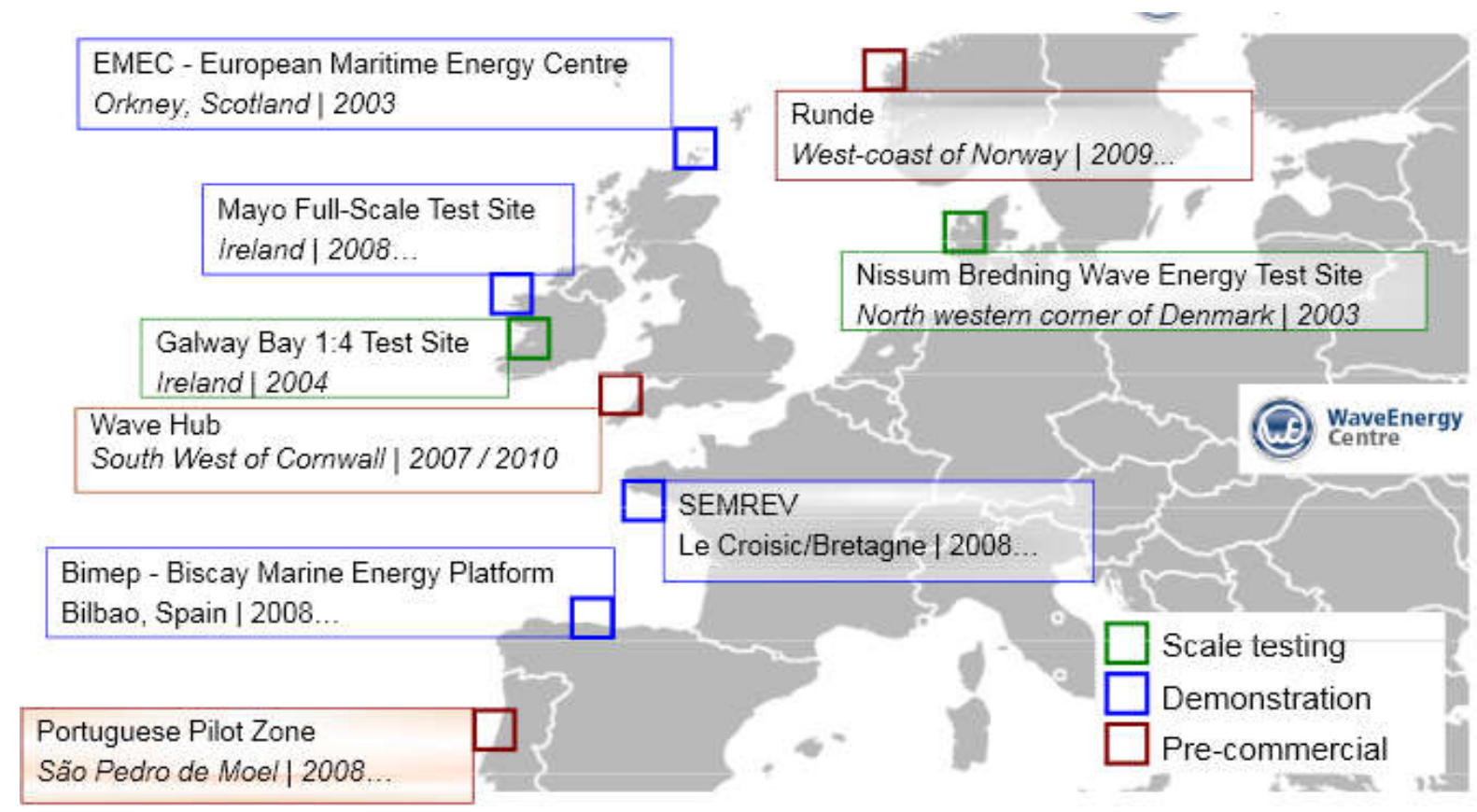

Source: WAVEC - EnergyIN-Wavec Workshop Roadmap Energias Renováveis Offshore, June 2011.

DINÂMIA'CET - IUL, Centro de Estudos sobre a Mudança Socioeconómica e o Território ISCTE-IUL - Av. das Forças Armadas, 1649-026 Lisboa, PORTUGAL 


\subsection{Collective efforts of an emerging community}

Collective actions on behalf of an emerging wave energy niche become more evident in the early 1990s, particularly in Europe. These actions result from the activity of a growing community that starts engaging in the collection and aggregation of information originating from a variety of experiments taking place in and across different locations. At some point, wave energy actors were able to gain the interest of the European Commission that included the field in RTD funding programmes in 1993 and supported several initiatives, where knowledge and experiences were shared (Clément et al, 2002). Dedicated conferences had been taking place since the late 1970s (Falcão, 2010), but in the 1990s their scope was expanded and, over time, events such as the European Wave Energy (later also Tidal) Conferences (EWTC), started in 1993, or the International Conferences on Ocean Energy (ICOE), started in 2006, became regular discussion arenas (Nissila, 2015). Similar field building concerns are patent in the growing number of European structural projects. Examples of these are, among others, the Coordinated Action for Ocean Energies launched in 2004 (CA-OE, 2009), the 2010 ORECCA project, that produced a Roadmap (ORECCA, 2011), or the recent Strategic Initiative for Ocean Energy Development (SI-OCEAN) (Magagna et al, 2014).

Another important step was the launch, in 2001, in the context of the International European Agency, of an Implementing Agreement on Ocean Energy Systems (IEA-OES) with the explicit objective of facilitating and coordinating ocean energy research, development and demonstration through international cooperation and information exchange (OES, 2002). OES has become an important locus for aggregation of experiences, agenda definition and knowledge diffusion (OES, 2002-2014). Founder countries were UK, Portugal and Denmark, but some non-European countries Japan, Canada and the US - joined soon after. Membership reached 23 countries in 2014 (about 1/2 from Europe and $1 / 4$ from Asia). Although participation is at country level, the actual representatives tend to belong to the most active organisations in the field (OES 2002-2014). Figure 11 shows the evolution of membership, providing a snapshot of the growing interest of different world regions in formalising their presence in this field.

Figure 11 - Evolution of number of IEA-OES members by world region (2001-2014)

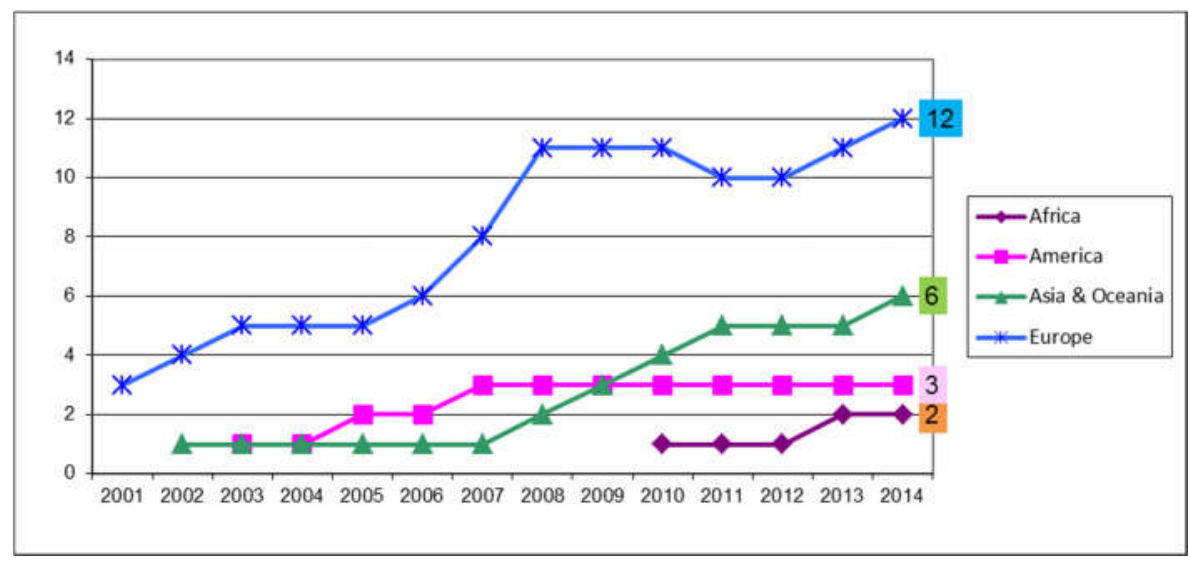

DINÂMIA'CET - IUL, Centro de Estudos sobre a Mudança Socioeconómica e o Território ISCTE-IUL - Av. das Forças Armadas, 1649-026 Lisboa, PORTUGAL

Tel. 210464031 - Extensão 293100 E-mail: dinamia@iscte.pt http://dinamiacet.iscte-iul.pt/ 
Finally, in 2006 a European Ocean Energy Association was launched, under the EC auspices. It involved, from start, large companies (including some energy utilities) and has increasingly assumed the role of the "voice" of the sector, producing a Vision document in 2013, at a moment when investment appeared to start dwindling (EU-OEA, 2013). It is currently involved in actions towards the launch of an Industrial Initiative in the context of the European Horizon 2020 Programme, in which ocean energies have become an important area of action. This is namely reflected in a more significant presence of the ocean-related energies (including wave energy) in European Union strategic policy documents, including the production an "Action Plan to support the development of blue energy" (EC, 2014) and a more extensive reference in the Strategic Energy Technology (SET) Plan (from which it was so far largely absent) (EC, 2015); and is likely to result in an increase in financing by the European RTD and other support programmes. In fact, as activity in the wave energy field extends beyond the traditional Atlantic region towards the Pacific, and Asian countries start investing heavily, European supra-national organisations are increasingly engaged with the need to maintain the "European leadership" (EU-OEA, 2013; EC, 2014).

Finally, several country level associations were also created in the mid/late 2000s in some European countries and outside Europe, namely in the US, Australia and Japan. Other supra-national networks, organisations and infrastructures have also emerged in this period.

These organisations and events have produced, over time, an intense stream of documents analysing the state of the art of technology and the opportunities and obstacles to the field and proposing directions for its development, targeting field actors and policy makers. Thus, they have been extremely active producing abstract knowledge and articulating expectations on the societal contribution of wave energy and the possible paths regarding its future development. Early expectations and proposed actions have, over time, been adjusted according to the sometimes disappointing results. This includes namely, the growing association of wave energy the with other ocean energies, in particular offshore wind that had started achieving positive results and experiencing fast growth. This move became more evident in mid-2000s and is currently reflected in the activity of the various collective organisations, as well as on policies (European and national) that generally target "ocean energies" (e.g. EC, 2014).

This collective action reflects the formation of an increasingly connected community that is strongly international from its inception. It also indicates its active efforts towards the development of niche level learning processes. That is, to produce and share collective knowledge and to use the results of these efforts to articulate expectations, providing directions for action across the niche space and striving to attract and maintain actors and resources. It also reveals the presence of a persistent core of actors that have managed to keep the process going over time, achieving a greater niche structuration, despite the difficulties in stabilising the technology and the uncertainty this signals to 
resource providers. The results in terms of overall niche evolution reflect a slow and non-linear development, even if the network of actors has increased and diversified and the amount of resources available for the niche has shown a positive evolution.

This analysis provided an overview of the niche development trajectory and offered some insights into the nature of processes at work, with particular emphasis on their spatial dynamics. However, a more precise understanding of the nature of the cognitive processes performed concerning both the production of generic knowledge and lessons, and the way these influenced the definition (or reconfiguration) of field-level visions and agendas and the expansion of supportive networks - will require a more in-depth examination of the community level aggregation activities enacted over time (namely drawing on their outputs), as well as a detailed assessment of the role played by intermediary actors.

The collective effort towards the construction of a wave energy space was grounded on the activities being conducted in or across a great variety of locations. However, some actors, mostly originating from a few countries located in one world region (Europe), were central in the process of niche formation and remained very important along its evolution. Thus activities at country, and in some cases at regional level (e.g. Scotland in the UK), were an important element of this process. As pointed out above, territorial conditions are likely to have led to differences in the way niche processes were conducted and in the actual contributions to overall niche development. This question will be addressed below.

\section{THE DEVELOPMENT OF THE WAVE ENERGY NICHE IN PORTUGAL}

In this section we will focus on the processes that took place in Portugal as part of the formation and attempted upscale of a wave energy niche. This will enable a more detailed analysis of these processes, as well as a better understanding of the impact of territorial elements on niche development.

The niche processes taking place in the Portuguese context are addressed from the standpoint of the actors, with a view to identify the main actors and the timing, nature and degree of their involvement in the niche, as well as to make a preliminary assessment of the type of strategies they adopted and the relationships they established. The processes are also addressed from the perspective of the system, namely to gain some insights into network formation and expansion (or contraction), the type of actors the niche is able to attract, the resources it can mobilise and its capacity to influence the launch of favourable policies; and into the impact on niche evolution of developments taking place outside the niche, i.e. in the energy regime, in competing niches, in adjacent fields and in the economy as a whole.

DINÂMIA'CET - IUL, Centro de Estudos sobre a Mudança Socioeconómica e o Território ISCTE-IUL - Av. das Forças Armadas, 1649-026 Lisboa, PORTUGAL 
The analysis started by building a detailed map and chronology of actions (actors, activities, relationships, outcomes), drawing on the different sets of data compiled for the Portuguese case, and on the qualitative information collected both from the niche actors and from documents addressing specific aspects of niche activity. This supported a more detailed analysis that aimed at: i) identifying significant social and cognitive activities that were conducted over time and delineating their spatial scope; ii) understanding the outcomes of these activities and the implications for the niche trajectory; iii) tracing specific configurations assumed by the niche processes over time, and the role played by the interplay between territorial and niche level effects.

\subsection{Brief overview of niche evolution}

For analytical purposes the niche trajectory was organised in six main "periods". Criteria for the definition of the periods were relevant changes in the niche configuration, which could derive from intensity of actor entry (or exit); changes in the nature or mix of activities (e.g. move from essentially $R \& D$ to experimental activities), attraction of new resources and/or new types of actors (e.g. regime actors; foreign technology developers); changes in actor expectations; changes in policies. The following periods were identified, which were labelled according to their dominant feature:

- $\quad$ P1 Before 1988 - Antecedents

- P2 1988-1993 - Raising awareness

- P3 1994-1999 - First experiments

- P4 2000-2005 - Early niche expansion

- P5 2006-2010 - High expectations

- $\quad$ P6 After 2010 - Disappointment \& uncertainty

In this section we present a first overview of the evolution of the Portuguese wave energy niche along these periods, based on a quantitative assessment of the (documented) actions conducted, over time, by the actors involved in the niche. The analysis starts in P2, which effectively corresponds to early niche formation.

A first set of data concerns the creation of a network of actors and the level and nature of actual involvement of these actors. Figure 12 presents data on first entry - through formal activities and on new actions by actors already acting in the niche, distinguishing, for the latter, between actions that correspond to the performance of the same type of activity (repeat activities) and of new ones. For this purpose the activities performed in the niche are categorised in four types: research, experimental activities; business investment (including firm creation) and structural activities (e.g. creation of infrastructures and collective organisations; support to policy formulation; dissemination). The 
number of actors performing each type of function in each of the five periods is presented in Figure 13, while Figure 14 shows in more detail the actual activities performed.

Figure 12 shows that new entry of supportive actors grows steadily during the first three periods, register a sudden explosion in the fourth period and falls again, returning to the level of the first period. A similar pattern can be observed for the new actions of actors already in the niche. It is also worth noticing that during the main growth period (P5 - High Expectations) the actions of existing actors along similar functions multiplied and that, although these also fell sharply in P6 (Disappointment), there was a "core" network that continued engaging in repeat activities.

Figure 12 - Number of actors involved in formal activities, in each period

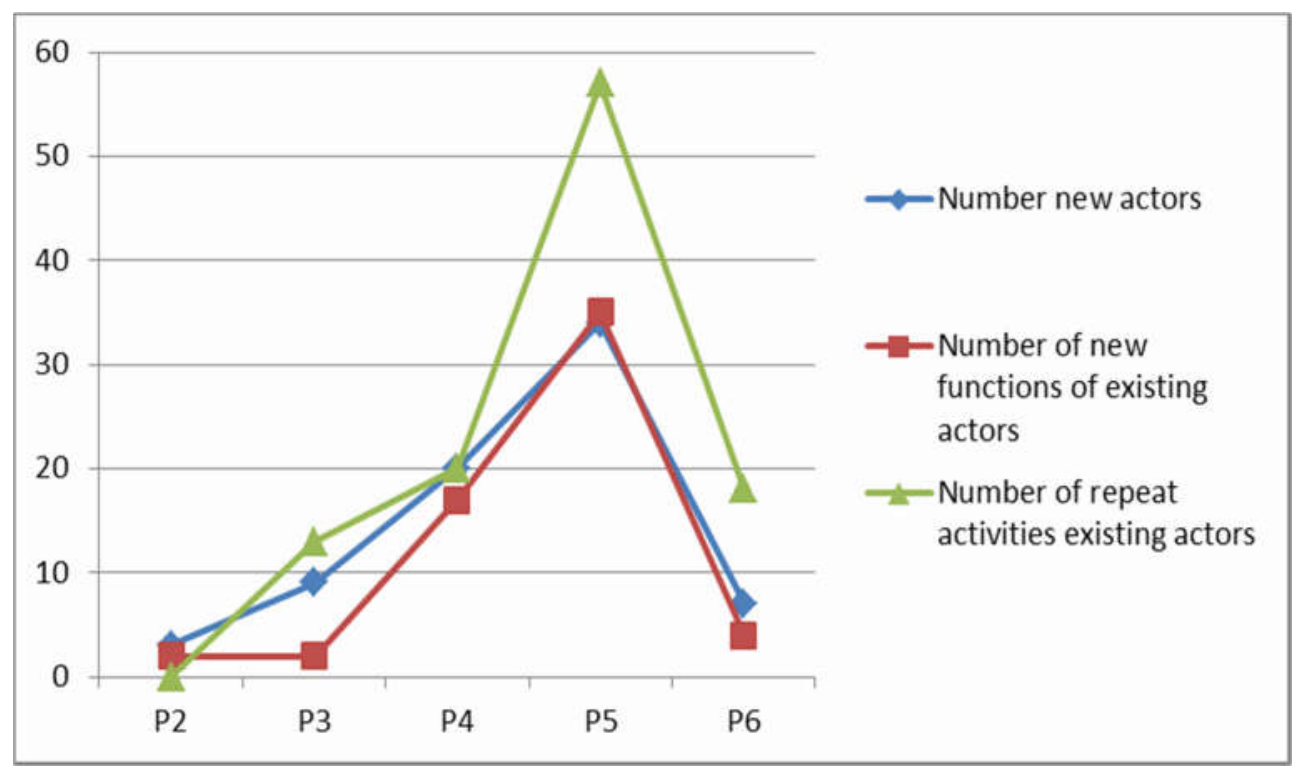

Figure 13 shows that the pattern of early evolution of the various types of activity differed. The number of organisations involved in experiments had a steady growth, while business investments basically creation of new organisations to develop technologies or to partner with foreign organisations in new projects - was largely concentrated on the high growth period. In Figure 14, experiments and business investments that materialised and those that were only announced (intentions) are distinguished, confirming the presence of a hype in Period 5. Structural activities gain some momentum in Period 4 suggesting an attempt of consolidation of the niche. The number of actors performing research activities is relatively stable in the first periods and returns to the same level after the peak in Period 5. Finally Figure 14 also shows that not only the number but also the variety of activities increased in the two growth periods (4 and 5).

DINÂMIA'CET - IUL, Centro de Estudos sobre a Mudança Socioeconómica e o Território 
Figure 13 - Type of activities: number of actors in formal activities by type in each period

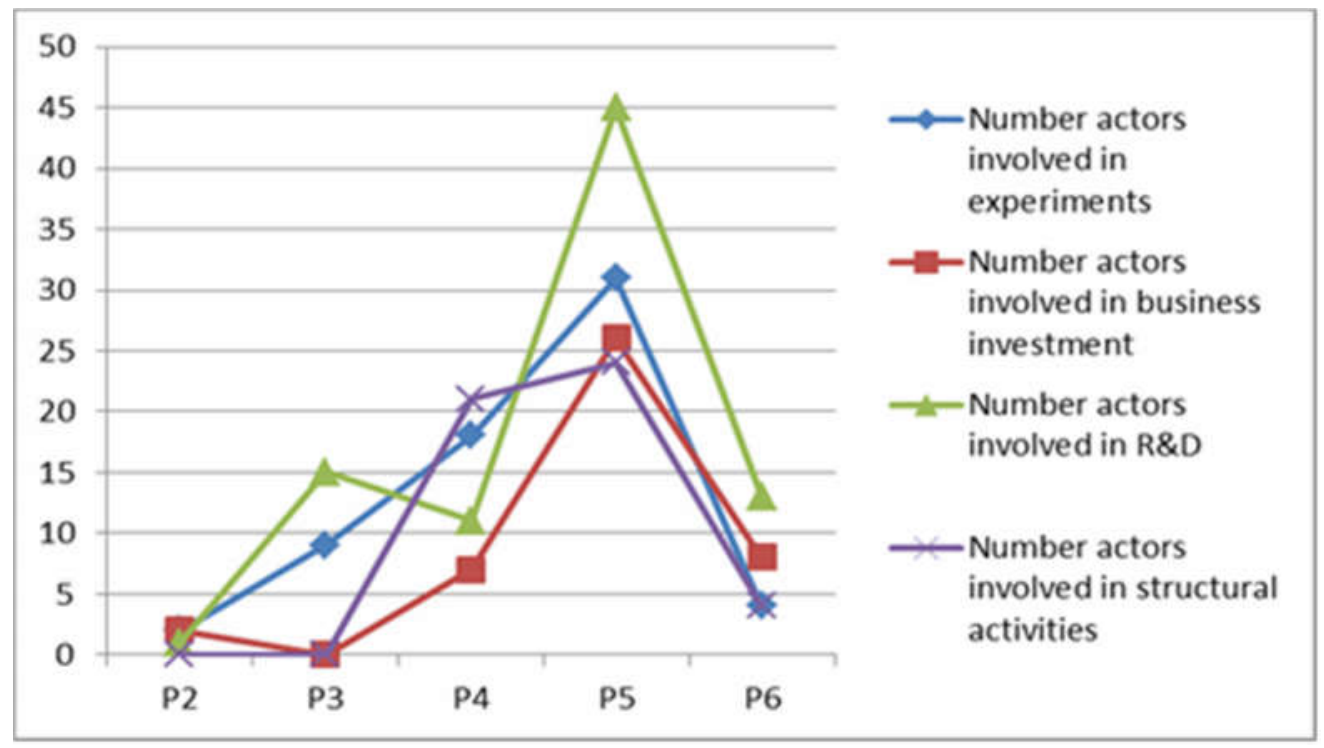

Figure 14 - Activities performed in the niche: number of actors involved by period

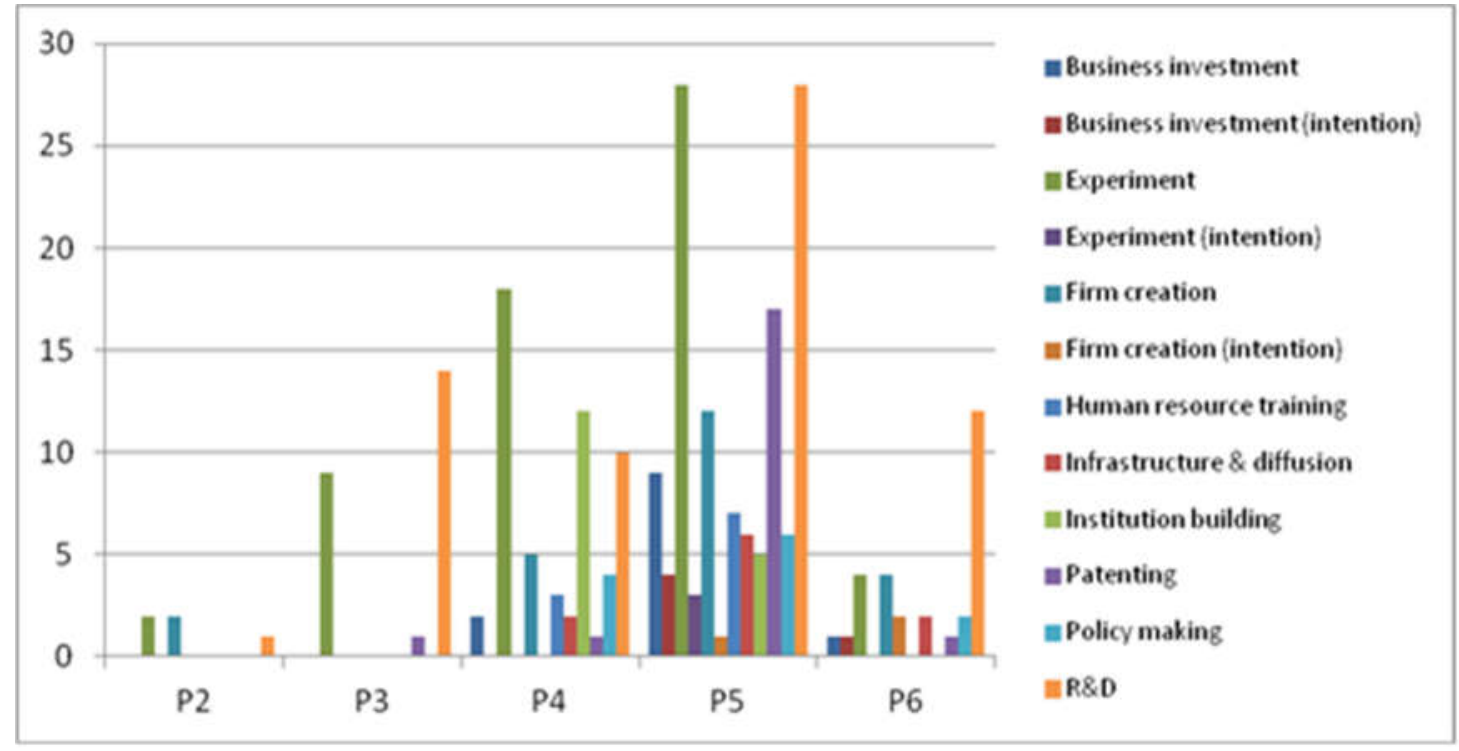

The next set of data concerns the type of actors active in the niche in every period. The different actors are aggregated in four types: research organisations; new firms - which includes technology developers and other firms created purposefully for developing activities within the niche (e.g. joint ventures); existing firms - which includes regime incumbents operating in the niche and also companies in complementary activities along the value chain; other - which includes collective actors, government bodies and local authorities and funding bodies.

DINÂMIA'CET - IUL, Centro de Estudos sobre a Mudança Socioeconómica e o Território ISCTE-IUL - Av. das Forças Armadas, 1649-026 Lisboa, PORTUGAL 
Figure 15 presents the number of actors of each type active in each period. It shows that new nichededicated firms start emerging in Period 4, when they are mostly Portuguese technology start-ups; and that their numbers jump associated with the attraction of foreign firms, returning again to smaller numbers, basically the early start-ups that resisted closure in Period 6. The number of research organisations involved remains small over time, despite a slight increase in the growth period, converging again to the early pioneers in the last period. It also shows that energy incumbents entered relatively early in the niche network and that their participation in the early experimental activities brought along some firms in complementary activities along the value chain.

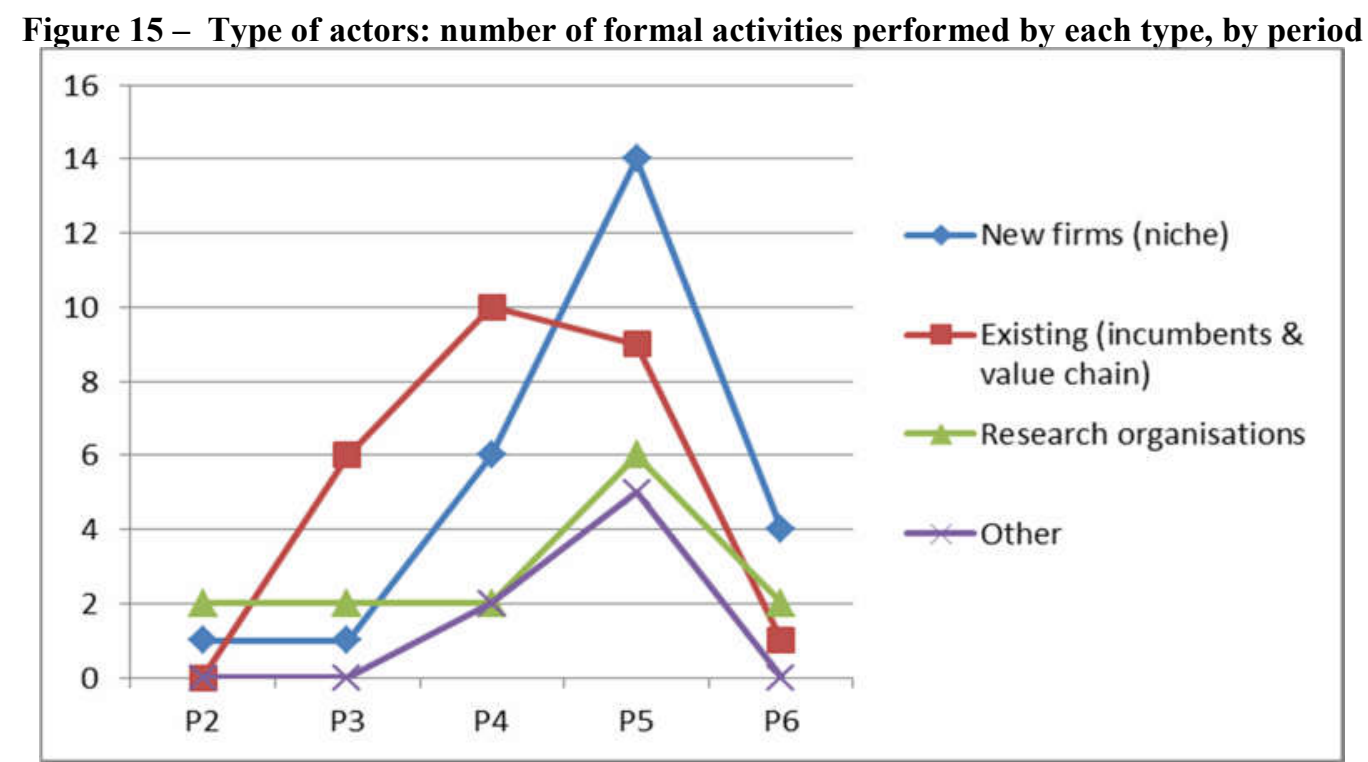

Interestingly established firms are the only type of actor whose actions do not register a sudden increase in Period 5, the numbers remaining stable from Period 4 to 5 . This may be explained by the fact that that practically no new experiment effectively started in Period 5, despite the statement of intentions and the creation of joint-ventures for that purpose, and thus there was no new entry by value chain companies. But, on the other hand, for several incumbents new activities effectively took place through the joint ventures they launched. Thus regime incumbents may have been more active during this period than this data suggests. Figure 16 shows as much, presenting a more precise snapshot of the involvement of established companies in the beginning of the period, associated with (expectations on) experimental projects involving foreign technologies, although it also indicates an early abandon.

DINÂMIA'CET - IUL, Centro de Estudos sobre a Mudança Socioeconómica e o Território ISCTE-IUL - Av. das Forças Armadas, 1649-026 Lisboa, PORTUGAL 
Figure 16 - Number of activities (new or repeat) performed in P5 (2006-2010) by type of firm

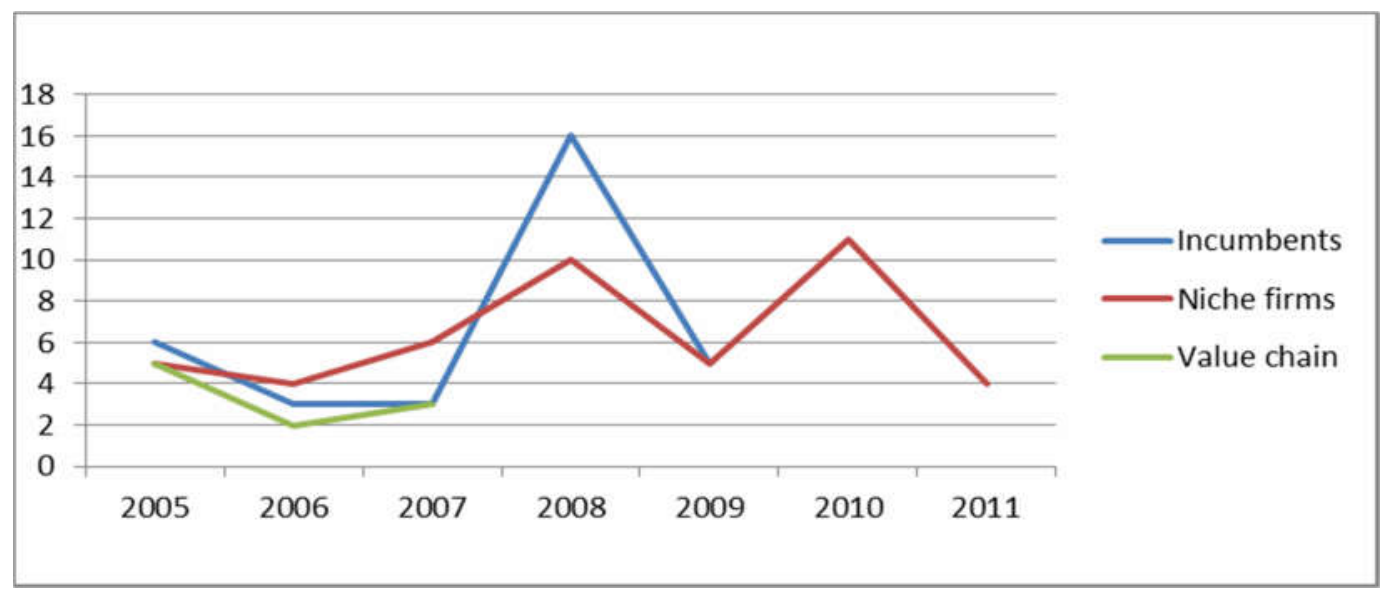

Finally we turn to entry of the foreign firms in activities taking place in Portugal. Figure 17 presents data on first entry, identifying both direct entry and the establishment of joint-venture with a local firm. It also documents repeat activities of those already operating. This data shows that attraction of foreign actors and joint ventures with local companies to implement local projects started in Period 4 with a small set of experiments, reached a peak with some new projects (and especially a high number of intentions) in Period 5 and fell in the last period leaving one company and one joint-venture active in Portugal.

Figure 17 - Number of activities of foreign actors, by period

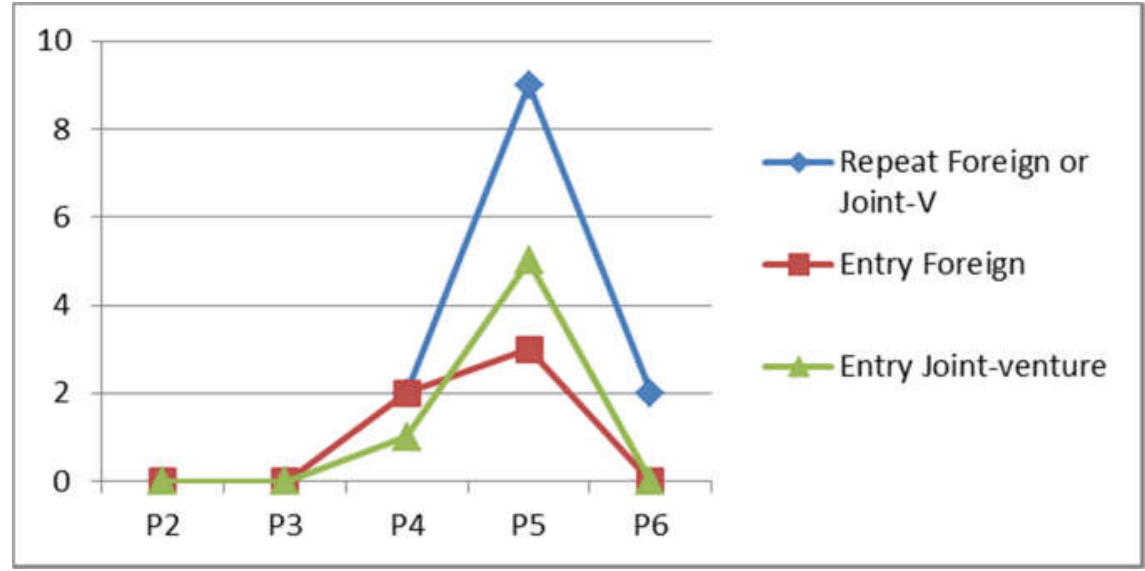

Overall, these figures show a clear pattern of slow growth, take off, hype and decline, whereby new entry of supportive actors, as well as the variety of actors and activities they perform, grow more or less steadily during the first three periods, register a sudden explosion and fall again, leaving only a "core" network active. However a closer inspection also confirms that different types of actors and different activities show slightly diverse dynamics over these periods. These patterns will be explained

DINÂMIA'CET - IUL, Centro de Estudos sobre a Mudança Socioeconómica e o Território ISCTE-IUL - Av. das Forças Armadas, 1649-026 Lisboa, PORTUGAL 
in greater detail below, through a more detailed analysis of the processes that took place, as well as the context where these processes unfolded. But before discussing the processes, we will provide some more detailed information about the actors and actions enacted by them.

\subsection{Niche actors and activities}

The actions summarised above resulted from the engagement of a variety of public, private and collective organisations in the development of scientific and technological knowledge as well as in the conduction of a variety of activities - at economic, social and political level - with a view to obtain develop and commercialise wave energy innovations.

\subsubsection{Knowledge production}

As already pointed out in section 4.1, Portuguese organisations were among the pioneers in knowledge production activities in the field of wave energy. These activities were largely supported by public funds, through research, technology and development programmes, first mostly at European level, but with national funding becoming increasingly being present throughout the 2000s. In this section we look in greater detail into the projects funded and their evolution along the periods identified in the niche trajectory. Data on projects funded by European programmes encompass all RTD projects with Portuguese participation (extracted from the dataset described in section 4.1). Data on Portuguese projects encompass projects supported by all national programmes launched since the $2^{\text {nd }}$ Framework Programme for Portugal (1994-1999). Table 4 summarises key data from both groups of projects.

Table 4 - Projects funded by Portuguese and European programmes

\begin{tabular}{|c|c|c|}
\hline & $\begin{array}{l}\text { Projects funded by } \\
\text { PT Programmes }\end{array}$ & $\begin{array}{c}\text { European projects } \\
\text { with PT participation }\end{array}$ \\
\hline № projects & 24 & 43 \\
\hline № participations & 62 & 62 \\
\hline № organisations involved & 25 & 27 \\
\hline$\%$ companies & $52.0 \%$ & $55.6 \%$ \\
\hline$\%$ research organisations & $36.0 \%$ & $25.9 \%$ \\
\hline$\%$ other & $12.0 \%$ & $18.5 \%$ \\
\hline Total funding obtained (euro) $^{a}$ & $6,358,107$ & $78,933,091^{a}$ \\
\hline in projects coordinated by PT & $6,358,107$ & $11,375,277^{a}$ \\
\hline
\end{tabular}

A total of 24 projects funded by Portuguese programmes were identified. These includes projects whose activities were exclusively focused on the wave energy field (21) and a smaller group where wave energy was an element of a broader project concerned with ocean energies (3). An additional group of projects concerned with offshore activities (7 projects) was also identified as having some potential implications for the wave energy field, but since they were only remotely related with the

DINÂMIA'CET - IUL, Centro de Estudos sobre a Mudança Socioeconómica e o Território

ISCTE-IUL - Av. das Forças Armadas, 1649-026 Lisboa, PORTUGAL

Tel. 210464031 - Extensão 293100 E-mail: dinamia@iscte.pt http://dinamiacet.iscte-iul.pt/ 
field it was decided to exclude them from this analysis. About $60 \%$ of the projects were classified as $R \& D^{5}$. Most of the remaining involved experimental activities and two projects were concerned with structural activities.

The 24 projects involved 25 organisations in a total of 62 participations. Companies represented half of the individual organisations, but research organisations, although in smaller number $(36 \%)$ were more frequently present in the projects $(63 \%$ of the participations). Other organisations included mostly government agencies, associations and local authorities. Organisations located in the metropolitan area of Lisboa represented about $2 / 3$ of the participants. IST, followed at some distance by LNEG and WAVEC were the main actors and were present in both R\&D and experimental projects. Firms only participated in one, maximum two projects and, as would be expected, were more frequently present in experimental projects. Figure 18 shows the distribution of projects and participations over time. The pattern identified in the Portuguese case is broadly similar to the one described in section 4.1 for the wave energy field in general.

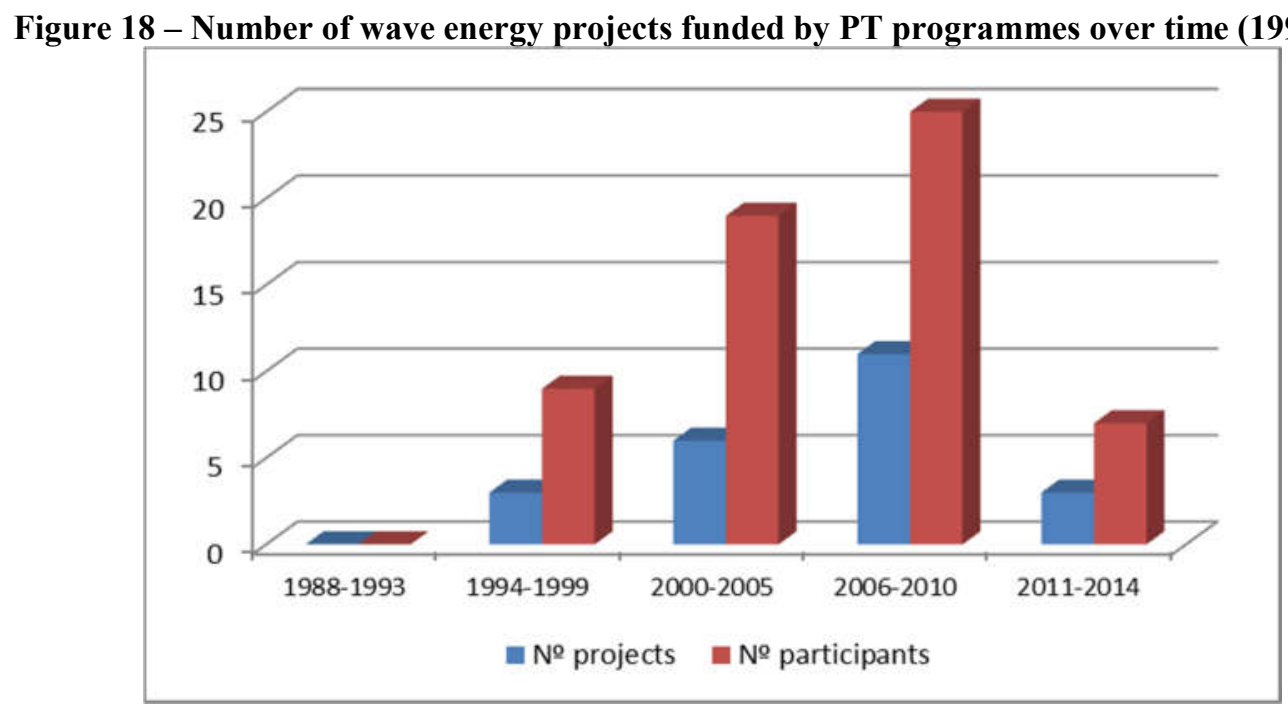

In what regards European funded projects, a total of 43 projects with Portuguese participation were identified (Table 4), corresponding to over half of all wave energy projects funded in that period. Also in this case we have included projects whose activities were exclusively focused on the wave energy field (34) and a smaller group where wave energy was an element of a broader project concerned with ocean energies (9). About half of the projects involved experimental activities and about 1/3 were concerned with structural activities. Only a small number involved exclusively research activities (7).

\footnotetext{
${ }^{5}$ The projects were distinguished between R\&D and experimental according to typology of the programmes that funded them. Thus, these two categories may not be strictly comparable with the European projects, which were classified according to the nature of the project. "Structure" projects were selected from both groups according to the criteria defined for European programmes.
}

DINÂMIA'CET - IUL, Centro de Estudos sobre a Mudança Socioeconómica e o Território ISCTE-IUL - Av. das Forças Armadas, 1649-026 Lisboa, PORTUGAL 
Portuguese organisations coordinated 14 projects (32.6\%). Table 4 also shows the amount of funding obtained in these projects and also in the sub-set with Portuguese coordination.

The 43 projects involved 27 Portuguese organisations in a total 86 Portuguese participations (about $20 \%$ of the total participations from all countries). Also in this case, companies represented more than half of the individual organisations, but research organisations, although in smaller number (30\%) were more frequently present (44\% of participations). However, both firms and other organisations (e.g. government agencies, associations and local authorities) had a higher participation than in national projects, which in the case of the latter group can be explained by the extensive international activity of the wave energy association. Figure 19 presents the distribution of European funded projects and participations over time, showing a slightly different pattern in the growing period as compared with the national projects (Figure 18) - which may be related with the of the launching timings of European programmes - although it also confirms a great reduction in project participation in the last period. The similarities and differences between European and Portuguese projects in what concerns the type of organisations involved and the extent of their participation are summarised in Figure 20.

Figure 19 - Number of European wave energy projects with PT participation over time (1992-2014)

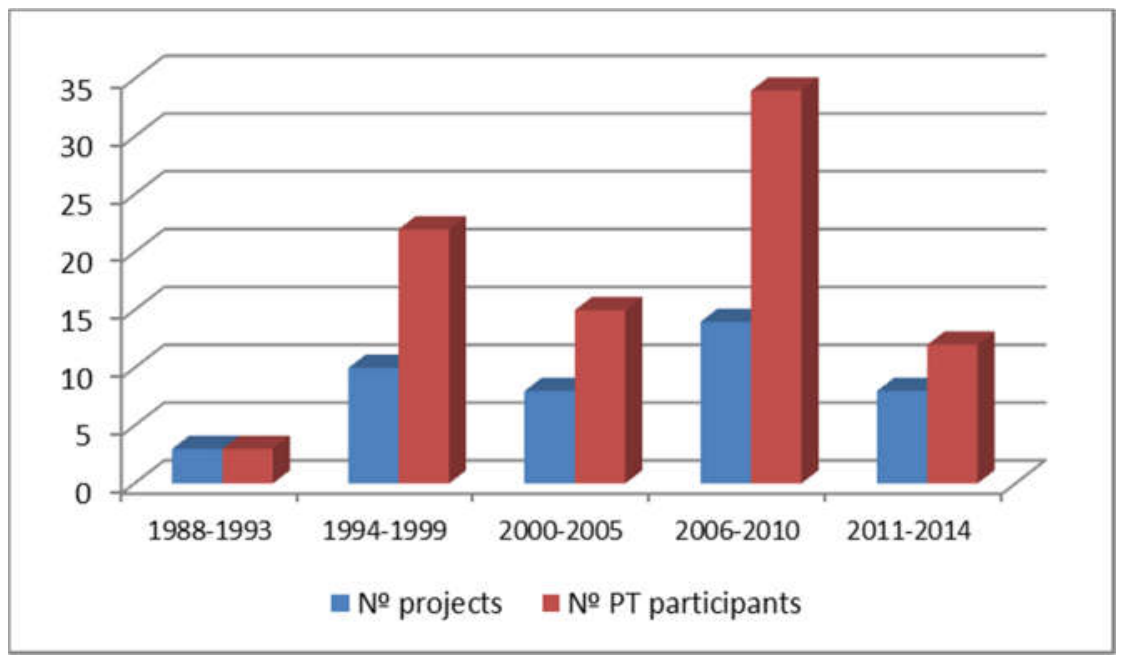

DINÂMIA'CET - IUL, Centro de Estudos sobre a Mudança Socioeconómica e o Território ISCTE-IUL - Av. das Forças Armadas, 1649-026 Lisboa, PORTUGAL 
Figure 20 - Actor participation in European and Portuguese funded projects

\section{European programmes}

Portuguese programmes

Type of organisations in projects
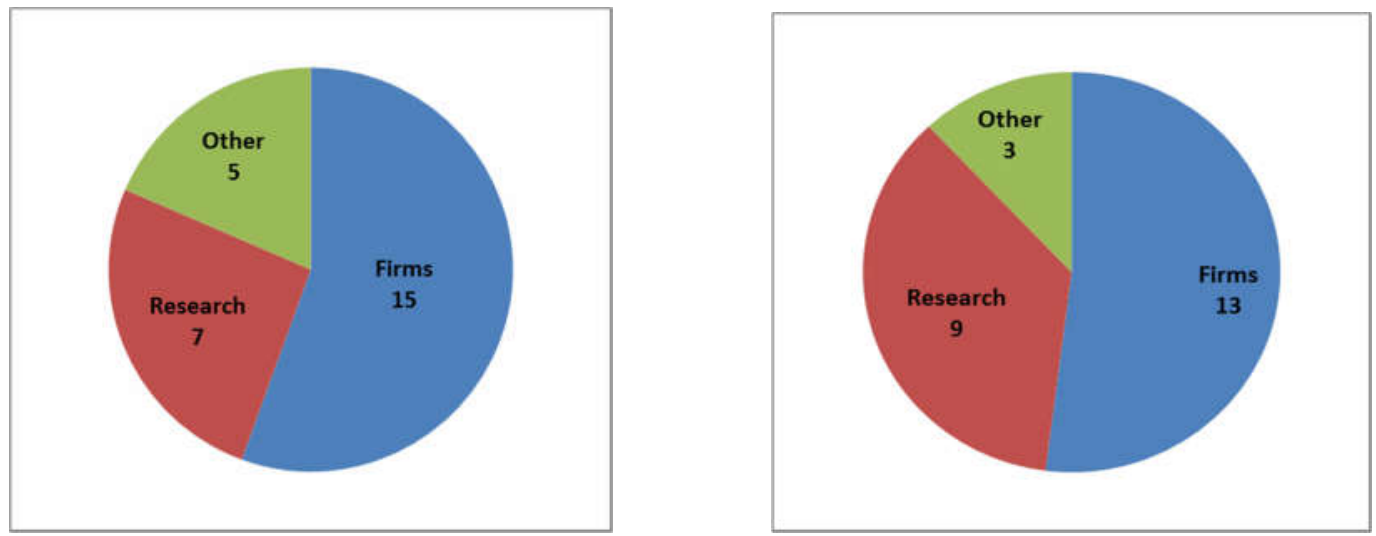

Total participations by type of organisation
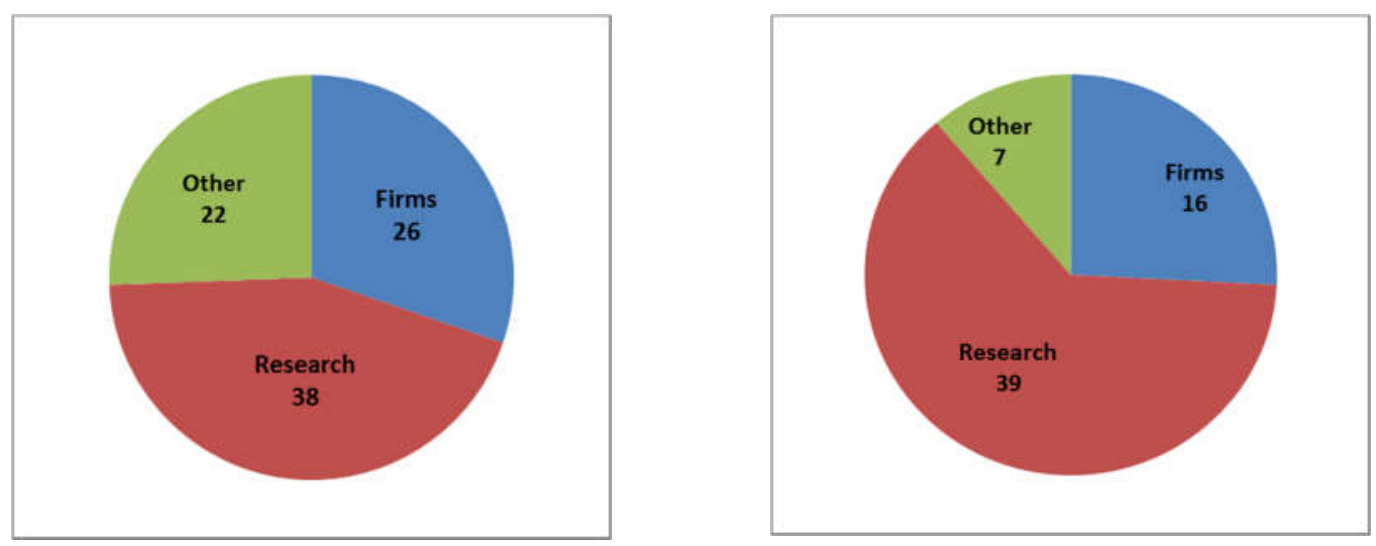

Table 5 lists the organisations with higher total project participation, combining both funding sources. IST, WAVEC and LNEG were the most active in both cases, participating in R\&D, experimental and structural activities. But it is relevant to point out the presence of a small group of Portuguese firms in several projects and, in particular, the participation of the energy utility EDP in five European projects. Among the new ventures, Kymaner was the most active and the only one that was able to obtain European funding. From the remaining technology developers, only Sea for Life and Martifer obtained funding for their projects, and exclusively through national programmes. It is also worth mentioning that one project proposed by a foreign technology developer in joint-venture with a Portuguese company - Pelamis - benefited from Portuguese funding, which added to the support obtained from European programmes.

DINÂMIA'CET - IUL, Centro de Estudos sobre a Mudança Socioeconómica e o Território

ISCTE-IUL - Av. das Forças Armadas, 1649-026 Lisboa, PORTUGAL

Tel. 210464031 - Extensão 293100 E-mail: dinamia@iscte.pt http://dinamiacet.iscte-iul.pt/ 
Table 5 - Organisations with higher project participation (European and Portuguese projects)

\begin{tabular}{|l|c|c|c|c|}
\hline Organisation & Type & $\begin{array}{c}\text { European } \\
\text { projects }\end{array}$ & $\begin{array}{c}\text { Portuguese } \\
\text { projects }\end{array}$ & Total \\
\hline Instituto Superior Técnico (IST) & University & 20 & 18 & 38 \\
WavEC & Collective & 18 & 5 & 23 \\
LNEG & Research centre & 13 & 7 & 20 \\
EDP & Energy utility & 5 & 1 & 6 \\
Kymaner & Company & 3 & 2 & 5 \\
EFACEC & Company & 3 & 1 & 4 \\
Empresa de Electricidade dos Açores & Energy utility & 3 & 1 & 4 \\
Universidade Nova de Lisboa (UNL-FCT) & University & 0 & 4 & 4 \\
CONSULMAR & Company & 0 & 4 & 4 \\
\hline
\end{tabular}

The knowledge production activities in the field of wave energy can also be documented through an analysis of the scientific publications produced by Portuguese authors. Data collected from Thomson and Reuters Web of Science ${ }^{6}$, permitted to identify 180 publications, between 1973 and 2014. Figure 21 shows that publication by Portuguese authors followed the world trend, taking off in the 2000s and growing steadily afterwards.

Figure 21 - Number of scientific publications with Portuguese authors over time (1973-2014)

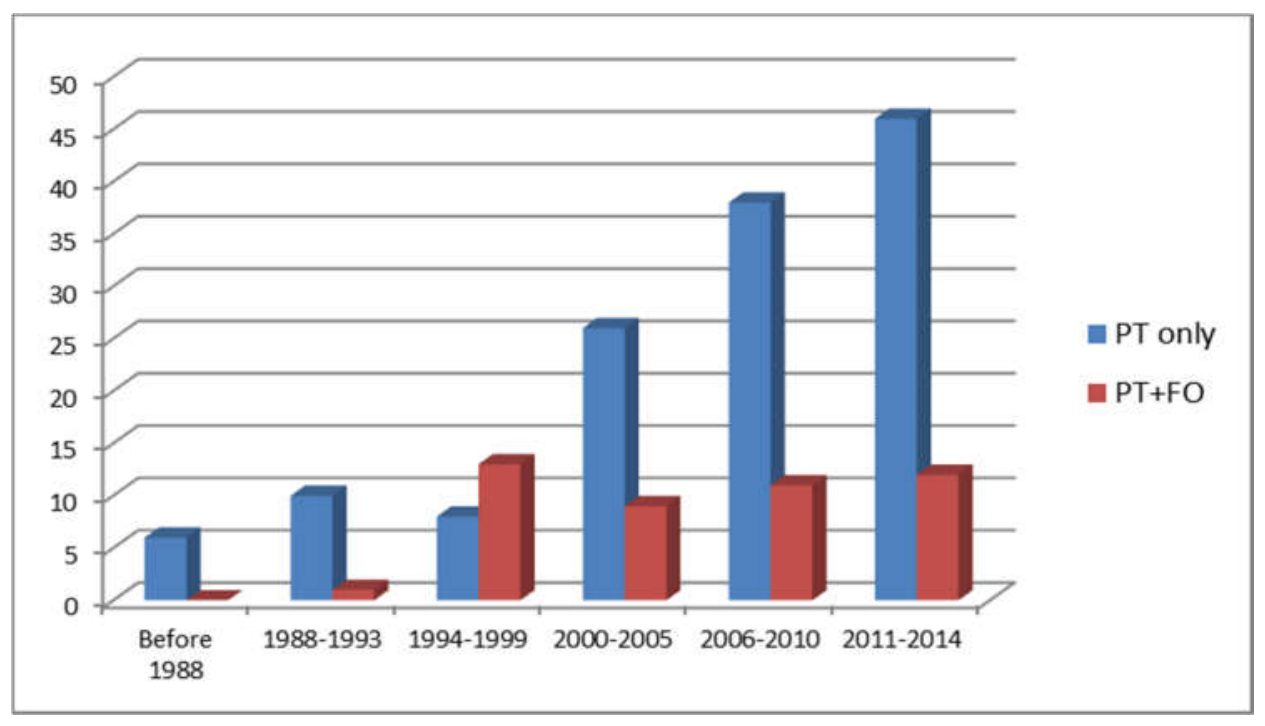

About $1 / 4$ of these publications are co-authored by scientists from foreign organisations. The peak of foreign co-authorship is in the early period (1994-1999) - with $61.9 \%$ of publications co-authored lowering to between 25 and $20 \%$ in the most recent periods. This may be explained by the formation,

\footnotetext{
${ }^{6}$ Data was collected from the Web of Science Core Collection using keywords "wave energy", "wave power" and "wave turbine" and included all publications produced by scientists whose address was Portugal. This was complemented with a specific search with the names of pioneer authors (Falcão, Sarmento, Gato, Pontes), in order to identify early publications still not including these keywords. The data had to be manually cleaned, since these keywords produce several publications from other fields (e.g. "wave energy" is a concept also present in physics). A total of 248 publications were obtained, but only 180 were retained after validation.
} 
over time, of a local community that become more autonomous in knowledge terms, even if keeping the strong international linkages that characterise the field. Interestingly, in the later periods a new type of international collaboration has emerged: the mobility of foreign scientists to Portuguese organisations, which started in the 2000s, involving both $\mathrm{PhD}$ students and post-doctoral researchers and scientists in more stable positions. Table 6 shows the number of publications involving foreign nationals who were working or studying in Portuguese organisations.

Table 6 - Incidence of foreign nationals publishing in Portuguese organisations

\begin{tabular}{|l|c|c|c|}
\hline & $\begin{array}{c}\text { Foreign authors in } \\
\text { PT organisations }\end{array}$ & $\begin{array}{c}\text { Portuguese } \\
\text { authors }\end{array}$ & $\begin{array}{c}\text { \% Foreign } \\
\text { authors }\end{array}$ \\
\hline P4 - 2000-2005 & 4 & 26 & $15.4 \%$ \\
P5 - 2006-2010 & 8 & 38 & $21.1 \%$ \\
P6 - 2011-2014 & 10 & 46 & $21.7 \%$ \\
\hline Total & 22 & 110 & $20.0 \%$ \\
\hline
\end{tabular}

The publications produced during this period involved 124 authors from 17 Portuguese organisations, totalling 435 authorships. Table 7 lists the more productive Portuguese organisations number of authorships (over 5). It shows that the core of the knowledge production in the field has been centred in scientists from a few research organisations, with a particular role being played by IST which was the pioneer organisation in the field and has remained a central source of knowledge. The foreign coauthorships involved 80 scientists from 40 organisations belonging to 15 countries. This data confirms the intense international networking of Portuguese wave energy scientists and more generally the presence of a very active international knowledge community in the field.

Table 7 - Most productive Portuguese organisations (nº authorships)

\begin{tabular}{|l|r|}
\hline Organisations (10+) & № \\
\hline IST & 293 \\
LNEG & 46 \\
WAVEC & 27 \\
Universidade do Porto & 15 \\
Universidade Beira Interior & 13 \\
\hline Total & 394 \\
\hline
\end{tabular}

These features become more evident when we visualise the network of collaboration through copublishing (Figures 22 and 23). Figure 22 presents the inter-organisational network of co-authorships, using the author's affiliations, with Portuguese organisations shown in red. The size of nodes reflects degree of centrality, thus indicating the organisations whose scientists have authored a higher number of papers and/or with a higher number of co-authors. Figure 22 confirms the central role played in the

DINÂMIA'CET - IUL, Centro de Estudos sobre a Mudança Socioeconómica e o Território ISCTE-IUL - Av. das Forças Armadas, 1649-026 Lisboa, PORTUGAL 
Portuguese wave energy knowledge network by the small group of organisations already identified above (IST, LNEG, WAVEC), which not only are the most productive in terms of number of authorships, but also have an important role in knowledge circulation across the network, through extensive co-authorships involving Portuguese and foreign organisations. It equally confirms the international nature of the network, and highlights the presence of intense interactions with several foreign organisations (including organisations that were identified as central in the European network, such as University College of Cork, École Centrale de Nantes or University of Edinburgh), suggesting a good integration of Portuguese scientists in the core international knowledge community. Finally, it is worth noticing that, while Portuguese authors originate almost exclusively from research organisations, the most central ones publish in co-authorship with a number of foreign companies. These co-authorships reflect the involvement of Portuguese scientists in a variety of experimental activities taking place in different locations.

Figure 23 presents the networks of individual authors, with Portuguese authors similarly represented in red, but with the size of node reflecting betweenness centrality, i.e. indicating actors that are located between several different actors, acting as brokers in the network. It shows that a number of scientists - mostly, but not exclusively, from the above mentioned central organisations have effectively played a pivotal role in the network, both structuring the Portuguese knowledge community in the field and linking between it and the international community.

Figure 22 - Inter-organisational network of co-authorships (by author affiliation) (1973-2014)

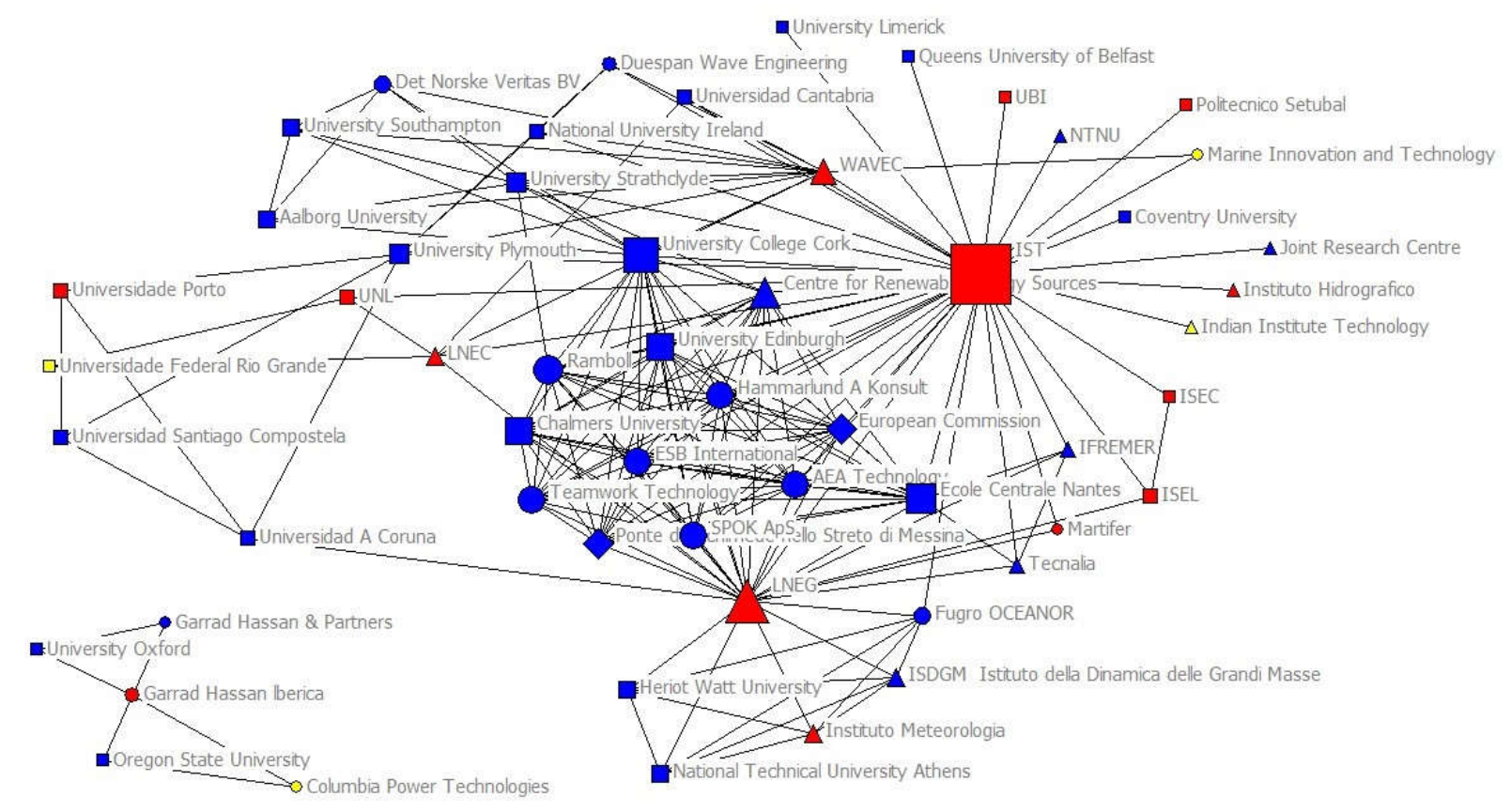

Legend: Squares - Universities; Triangles - Research centres; Circles - Firms; Diamonds - Other.

Colour: Red - Portuguese; Blue - European; Yellow - Outside Europe.

DINÂMIA'CET - IUL, Centro de Estudos sobre a Mudança Socioeconómica e o Território ISCTE-IUL - Av. das Forças Armadas, 1649-026 Lisboa, PORTUGAL

Tel. 210464031 - Extensão 293100 E-mail: dinamia@iscte.pt http://dinamiacet.iscte-iul.pt/ 
Figure 23 - Network of co-authorships (1973-2014)

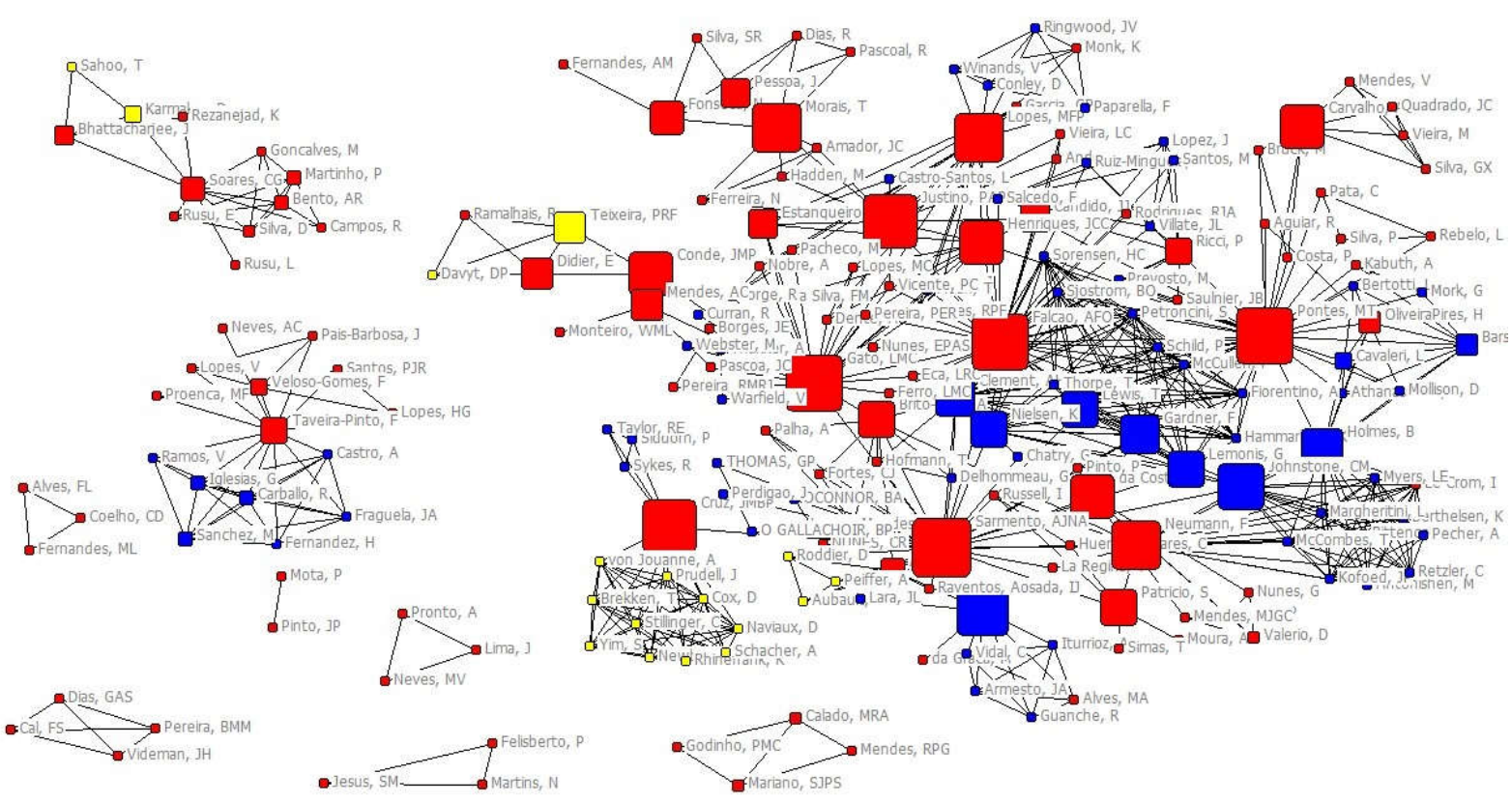

Legend: Squares - Universities; Triangles - Research centres; Circles - Firms; Diamonds - Other. Colour: Red - Portuguese; Blue - European; Yellow - Outside Europe.

Finally, some additional information on the knowledge production activities conducted by Portuguese organisations in the wave energy field, can be obtained from data on the PhDs awarded by Portuguese universities, which include PhDs conducted in Portugal and the formal accreditation of PhDs awarded abroad. A total of $53 \mathrm{PhDs}$ were identified in wave energy and associated areas ${ }^{7}$, their distribution over time being presented in Figure 24.

\footnotetext{
${ }^{7}$ Data collected from the online database on PhDs awarded or recognised in Portugal, compiled by the Ministry of Higher Education and Science since 1971, using a set of keywords related with wave energy. While we are aware that, particularly in the early years, there might have been $\mathrm{PhD}$ thesis relevant for wave energy research that did not explicitly refer to the field, we believe that we were able to identify the majority of cases.
} 
Figure 24 - Number of PhDs in wave energy awarded/recognised by Portuguese universities (1978-2014)

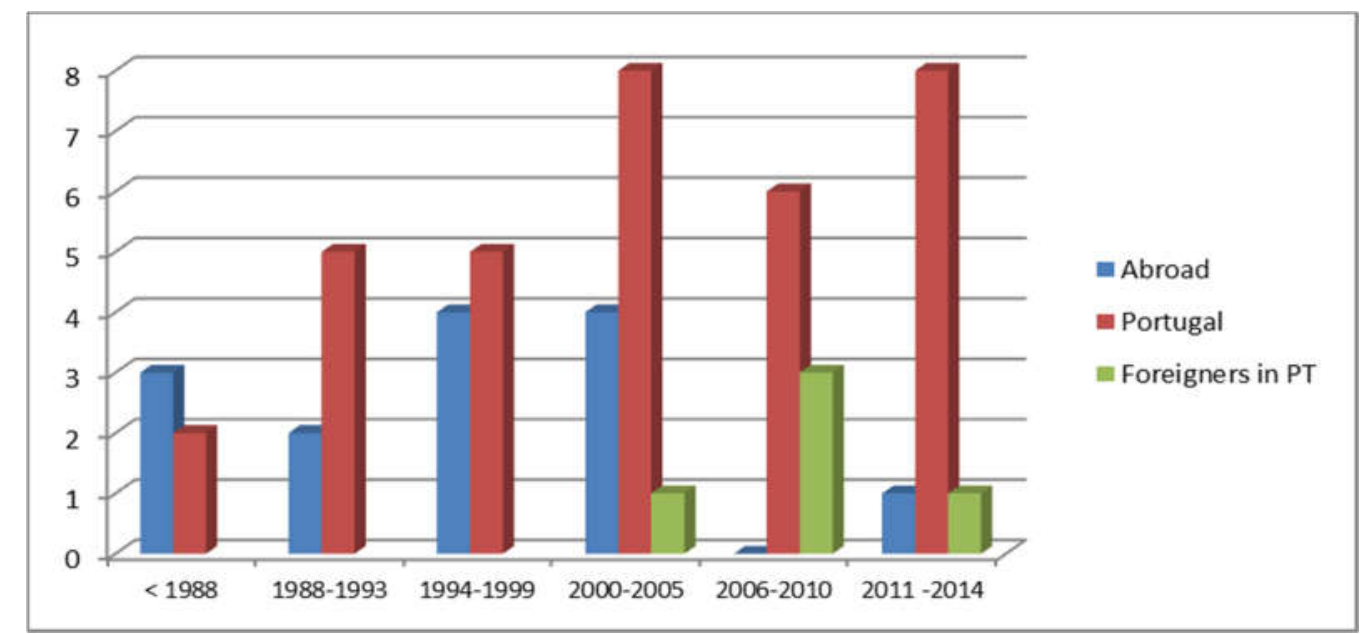

Source: Data base on PhDs granted / accredited in Portugal, DGEEC

The data shows that in the early years a substantial number of wave energy researchers moved abroad - in particular to the UK - to conduct their PhDs, a behaviour that is not exclusive of this field, being associated with an effort of Portuguese government to develop the Portuguese science base encouraging scientists to move to foreign centres of excellence, namely through the provision of $\mathrm{PhDs}$ grants (Fontes et al, 2013). However, PhDs awarded by Portuguese universities become increasingly prevalent, reflecting the country's growing scientific competence in the field, which also started attracting some young foreign scientists to conduct their $\mathrm{PhD}$ research in Portugal.

It is also worth mentioning that University level training in the field, in the form of specific courses or modules, has also started to being offered by some universities. For instance IST included in the curricula in 2012 a "Diploma of Advanced Training in Marine Renewable Energies (with two profiles, one of which also includes offshore wind), following the development of a module on "Ocean Energy" to be included in the European Master in Renewable Energies promoted by European Renewable Energy Centres Agency (2012-2013). A number of specific training courses have also been promoted in the context of European structural programmes.

\subsubsection{Technology development \& experimental activities}

Among the "visible" actions being conducted in Portugal by the core wave energy actors emerges as particularly interesting the development and attempted scale-up and deployment of a number of energy conversion systems, often undertaken in collaboration with other organisations they had been able to attract to their networks. These activities were conducted by both Portuguese entrepreneurial companies and by foreign technology developers, the latter usually involving joint ventures with Portuguese partners.

DINÂMIA'CET - IUL, Centro de Estudos sobre a Mudança Socioeconómica e o Território ISCTE-IUL - Av. das Forças Armadas, 1649-026 Lisboa, PORTUGAL 
Table 8 provides some information on the Portuguese companies and the evolution of their projects and Figure 25 illustrates the main systems being developed. As is typical in the wave energy field, all but one of the companies identified were new entrepreneurial firms, launched to pursue with the development of a technology, which in most cases had started in a university context. The only exception was Martifer, a larger energy company already operating in the renewable energy field.

Table 8 - Portuguese companies developing proprietary wave energy technologies

\begin{tabular}{|c|c|c|c|c|}
\hline Firm & Technology & $\begin{array}{l}\text { Created } \\
\text { (closed) }\end{array}$ & Origin & Stage \\
\hline Hidromod & Wave modelling & 1992 & $\begin{array}{l}\text { Academic spin- } \\
\text { off }\end{array}$ & $\begin{array}{l}\text { Diversified to water management } \\
\text { services }\end{array}$ \\
\hline Enerwave & $\begin{array}{l}\text { Wave energy conversion unit } \\
\text { coupled with maritime } \\
\text { infrastructures (patent) }\end{array}$ & $2003(2008)$ & Independent & $\begin{array}{l}\text { Did not pursue patent } \\
\text { development. } \\
\text { Closed. }\end{array}$ \\
\hline Kymaner & $\begin{array}{l}\text { KymanOS energy converter } \\
\text { (OWC ) } \\
\text { KymanAIR turbine (patent) }\end{array}$ & 2005 & $\begin{array}{l}\text { Academic spin- } \\
\text { off }\end{array}$ & $\begin{array}{l}\text { Built \& tested several turbines. } \\
\text { Participate in Pico OWC Plant } \\
\text { refurbishment \& operation. } \\
\text { In stand-by }\end{array}$ \\
\hline $\begin{array}{l}\text { Sea for } \\
\text { Life }\end{array}$ & $\begin{array}{l}\text { WEGA (Wave Energy } \\
\text { Gravitational Absorber) } \\
\text { (patents) }\end{array}$ & 2007 & Independent & $\begin{array}{l}\text { Prototype tested in large wave } \\
\text { tank (2010). } \\
\text { In stand-by }\end{array}$ \\
\hline E-move & $\begin{array}{l}\text { Bluesphere - Electrical } \\
\text { Spherical Generator (patent) }\end{array}$ & $2010(2014)$ & $\begin{array}{l}\text { Academic spin- } \\
\text { off }\end{array}$ & $\begin{array}{l}\text { Built early prototype. } \\
\text { Diversified to wind. } \\
\text { Closed }\end{array}$ \\
\hline Reefpower & $\begin{array}{l}\text { Modular wave energy } \\
\text { converter SPIDER RP05 } \\
\text { (patent) }\end{array}$ & $2011(2014)$ & $\begin{array}{l}\text { Independent } \\
\text { (MSc at Algarve } \\
\text { Univ.) }\end{array}$ & $\begin{array}{l}\text { Several prototypes built and early } \\
\text { sea tested (in estuary). } \\
\text { Closed }\end{array}$ \\
\hline Martifer & $\begin{array}{l}\text { FLOW - two-body wave power } \\
\text { device (patent) }\end{array}$ & Project start 2004 & Energy group & $\begin{array}{l}\text { Early prototype tank tested. } \\
\text { Abandoned wave energy. }\end{array}$ \\
\hline
\end{tabular}

Most companies that were developing wave conversion systems were able to build early prototypes of their systems and in some cases to conduct first tests. But only Kymaner, a university spin-off that developed a technology originating from IST, was able to develop an actual product (a turbine). None of the companies was able to pursue with experimental tests in real sea conditions, given the high costs involved and the lack of funding for scaling-up the technologies. As becomes clear from Table 8 only one of the entrepreneurial firms is currently in full activity, having diversified early on to an adjacent field. The others have closed down or mentioned to have (temporarily) suspended the wave energy activities. A few other company projects have surfaced in entrepreneurial ideas contests after the mid2000 s, but have not pursued to firm creation. Finally, it also worth mentioning that, besides the companies directly engaged in the development of wave energy technologies, a small group of technology intensive companies active in other ocean-related fields (e.g. underwater equipment, instruments and systems) have contributed to some projects in this field (e.g. the case of Blue-Edge) and/or have indicated wave energy as one of their potential markets. 
Figure 25 - Technologies developed by Portuguese companies
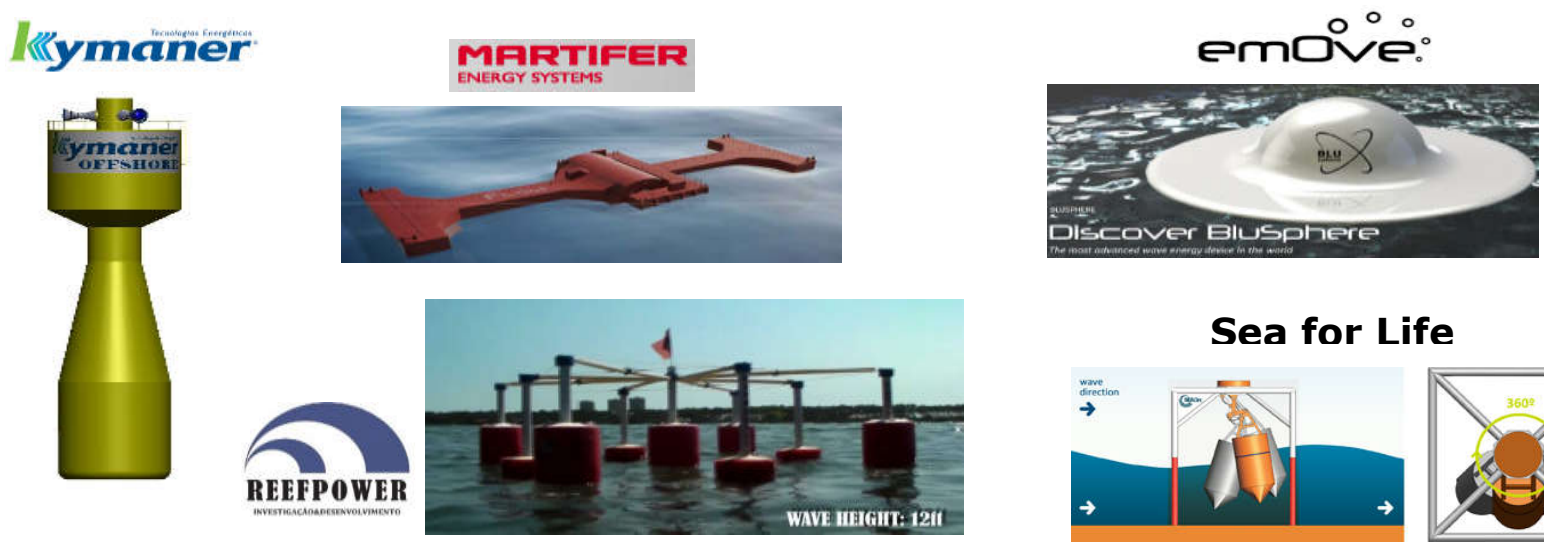

Sea for Life

Source: Company webpages and reports.

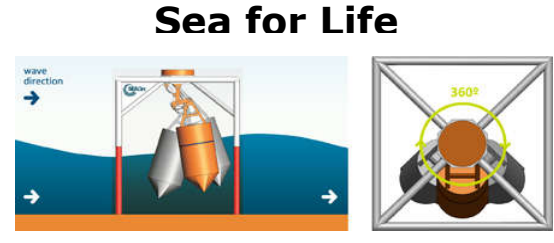

Table 9 provides additional information on technology oriented activities in the field, presenting data on the patents filed by Portuguese inventors (organisations and individuals). The analysis includes both patents that were exclusively submitted to the domestic patent office $(50 \%)$ and patents that were subsequently pursued at international level (50\%). The number of exclusively domestic patent suggesting that a substantial number of inventors decided it was not worth (or had no conditions) to seek protection beyond the Portuguese borders.

Table 9 - Patent applications filed by Portuguese inventors in wave energy technologies (1978-2014) ${ }^{8}$

\begin{tabular}{|c|c|c|c|}
\hline & $\begin{array}{l}\text { Domestic } \\
\text { only }\end{array}$ & $\begin{array}{l}\text { International } \\
\text { (EP, US, PCT) }\end{array}$ & Total \\
\hline \multicolumn{4}{|l|}{ RESEARCH ORGANISATIONS } \\
\hline Instituto Superior Técnico (IST) & $7^{1}$ & $2^{2}$ & 9 \\
\hline Universidade da Beira Interior & 0 & 2 & 2 \\
\hline Universidade de Aveiro & 0 & 1 & 1 \\
\hline \multicolumn{4}{|l|}{ COMPANIES } \\
\hline Martifer Energia & 2 & 2 & 4 \\
\hline Sea for Life & 0 & 3 & 3 \\
\hline E-move & 0 & $1^{3}$ & 1 \\
\hline Reef Power & 1 & 0 & 1 \\
\hline Enerwave & 0 & 1 & 1 \\
\hline Methanpetrol & 0 & 1 & 1 \\
\hline Minorça & 1 & 0 & 1 \\
\hline TOTAL ORGANISATIONS & 12 & 13 & 25 \\
\hline INDIVIDUALS & 8 & 7 & 15 \\
\hline Total & 20 & 20 & 40 \\
\hline
\end{tabular}

\footnotetext{
${ }^{8}$ Includes all patents whose applicant had Portuguese nationality or residence. Only one patent is considered per patent family. Domestic applications are only counted when no international ones had been filed.
} 
This data confirms the development of proprietary technologies by some of the companies listed above, but it also shows the weight of individual inventors in this field, which persist along the whole period (Figure 26). The data shown in Table 9 and Figure 26 also depicts the changing behaviour of universities and other research organisations (RTO) that, by the mid-2000s, start patenting some of their technologies. Among these stands IST that was already identified above as one of the central organisations in knowledge development in the wave energy field at European level.

Figure 26 - Number of patents application by Portuguese inventors (1978-2014)

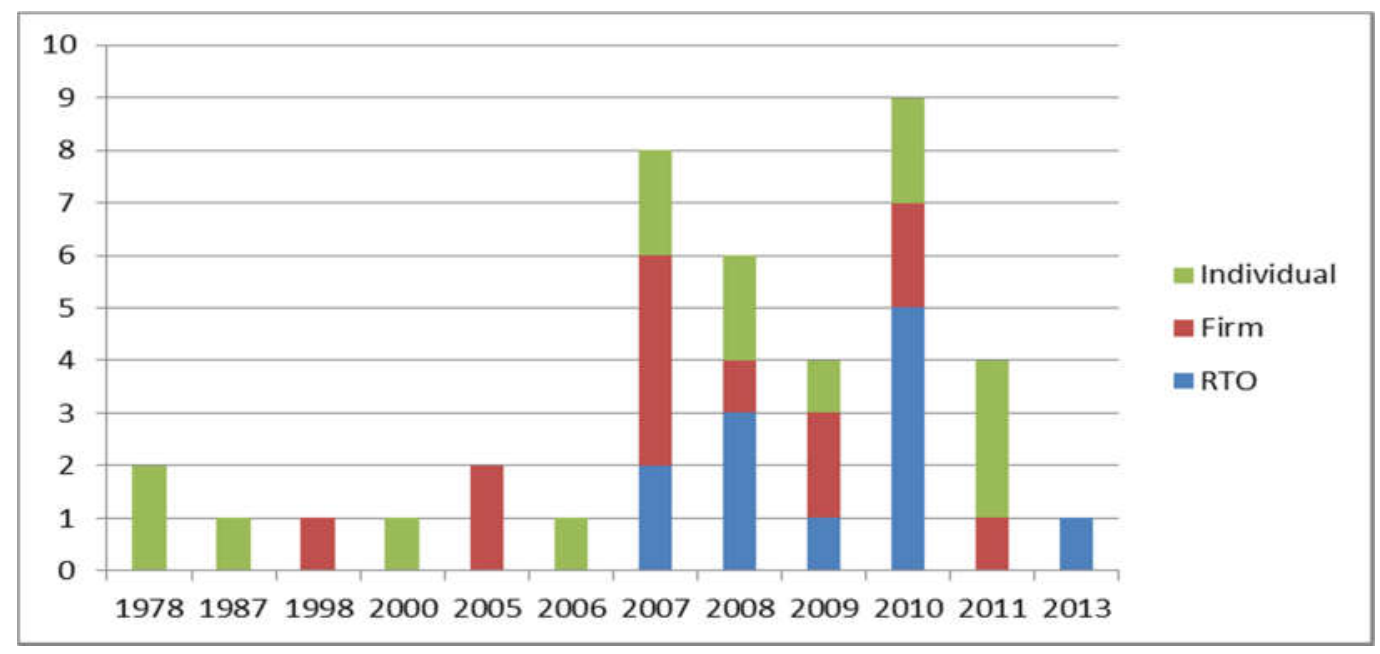

We turn now to the activities conducted, or proposed to be conducted in Portugal by foreign technology developers, which are presented in Table 10. Only 3 of the projects announced led to actual installation and test of a system in Portugal. The Dutch Teamwork Technology (now AWS Energy) successfully tested an early prototype of the Archimedes Wave Swing in 2004, in a joint venture with the Portuguese ENERSIS. A second version was announced but ended-up being installed elsewhere. The UK Pelamis Wave Power installed the Pelamis wave farm in 2008, also in partnership with ENERSIS, later joined by EDP and EFACEC, but the system experienced severe problems, which combined with financial difficulties ended-up with its abandon, despite a rescue attempt conducted by a EDP led consortium. Subsequent versions were tested by Pelamis in Scotland, but the company went out of business in 2014. Finally, the Finish AW Energy, in joint-venture with the Portuguese Eneólica, tested several generations of the Waveroller system, starting in 2007. The most recent version was successfully connected to the grid in 2012, being currently the only system still in Portuguese waters. In 2014, AW Energy obtained funding from the NER 300 European scheme, for a commercial scale plant (5.6 MW) to be installed in Portugal.

These projects required the set-up, by its promoters, of dedicated infrastructures - at Aguçadoura (Póvoa do Varzim) for the AWS test, later further refurbished to install the Pelamis system; and at Peniche for the Waveroller system. The proposals advanced for the remaining experiments were mostly based on the expectation of the availability of a Wave Energy Pilot Zone - a

DINÂMIA'CET - IUL, Centro de Estudos sobre a Mudança Socioeconómica e o Território ISCTE-IUL - Av. das Forças Armadas, 1649-026 Lisboa, PORTUGAL 
fully equipped test and demonstration infrastructure announced by the government in 2006 and officially created in 2008. However, the delays in its implementation forced the promoters to choose other locations for their experimental activities. Two projects, by Wave Dragon and Oceanlinx, still involved the formation of joint ventures with Portuguese companies, but did not pursue to the actual installation, which ended-up being conducted elsewhere. Three other projects were announced and involved some negotiations with Portuguese companies (in two cases involving participation in a European project), but were not pursued further.

Table 10 - Foreign wave energy companies with operation in Portugal

\begin{tabular}{|c|c|c|c|c|}
\hline Foreign Firm & Joint-venture & Technology & $\begin{array}{c}\text { Date joint } \\
\text { venture }\end{array}$ & Stage \\
\hline $\begin{array}{l}\text { Teamwork Technology (NL) } \\
\text { later } \\
\text { AWS Ocean Energy (UK) }\end{array}$ & Oceanergia (with Enersis) & $\begin{array}{l}\text { Archimedes } \\
\text { Wave Swing } \\
\text { (AWS) }\end{array}$ & $\begin{array}{l}2001 \\
\text { (end 2005) }\end{array}$ & $\begin{array}{l}\text { Prototype installed \& } \\
\text { tested in Póvoa do Varzim. } \\
\text { Concluded } 2004 . \\
\text { New project announced } \\
\text { (2007) but not pursued. } \\
\text { AWS-III installed in } \\
\text { Scotland (2014). }\end{array}$ \\
\hline $\begin{array}{l}\text { Pelamis Wave Power (UK) } \\
\text { previously } \\
\text { Ocean Power Delivery }\end{array}$ & $\begin{array}{l}\text { Companhia Energia Oceanica } \\
\text { (with Enersis) } \\
\text { Consortium Ondas Portugal } \\
\text { (with Enersis , EDP, EFACEC) }\end{array}$ & Pelamis & 2003 & $\begin{array}{l}\text { System installed in } \\
\text { Aguçadoura test site } \\
\text { (Póvoa do Varzim), failed } \\
\text { and stopped (2008). } \\
\text { Pelamis moved to UK to } \\
\text { install new system. } \\
\text { Closed } 2014 .\end{array}$ \\
\hline AW Energy (FI) & $\begin{array}{l}\text { Seaner ( with Eneólica) } \\
\text { Project Surge (with Eneolica, } \\
\text { Peniche Shipyards, Peniche } \\
\text { Local Authority, WAVEC) }\end{array}$ & WaveRoller & 2007 & $\begin{array}{l}\text { 1st semi-scale prototype } \\
\text { tested in Peniche (2007). } \\
300 \mathrm{~kW} \text { demonstration farm } \\
\text { installed \& grid connected } \\
\text { (2012). } \\
\text { NER } 300 \text { funding for } \\
\text { commercial 5,6 MW plant } \\
\text { in Peniche (2014) }\end{array}$ \\
\hline WaveDragon (DK/UK) & $\begin{array}{l}\text { Tecdragon (with Casais Invest, } \\
\text { ETEC). }\end{array}$ & WaveDragon & 2006 & $\begin{array}{l}\text { To install in Pilot Zone. } \\
\text { Project in PT abandoned } \\
\text { WaveDragon pursued } \\
\text { project in Wales. }\end{array}$ \\
\hline Oceanlinx (AU) & $\begin{array}{l}\text { Wavelinx (local filial of } \\
\text { Oceanlinx where PT New } \\
\text { Energy Fund is majority } \\
\text { shareholder). }\end{array}$ & OLX & 2008 & $\begin{array}{l}\text { To install in Pilot Zone. } \\
\text { Project in PT abandoned } \\
\text { Oceanlinx pursued project } \\
\text { in Australia, } \\
\text { Closed in } 2014 .\end{array}$ \\
\hline \multicolumn{5}{|l|}{ Announced } \\
\hline Finavera (CA) & $\begin{array}{l}\text { Partnership with several PT } \\
\text { companies in EU project } \\
\text { Aquabuoy. Demonstration } \\
\text { plant proposed to Pilot Zone. }\end{array}$ & Aquabuoy & (2007) & $\begin{array}{l}\text { Not pursued. } \\
\text { Finavera abandoned wave } \\
\text { (2009) }\end{array}$ \\
\hline Wavebob (IE) & $\begin{array}{l}\text { Partnership with Generg in EU } \\
\text { project Standpoint. Pilot Zone } \\
\text { proposed for technology test }\end{array}$ & Powerbuoy & (2009) & $\begin{array}{l}\text { Not pursued. } \\
\text { Wavebob closed in } 2013\end{array}$ \\
\hline OreCon (UK) & $\begin{array}{l}\text { Agreement with Eneolica, } \\
\text { Estaleiros Navais Mondego }\end{array}$ & OreCon OWC & (2009) & $\begin{array}{l}\text { Not pursued due to } \\
\text { OreCon closure (2010) }\end{array}$ \\
\hline
\end{tabular}


The conduction of experimental activities in Portugal and, more generally, the growing position of Portugal in wave energy activities, are likely to have led foreign organisations to consider seeking protection for their technologies locally. As shown in Figure 27, applications to the Portuguese patent office by foreign inventors and particularly by foreign organisations, effectively shows an increase in the growth periods (P4 and P5) starting to fall afterwards. As would be expected, applicants are mostly firms and originate mainly from the US and from the European countries more involved in wave technology development, in particular the UK, followed by Nordic countries.

Figure 27 - Number of patents filed by foreign organisations in the PT patent office by application date ${ }^{9}$

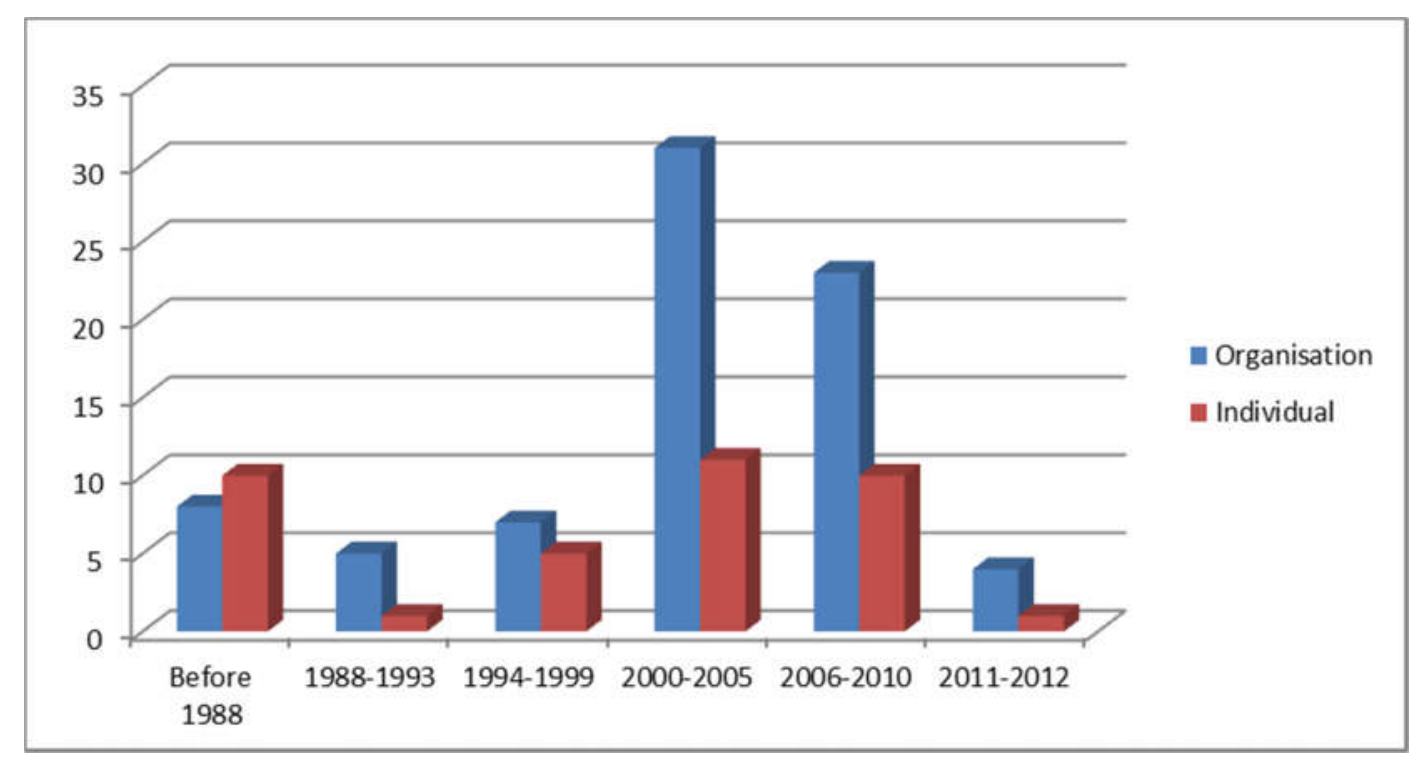

Finally, Table 11 lists the experimental activities conducted in Portugal in chronological terms. Besides the projects already described, it is particularly worth mentioning the project that led to the set-up of the first European wave energy plant - the Pico Pilot Plant - conducted by a IST led partnership of Portuguese and other European organisations and funded by a sequence of EU projects. The shoreline wave power plant was installed in the Azorean island of Pico and has been in operation since 1999, despite several interruptions due to technical and financial problems. The Table also documents the attempt to build a wave power plant incorporated in a breakwater at the Douro river mouth (Breakwater Foz do Douro), which also obtained European funding but was not materialised due to the lack of interest of the port authorities. The experimental projects involved a variety of Portuguese organisations, both research organisations and companies. The latter included energyrelated companies - where the utility EDP assumes a particularly relevant position, being engaged

\footnotetext{
${ }^{9}$ Application date is used instead of publication date, because it reflects better the perception of inventors regarding the attractiveness of the Portugal as a setting for wave energy development. For this reason data is only available until 2012 , but the decrease is patenting is already visible in the last years of the first decade.
} 
(and sometimes leading) several projects - and companies related with engineering, naval construction and other sea-related activities.

Table 11 - Chronology of experimental activities conducted or proposed to be conducted in Portugal

\begin{tabular}{|c|c|c|}
\hline \multirow[t]{2}{*}{ P3 } & 1994 & $\begin{array}{l}\text { Pico Pilot Plant - European wave energy pilot plant to be installed at Pico island (Azores) - } \\
\text { sequence of EU projects (between } 1992 \text { and 1999) involving several PT research organisations } \\
\text { and companies, including the utility EDP. }\end{array}$ \\
\hline & 1999 & Pico Pilot Plant connected to grid \\
\hline \multirow{3}{*}{ P4 } & 2000 & Problems in Pico Pilot Plant turbine, repairs start \\
\hline & 2004 & $\begin{array}{l}\text { Archimedes Wave Swing (AWS) (first prototype) installed and tested at Aguçadoura. } \\
\text { Breakwater Foz Douro: PT project CEDOURO (IST and CONSULMAR) for OWC plant } \\
\text { incorporated in breakwater launched. }\end{array}$ \\
\hline & 2005 & $\begin{array}{l}\text { Pelamis wave farm proposal: } 3 \times 750 \mathrm{MW} \text { machines to be installed off Póvoa Varzim } \\
\text { Pico Pilot Plant refurbishment - PT project DEMO-CAO (include new partners, led by WAVEC) }\end{array}$ \\
\hline \multirow{5}{*}{ P5 } & 2006 & $\begin{array}{l}\text { Pelamis start machine assembly at Peniche shipyards (deployment expected 2007); PT project } \\
\text { OKEANOS (Ca Energia Oceanica \& Pelamis) } \\
\text { Breakwater Foz Douro: call for tenders for equipment supply (expected to start 2008); } \\
\text { Pico Pilot Plant tests restart } \\
\text { Pilot Zone for Wave Energy announced (created working part to set-up) }\end{array}$ \\
\hline & 2007 & $\begin{array}{l}\text { Waveroller \#1 by AW Energy - semi-scale prototype device installed and tested in Peniche } \\
\text { Breakwater Foz Douro - EU project Breakwave launched (led by EDP and involving several PT } \\
\text { organisations); but project stops due to problems with Port authorities }\end{array}$ \\
\hline & 2008 & $\begin{array}{l}\text { Pelamis system put to sea at Aguçadoura - stopped later due to technical \& financial problems } \\
\text { Waveroller \#2 (AW-Energy): simulation and tank tests (IST \& UP) \& larger prototype building } \\
\text { Pilot Zone created in S. Pedro de Moel - concession of exploitation to REN }\end{array}$ \\
\hline & 2009 & $\begin{array}{l}\text { Waveroller } 2 \text { nd phase - EU project SURGE to develop commercial scale demonstration wave } \\
\text { farm ( } 300 \mathrm{~kW} \text { ), involving several PT organisations } \\
\text { Aguçadoura site aquired by national consortium led to resume Pelamis project. Not pursued. }\end{array}$ \\
\hline & 2010 & Ocean Plug - firm to exploit Pilot Zone, expected to start functioning 2013 \\
\hline \multirow{4}{*}{ P6 } & 2011 & $\begin{array}{l}\text { Pico Pilot Plant included in EU MARINET programme that coordinates experiments and } \\
\text { provide access to test facilities, But needs investment to be operational }\end{array}$ \\
\hline & 2012 & $\begin{array}{l}\text { Waveroller demonstration } 300 \mathrm{~kW} \text { farm installed in Peniche and grid connected with success; } \\
\text { company raises funds to plan and design next generation commercial scale 500kW device; } \\
\text { Pico Pilot Plant - WAVEC launches Campaign "Help the Pico power plant"; }\end{array}$ \\
\hline & 2013 & Waveroller brought to harbour for O\&M and deployed again - continues in operation. \\
\hline & 2014 & $\begin{array}{l}\text { Waveroller - AW Energy wins NER } 300 \text { to deploy commercial scale array of } 16 \text { machines } \\
(5.6 \mathrm{KW}) \text { in Peniche. }\end{array}$ \\
\hline
\end{tabular}

DINÂMIA'CET - IUL, Centro de Estudos sobre a Mudança Socioeconómica e o Território ISCTE-IUL - Av. das Forças Armadas, 1649-026 Lisboa, PORTUGAL

Tel. 210464031 - Extensão 293100 E-mail: dinamia@iscte.pt http://dinamiacet.iscte-iul.pt/ 


\subsection{An in-depth analysis of niche formation and evolution from a Portuguese perspective}

The data provided above permitted to put some flesh into the generic patterns presented in section 5.1, offering a more detailed account of the type of activities performed in the wave energy field and permitting to name the key actors. This data will form the background for the more in-depth analysis of the processes that took place in Portugal as part of the formation, development and attempted break out of a wave energy niche, as well as the conditions in which these processes occurred, which will be conducted in this section.

The activities conducted in Portugal are set against the overall niche space, which is represented, in each period, by the knowledge network formed by the organisations active in European funded RTD projects. The network involving Portuguese organisations is highlighted in red. Larger nodes represent more central actors, based on the calculation of degree centrality that indicates the actors that participated in the highest number projects and/or in large consortia. The shape of nodes denotes the type of organisation: research organisations (square), firms (triangle), other, such as collective organisations or government agencies (circle). A table characterising the knowledge network formed in each period, in terms of size (number of organisations and number of ties) and degree centrality (average, maximum and minimum) is presented in Appendix 1. Finally a list of policies or policy incentives directed to or with impact in the development of wave energy is presented in Appendix 2.

\section{Period 1 - Antecedents - Before 1988}

The first period corresponds to the "pre-history" of wave development in Portugal. An embryo of research group in this field started being formed in the late 1970s, based on a small number of scientists from an engineering university - Instituto Superior Técnico (IST). Most of these scientists, who would become central actors in the development of the niche at country level, did their $\mathrm{PhD}$ in the UK and maintained close connections with other members of the then emerging wave energy community. Interestingly, we find a number of individual patent applications (by non-scientists), never pursued to the development of actual conversion systems, a practice that would continue over time, suggesting that the proximity to the ocean raised the interest of inventors originating from the community.

In the early 1980s the first government policy towards renewable energies is set-up (a system of generic fiscal incentives) and in 1988 there is the first great transformation in the energy system - a law that establishes the liberalisation of the electricity market, terminating the monopoly of the electricity utility (EDP) and authorising the independent production of energy, thus opening the space for renewable energy development.

DINÂMIA'CET - IUL, Centro de Estudos sobre a Mudança Socioeconómica e o Território ISCTE-IUL - Av. das Forças Armadas, 1649-026 Lisboa, PORTUGAL 


\section{Period 2 - Raising Awareness (1988-1993)}

Figure 28 - Position of Portuguese actors in the European knowledge network in wave energy: organisations in projects 1988-1993 (networks of Portuguese actors highlited in red)

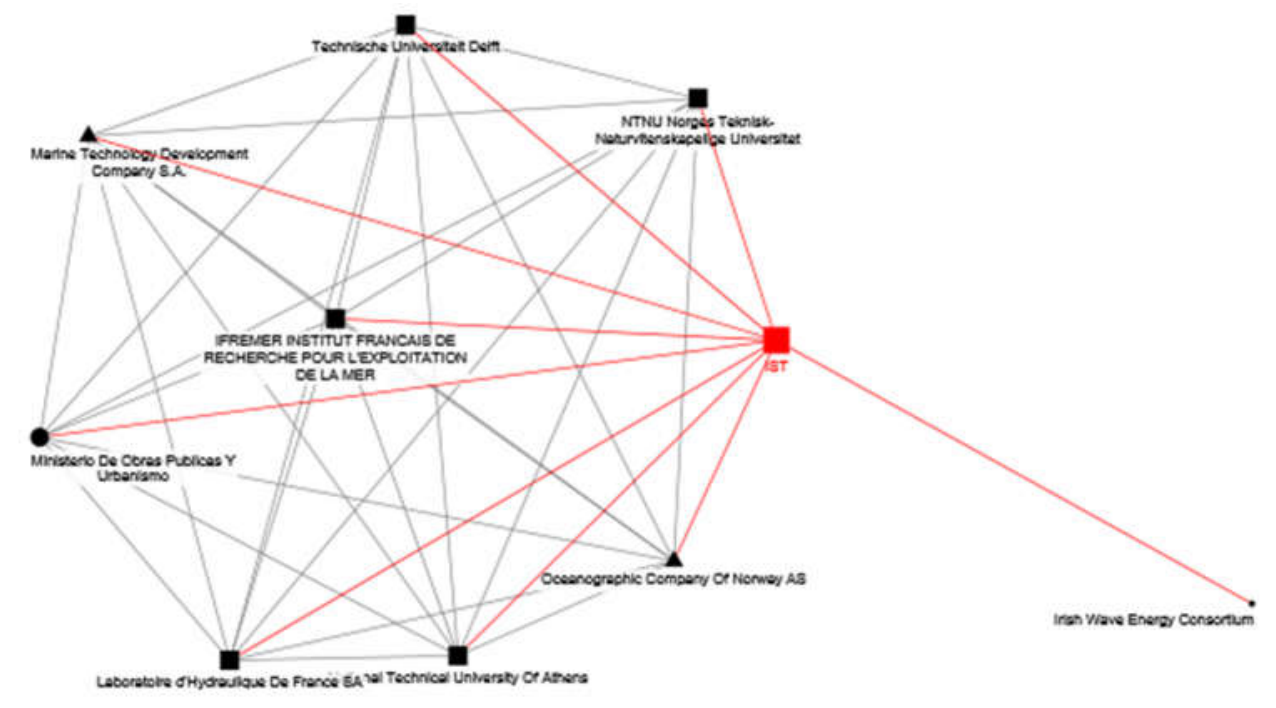

This period combines the first steps towards the liberalisation of the electricity market with the set-up of the first government programme specifically targeting the energy sector. The small group of scientists active in the wave energy field includes, besides IST, a government laboratory that will equally become a central actor - LNEG (National Laboratory for Energy and Geology). The still limited recognition of the field in national programmes means that research activities are mostly conducted in the context of European projects, involving actors from the other "pioneer" countries. As a result of the early learning efforts of this international community, it is decided to pursue to the first large scale experimental activities. For this purpose resource evaluation is conducted in a number of locations in Portugal, UK, and Ireland with a view to building experimental sites, in the context of European projects. In Portugal, the experimental project is led by IST that, together with LNEG, also participates in similar activities in the other locations.

Thus, from an early stage, "individual experiments" are conducted by a network of actors originating from different locations (Figure 28), who also start creating specific arenas for exchanging the contextual knowledge produced in these experiments (Falcão, 2010). Portuguese scientists occupy a relevant position in this network: IST is the most central organisation, being connected with all the other actors (Figure 28). In the meanwhile, at country level, the development of scientific competences pursues with new PhDs (conducted in Portugal and abroad). A first spin-off from IST is formed offering wave modelling services.

DINÂMIA'CET - IUL, Centro de Estudos sobre a Mudança Socioeconómica e o Território ISCTE-IUL - Av. das Forças Armadas, 1649-026 Lisboa, PORTUGAL 


\section{Period 3 - First Experiments (1994-1999)}

Figure 29 - Position of Portuguese actors in the European knowledge network in wave energy: organisations in projects $1994-1999{ }^{a}$

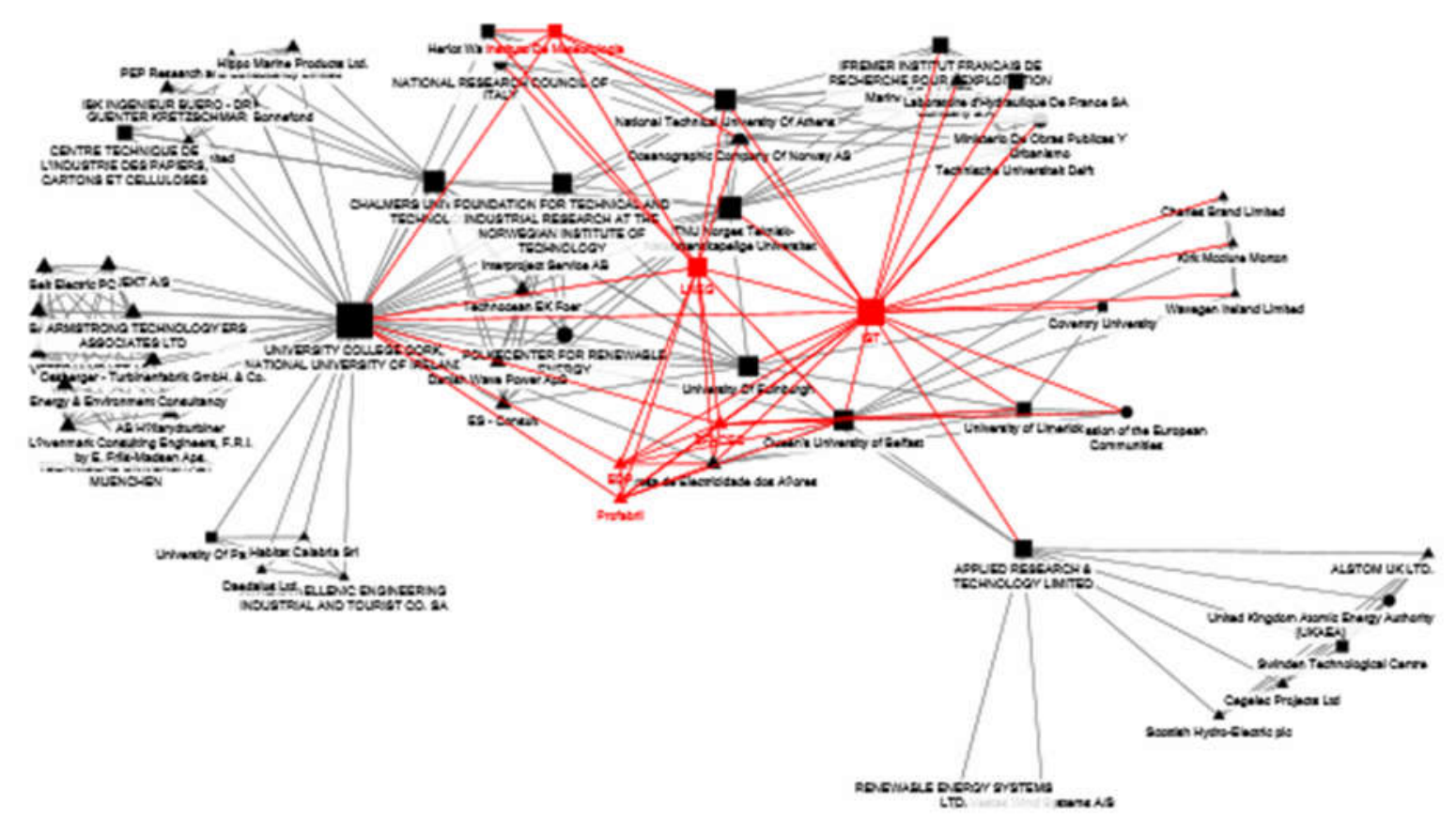

${ }^{a}$ University College of Cork and IST are the most central organisations, followed at a certain distance by LNEG, Queen's University of Belfast, Azores Electricity Company (Portuguese utility), Technical University Athens and NTNU.

Following the positive results from resource evaluation, it is decided to pursue with the set-up of the world first experimental site - the European Wave Energy Pilot Plant in the Portuguese Azores island of PICO, funded by European programmes. This project is a critical step in the expansion of the niche network in Portugal. In fact, the scientists behind the project are able to attract two important regime actors: the utility (EDP) and the main national energy equipment manufacturer (EFACEC). This is the first move of the utility into a field where it would play a significant role. The participation of scientists from other countries ensures that knowledge inputs and learning outcomes go beyond the local level. In a similar vein, a few years later, IST participates in a project to install an experimental site in the UK (the Limpet pilot plant). These pioneer projects are an important element in the learning process at global niche level, both in technological terms and in what concerns the involvement of new actors along the value chain.

In addition to experimental activities, the group of pioneer IST and LNEG scientists go on conducting fundamental (modelling) and applied (e.g. turbine development, resource assessment) research, contributing to reinforce the knowledge base. They maintain important positions in the expanding international scientific community (largely centred in the North Atlantic countries), where 
they are now joined by the regime actors (Figure 29). But research is still mostly conducted in the context of European projects. In fact, despite the launch, in 1994, of a dedicated "Operational Programme for Energy", only by the end of the period (1999) we find projects supported by national funds.

\section{Period 4 - Early Niche Expansion - 2000-2005}

Figure 30 - Position of Portuguese actors in the European knowledge network in wave energy: organisations in projects $2000-2005{ }^{a}$

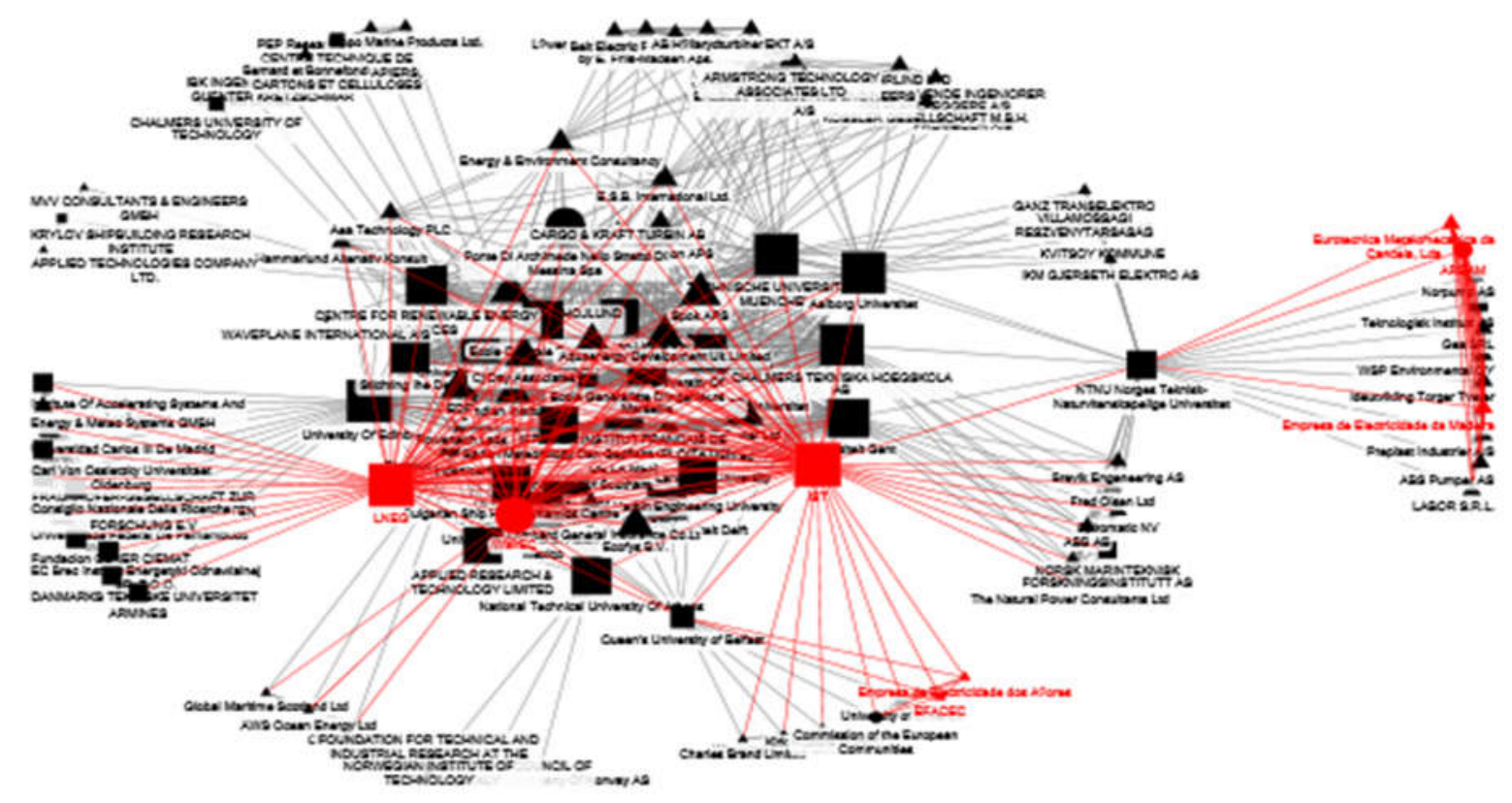

${ }^{a}$ IST and University College of Cork, LNEG, University of Edinburgh and Munich Technical University are the most central organisations

The 2000s represent a major turning point in the Portuguese policies towards renewable energies. Ambitious targets are established in response to the EU Directive on Renewables (2001/77/CE) and a new Programme (E4 - Energy Efficiency and Endogenous Energies) is launched, establishing objectives for renewable energy production and mechanisms to support it. Among these is the introduction of feed-in tariffs, including a special tariff for wave energy, and support to investment projects. In spite of this, the number of wave projects supported remains relatively small, with the largest amount of investment going to the more mature wind energy technology, which is starting to diffuse in the country (Bento and Fontes, 2015).

But the niche activities conducted by Portuguese wave energy actors intensify, encompassing different cognitive processes and spatial levels. Involvement in transnational activities increases, including both the conduction of more fundamental research and the participation in EU funded experimental projects, led by foreign firms in various other locations. IST and LNEG also participate 
in several projects and other actions that start being launched at European level with "structural" objectives, including projects whose explicit goal is to aggregate results from individual projects and other experiences taking place in different countries, convert them in abstract knowledge, and share it within the community. Some of these crystallise in the creation of stable networks or supra-national organisations, which are also concerned with producing (or reconfiguring) a vision for the field. IST and LNEG researchers remain central in the growing scientific community (Figure 30). They also occupy an important position in the new organisations: e.g. Portugal is founding member and first chair of IEA-OES, where it is represented by LNEG (OES, 2002). They are also actively involved in the organisation of a variety of events that act as arenas for knowledge circulation or wave energy promotion. Moreover, other Portuguese actors (including regime and policy actors) start joining the international network, often as part of projects led by these pioneer organisations.

The process of niche development at country level registers a turning point in this period, due to a new set of events. As several wave energy conversion systems reach a stage where larger scale testing in real sea conditions is required, some foreign technology developers start choosing Portuguese locations to conduct their experimental activities. Three main reasons can explain this decision. First, the country natural conditions that elect it as a promising location for wave energy production (WAVEC, 2004). Second, the extensive international connections and reputation of the main actors. Their position in the global niche community enables them to identify potential opportunities and to gain the interest of the foreign actors, while their previous record signals strong scientific and technical competences and local experience. Finally, the favourable policies for renewable energies, which are critical in a field where experiments require expensive infrastructures and a combination of different activities along the value chain (Falcão, 2010). By the end of the period, one experimental project has been launched and a couple of others are announced. These projects assume the form of joint ventures between the foreign technology developer and local large companies and are highly subsidised, usually involving a combination of national and European funds. The interest of established companies (often already involved in other renewable technologies) in wave energy projects is an additional source of attraction, since they can provide resources and offer legitimacy towards capital providers and other firms along the value chain. This model will continue being adopted in subsequent periods

As a result, the niche network expands both in number and variety of actors and in the spatial scope of activities. At country level, niche structuring increases with the creation, in 2003, of a wave energy association - WAVEC - involving research organisations and firms. WAVEC launches awareness and lobbying actions at country level and participate in structural EU projects, joining (and

DINÂMIA'CET - IUL, Centro de Estudos sobre a Mudança Socioeconómica e o Território ISCTE-IUL - Av. das Forças Armadas, 1649-026 Lisboa, PORTUGAL 
sometimes replacing) the research organisations that traditionally led the Portuguese participation in these activities (WAVEC, 2008) ${ }^{10}$.

Despite the growing interest in wave energy, technology development conducted by Portuguese firms is still limited. One spin-off is created to exploit university technology and one large company, already active in the wind energy field, starts developing its own technology, in collaboration with universities. One experimental project involving only national organisations is announced, but does not pursue till the end. At the same time the PICO pilot plant experiences problems and a recovery project is launched.

It is possible to argue that at the end of this period a national constituency is already being formed around wave energy in Portugal. Because R\&D activities are still critical, scientists remain central actors. But other actors have now joined the network, either gained to invest resources or involved in the development of technologies. They include a small group of regime actors, who play a significant role, given their investment capacity and the legitimacy that their presence bestows to the field. They also include a set of foreign technology developers, whose presence permits to extend the scope of learning from experimental activities. However, it is also possible to argue that a substantial part of the activity of what is sometimes described as the "country niche" is in fact taking place beyond the country territorial boundaries. That is, the emerging national network is complemented with the transnational networks that connect Portuguese actors to projects conducted elsewhere; and with the supra-national networks, concerned with aggregation activities, to which the core actors belong.

This international positioning of niche actors is also critical for strengthening their position at country level, increasing their capacity to enrol local actors and to influence the setting-up of favourable policies. It also implies that global niche processes, such as vision building and agenda setting, have an immediate impact at country-level, namely leading to the development of high expectations.

\footnotetext{
${ }^{10}$ WAVEC activity is extensively documented in its website: http://www.wavec.org/en 


\section{Period 5 - High Expectations - 2006-2010}

Figure 31 - Position of Portuguese actors in the European knowledge network in wave energy: organisations in projects $2006-2010{ }^{a}$

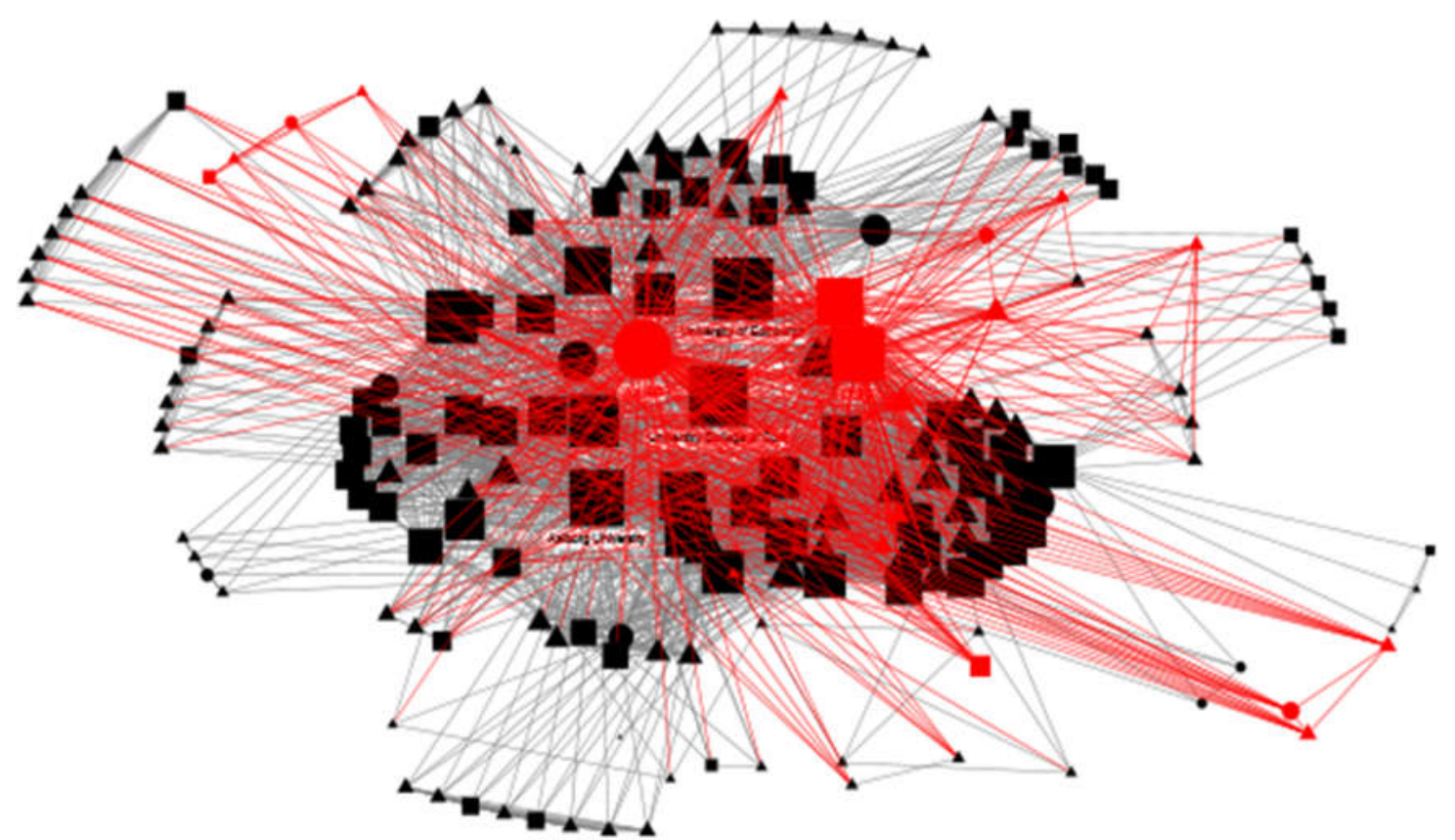

${ }^{a}$ The number of organisations precludes the use of labels for nodes. WAVEC and University College of Cork are the most central organisation, followed by University of Edinburgh, Aalborg University and LNEG.

The government bet in renewable energies was reinforced with the launch, in late 2005, of a National Strategy for Energy (ENE 2010, prolonged in 2009 by the ENE 2020 and the Action Plan for Renewable Energies (PNAER)), where renewable energy is presented as a priority and described as a driver of country development. Country targets are revised upwards. The ocean also becomes a focus of policies (National Strategy for the Sea) that aim at the development of an Ocean Cluster, which includes energy, generating a renewed interest in wave energy.

Against this background, there is a growing emphasis on the attraction of foreign technology developers. These are a mobile set, highly dependent on favourable policies, availability of infrastructures and of investors that enable them to endure the high costs of the sea level experimental projects (Løvdal and Neumann, 2011). The government, encouraged by national niche actors, decides to create a Pilot Zone for Wave Energy - i.e. a fully equipped test and demonstration infrastructure that differs from similar facilities set-up in competing countries, by admitting both experimental projects and small early stage commercial projects (Decreto-Lei $n^{\circ} 5 / 2008$ ).

The announcement of the Pilot Zone leads several foreign technology developers to express interest in testing their technologies there. The message put forward by these firms is that their technologies are approaching stabilisation and that these experiments, which move them from the relatively sheltered early test environments to real sea conditions, will swiftly lead to commercial 
installations. This expectation raises the interest of several established Portuguese companies and new joint ventures are prepared. Among these stands the utility EDP that is engaged in several projects and becomes a very proactive advocate of the field, deploying its considerable resources and political power. Some of these companies also invest in systems being developed in other countries, or in projects that are expected to create opportunities for future technology deployments in Portugal. Experimental projects start involving Portuguese firms located along the value chain (e.g. metalmechanicals, shipyards, sea equipment and logistics) and also attract some foreign companies specialised in these fields. They also show an early concern regarding environmental impacts and the need to avoid interference with other activities that share the ocean space. These individual experiments provide important learning opportunities, concerning the technological and organisational complementarities that need to be created in order to obtain a fully operating system (Markard and Hekkert, 2013) and the actors' alignment required to achieve it. Results and lessons learnt from these experiments circulate across projects and locations, given the presence of intermediary actors in several of them.

The involvement of a variety of new actors leads to a sudden expansion of the network centred in Portugal (Figure 32). It also contributes to reinforce the European knowledge network, where Portuguese organisations, such as LNEG and WAVEC strengthen their central position (Figure 30). Portuguese actors also continue to be highly active in the setting-up of community level infrastructures where knowledge circulates and debate takes place, and where aggregation activities are performed. This includes, for instance, the establishment of regular dedicated conferences (where they belong to scientific or organising committees), the reinforcement of OES aggregation activities, through the expansion of its work programme (OES, 2006-2010), or the creation of the European Ocean Energy Association, with WAVEC in the board of directors.

DINÂMIA'CET - IUL, Centro de Estudos sobre a Mudança Socioeconómica e o Território ISCTE-IUL - Av. das Forças Armadas, 1649-026 Lisboa, PORTUGAL 
Figure 32 - Organisations involved in wave energy activities in Portugal in $\mathrm{P5}^{11}$ (2006-2010)

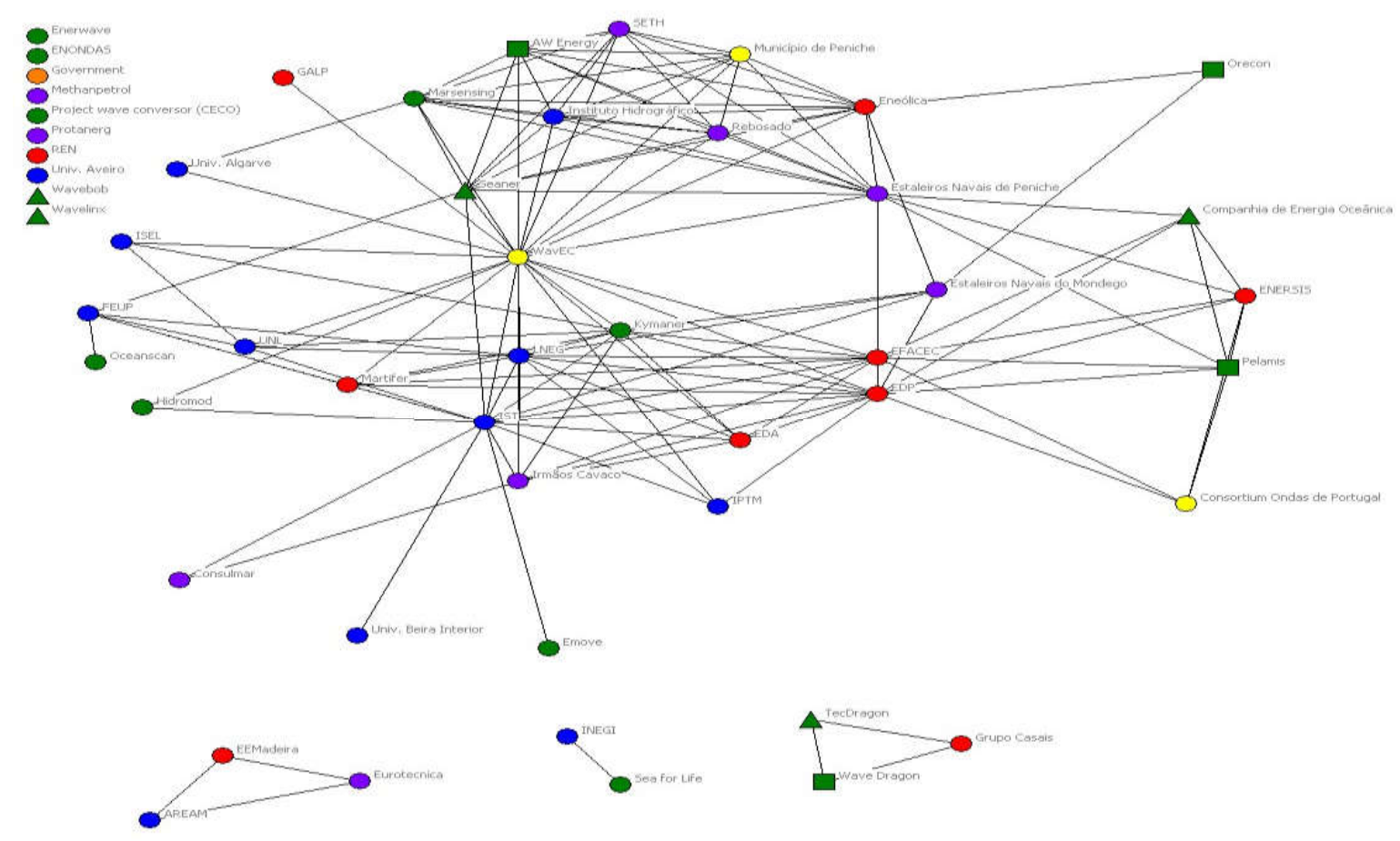

Legend: Circles - Portuguese; Squares - Foreign; Triangles - Joint ventures PT/foreign

Colours: Green - niche firms; Red - incumbents; Purple - value chain; Blue - research; Yellow - collective

At country level, the expansion of niche activities does not necessarily lead to a substantial increase in the resources available to local organisations. There is a small rise in the number of R\&D projects funded by national programmes, and also in patenting, by universities and new ventures ${ }^{12}$. However, the number of Portuguese companies developing proprietary systems remains very small. Despite the availability of public funding to support the early stages, the small group of new entrepreneurial firms created experience difficulties in up-scaling their technologies (and thus effectively testing them), given the high investments and the limited interest of private investors, who prefer the technologies potentially closest to market presented by foreign developers - and the absence of venture capital. This reduces the scope for local development and also for the emergence of radically new designs being pursued by some firms, which can be particularly important when technologies are still far from stability (Jeffrey et al, 2013).

\footnotetext{
${ }^{11}$ Include the individual organisations identified as active in Portugal in the period. Networks were only built for organisations involved in joint activities (formalised). The remaining are shown as isolated.

${ }^{12}$ Patent data used in this analysis include all patents whose applicants had Portuguese nationality, independently of the patenting office where the application was filed (only the first application was considered). Several patents were only submitted in Portugal, so they are not visible in the international databases analysed in the previous section. This fact reflects both the lack of resources that prevented inventors to proceed to the more expensive patenting at the European or US level; and the lack of opportunity to progress with further development and implementation of the technology.
} 
The period started with high expectations for the development of wave energy in Portugal. The network had extended, involving a growing number of actors prepared to invest in the field. Moreover, wave advocates had been able to capture the interest of both government and regime actors to a narrative that stressed the country's favourable conditions, and the opportunities opened by a first mover advantage in a new field full of potential and with strong synergies with other ocean activities (WAVEC, 2004). The implicit strategy was that the country could profit from the capacity to assist experimental projects, positioning itself for becoming a central location for wave energy production. The creation of a supportive industry around this activity (a "wave cluster") and the rejuvenation of traditional sectors (such as shipyards) and declining fishing communities were also part of this vision. Several elements appeared to be in place: strong international networks led by reputed scientists; a favourable energy policy; the Pilot Zone being installed and a number of experimental projects being negotiated or starting.

However, things did not progress as expected. First, the Pilot Zone, a central element of this strategy, registered delays and, by the end of the period, its set-up was not yet completed. Thus several projects ended-up being diverted to other countries (or did not pursue at all) frustrating the prospects of the local companies that had invested or proposed to invest in them. Second, expectations about the development of the technology grossly underestimated the problems to be faced in the harsh conditions of real sea experiments. Thus, the outcomes of the projects that did advance were much below expectations.

An exemplary case is the Pelamis project for the "first wave farm" ${ }^{13}$, which is presented as the first pre-commercial demonstration project, potentially leading to energy production in the near future. It is regarded by various players as a basis for the promised "wave cluster": the government makes it a flag project (Figure 33 and Box) and several companies - led by the utility EDP - invest in it. The visual image of the device (the "red serpents") is taken over by the media that follows up the progress of the project.

\footnotetext{
${ }^{13}$ Pelamis Wave Power went out of business in December 2014, but information about this particular experiment can still be found at the EU funded AquaRET dissemination project webpage: http://www.aquaret.com/images/stories/aquaret/pdf/cswavepelamis.pdf 
Figure 33 - Minister of Economy during Pelamis presentation in Peniche Shipyards (May 2006) and launch of Pelamis at Aguçadoura (September 2008)
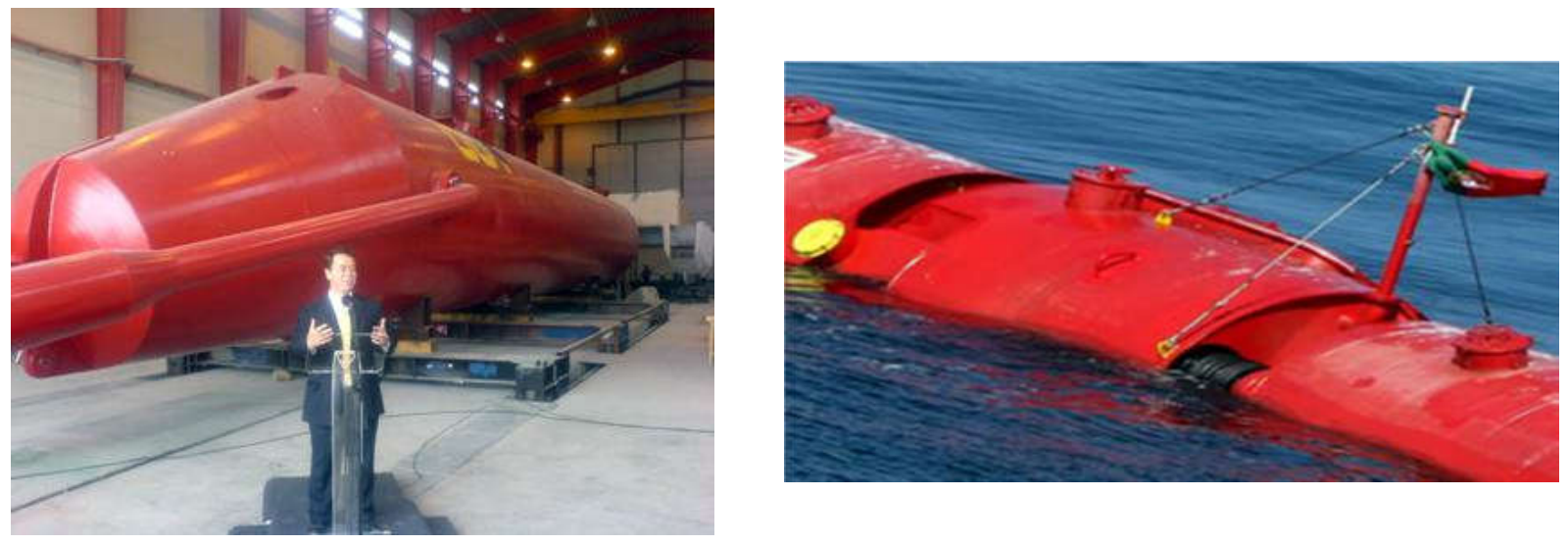

\section{Launch of Pelamis - 23 September 2008}

A high profile event was staged to signal the day, with the Minister of Economy (Manuel Pinho) and an entourage of CEOs and journalists embarking on the Portuguese Navy frigate Corte Real to follow the tug boat trailing the red serpent to its final resting place, $5 \mathrm{Km}$ off the coast, by the village of Aguçadoura.

The Oil Drum [europe.theoildrum.com/node/4575]

"The future of wave energy starts today", said Manuel Pinho. "Finland is very good in mobile phones; Portugal wants to be good in renewable energy. We are among the top five in the world, and we are just in the beginning of the process. Renewable energy is the source of energy for the future and we think this can create an industrial revolution and a lot of opportunities for jobs and research and we want to be ahead of the curve".

Guardian, 24 September 2008

[http://www.theguardian.com/environment/2008/sep/24/renewable.wave.energy.portugal]

Thus, the quick failure of the system - also widely reported in the media - has a strong impact. EDP faced with a third negative outcome in its wave energy projects abandons the field and moves, with its partners, to a field that is perceived as less uncertain: deep-water offshore wind. Even if deep-water offshore systems are still at an experimental stage, they bring to the sea environment a technology that EDP already dominates - wind conversion - and can take advantage of the assets and sea-operating experience gained in the wave energy projects. Thus EDP launches the prototype of a floating offshore wind system, in joint venture with a US technology developer and several Portuguese companies (some of which also had been active in wave experiments), thus repeating in the new field a strategy previously adopted in the wave energy field.

By the end of the period only one wave experimental project involving a foreign company is pursuing as planned, registering some success and advancing to a second phase - Waveroller promoted by the Finish AW Energy in partnership with the Portuguese Eneólica. But this is an exception. The 
disappointment follows the "hype" (Bakker and Budde, 2012) and the supportive country network dwindles.

\section{Period 6 - Disappointment \& uncertainty (2011 onwards)}

Figure 34 - Position of Portuguese actors in the European knowledge network in wave energy: organisations in projects 2011-2014

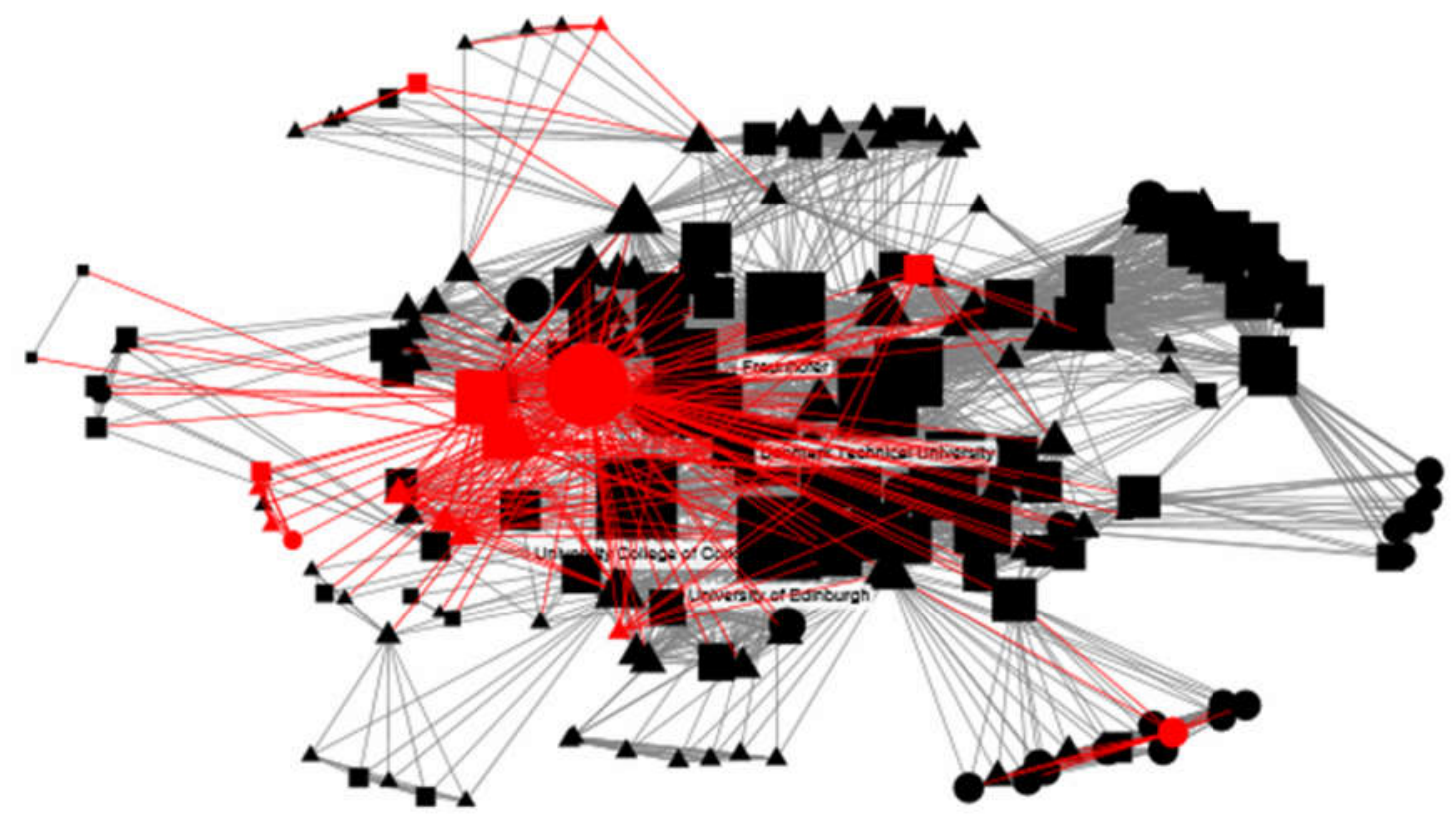

\footnotetext{
${ }^{a}$ The number of organisations precludes the use of labels for nodes. WAVEC is the most central organisation, followed by University College of Cork, University of Edinburgh, Fraunhofer Institute, Denmark Technical University.
}

The problems experienced by the wave energy niche are suddenly aggravated by the economic crisis, which leads to the country bailout. This also drives a change of government and of policy: renewable energies stop being a priority, targets are revised downwards and there is an explicit divestment from "less competitive energy technologies", which includes wave energy (Revision of Action Plan for Renewable Energies - PNAER).

For the niche, the abandon of EDP and its partners is a strong blow in the credibility. Combined with continued delays in the Pilot Zone and the consequent abandon of the few waiting projects and with the gradual withdrawal of policy support, this definitively clouds the high expectations created around wave energy. No new experimental projects are launched. Investment by local companies stops, financial problems adding to disappointment. Wave energy projects disappear from national funding programs. New ventures experience increasing difficulties in obtaining 
financing for developing or testing their technologies. They suspend activity or search for alternative areas of application, when the technology allows it $^{14}$.

The only exception to this bleak picture is still the Waveroller project, which was installed off the coast of Peniche, successfully connected to the grid and started producing energy, although still in an experimental way ${ }^{15}$ (Figure 35). This project - at whose core were a Finish technology developer, a Portuguese energy company and a local authority - evolved from the test of early devices in Portuguese waters with some support from Portuguese researchers, to the growing involvement of local and national actors (e.g. a shipbuilding firm, other suppliers), as subsequent versions of the system were developed, installed and tested over the years, thus becoming increasingly societal and territorially embedded (Hess, 2004). But it has, in fact, a wider scope. It is an evolving experiment where a variety of organisations, first from the two countries, later from additional ones, become involved over time, performing various functions at different spatial levels - funding, research, provision of facilities, contribution to test and demonstration activities - and also compiling data on outcomes and bringing them into aggregation exercises. Thus it emerges as a particularly interesting example of multi-spatial endeavour, where networks and learning processes span spatial boundaries, also contributing to reinforce the overall trajectory of the technology

Figure 35 - Waveroller wave energy device being deployed near Peniche (August 2012) and artist image of a Waveroller farm in operation
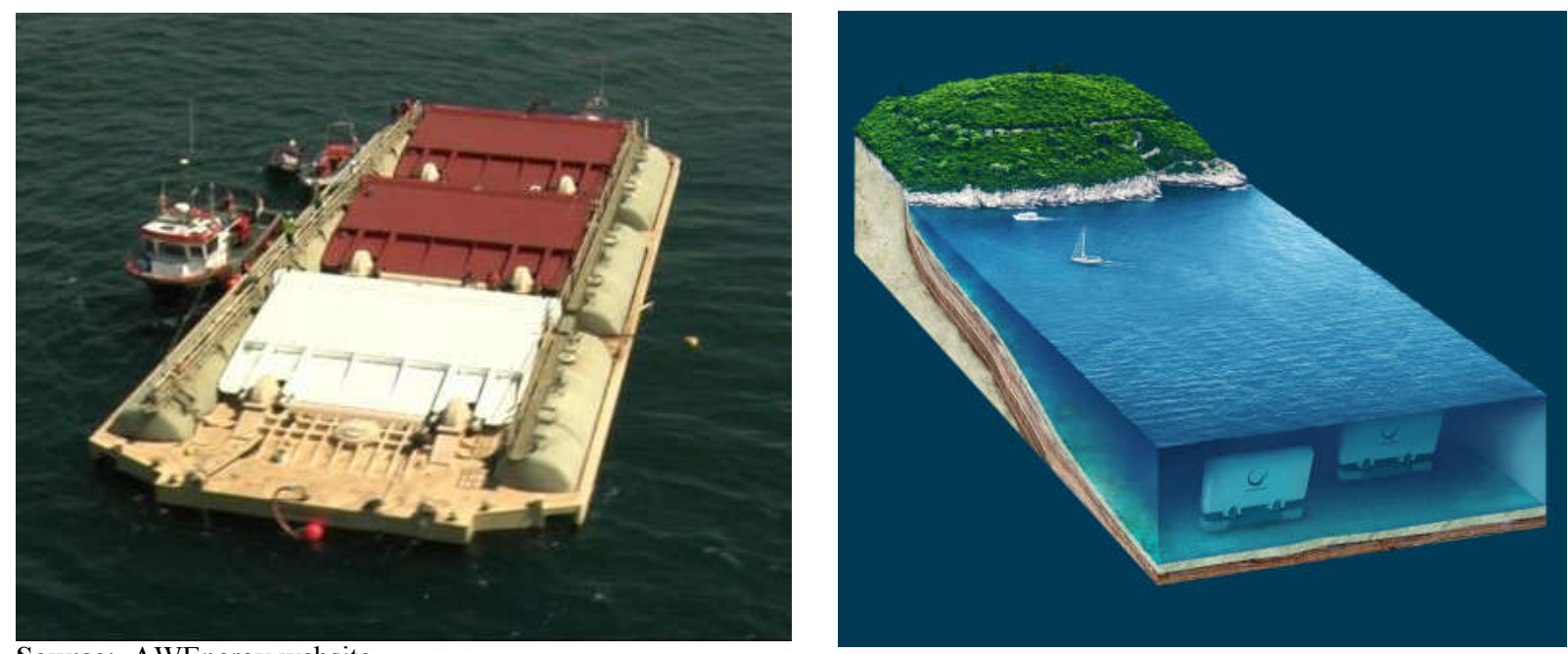

Source: AWEnergy website.

\footnotetext{
${ }^{14}$ Sea for Life and Reef Power are not operating anymore and Kymaner describes itself as being in "stand-by". Emove tries to apply its conversion technology to the wind field. Hidromod develops other lines of business allowed by its competence base.

${ }^{15}$ Information on Waveroller can be found at http://aw-energy.com/. In July 2014 a new project (SWELL) was awarded substantial financing from NER 300, the largest European funding system in the low-carbon energy area, whose aim is "to establish a demonstration programme comprising the best possible CCS and RES projects" (http://ec.europa.eu/clima/policies/lowcarbon/ ner300). The funding will support the installation of a 5,6 MW wave farm composed of 16 wave converters in the Portuguese coast.
} 
At niche level, the withdrawal of support, from both regime actors and policy makers, forces a strategic re-orientation. As part of their attempts at "repair work" (Geels and Raven, 2006), core niche actors search complementarities with other technologies that are achieving greater success and can help them overcome the current constraints, and also attempt to link to faster developing markets (Geels, 2005). This type of behaviour has been described for periods of disappointment after an hype (Konrad et al, 2012). The move of EDP and some its partners to deep-water offshore wind triggers, at country level, a movement already visible at international level - the focus is now increasingly on "ocean energies". In Portugal, the label "offshore energies" now prevails and offshore wind effectively supersedes wave, attracting attention and investments, largely due to EDP power and the early success of its floating offshore wind prototype - Windfloat. Although EDP still mentions wave as a "future target", it stopped being a driver of the wave niche development and effectively became a competitor.

Wave energy niche actors attempt to compensate for the difficulties, by adhering to the "offshore" label and, when possible, extending the scope of their activities to integrate with offshore wind. There is also an attempt to build synergies with other ocean related activities, profiting from the continuity of policies aiming at the development of an "ocean cluster" (Revision of National Strategy for the Sea \& Action Plan Sea-Portugal). The effort to revitalise the country level network and to restore the image of wave energy, culminates in 2014 in the widely participated development of a "Roadmap for Offshore Energies", that is expected to provide a new vision and directions for action, with the purpose of both influencing policy decisions and (re)engaging relevant actors (OTEO, 2014).

While activities and networks dwindle at country level, we observe a continued capacity of the overall niche advocates for sustaining visions of future potential, attracting large regime actors and maintaining political support (EU-OEA, 2010, 2013; EC, 2014; OES 2013). Core Portuguese actors benefit from these conditions to continue participating in a variety of transnational and supra-national activities - indeed WAVEC is now the most central actor in the European knowledge network (Figure 34). Even if the number of participating organisations, and also of those in central positions, diminishes, core actors retain their involvement in the supra-national structures where global level activities are performed. This positioning is also instrumental to support their attempts to reinstate wave energy at country level. Thus, to some extent, Portuguese actors are back to the early stages, where transnational networks sustained their niche activities at country level.

DINÂMIA'CET - IUL, Centro de Estudos sobre a Mudança Socioeconómica e o Território ISCTE-IUL - Av. das Forças Armadas, 1649-026 Lisboa, PORTUGAL 


\subsection{Discussion}

The above analysis of activities that took place in Portugal or involved Portuguese actors offers some insights into the social and cognitive processes that underlie the construction of a wave energy niche space. It equally permits to gain some insights into the spatial dynamics of these processes. In particular, it permitted to examine how territorial conditions influence (and in some cases are influenced by) niche development processes.

Portuguese actors were among the pioneers in the creation of a protected space for the emerging wave energy conversion technology. This early contribution was partly based on country related factors - natural resource endowments, economic and scientific orientation to sea-related activities - which might have also been behind similar activities in other North Atlantic countries. The pioneering activities being conducted in these locations led to the emergence of a proactive group of wave energy actors, from different origins, which pooled efforts from early years. This resulted in the formation of a (growing) transnational community that worked together in research and experimental activities, developing individual projects that frequently built on each other, or involved actors present in different networks, thus promoting the circulation of knowledge produced and lessons learnt. The early emergence of intermediary actors and formalization of arenas for debate - also mostly enacted by pioneer organisations - favoured the conduction of field-level aggregation activities. These were determinant to guide the niche trajectory and to articulate a compelling vision of future benefits that attracted support from policy makers. These activities permitted a (slow) niche structuration and, together with the presence of a close-knit core community, enabled the niche to withstand the difficulties associated with a progress much below expectations.

Turning again to Portugal, the case shows that some country-related factors permitted an acceleration of the niche development. One was the presence of favourable government policies. The other was the particular configuration of the transition process that made regime actors more open to the opportunities arising in wave energy and favoured their participation, bringing resources and legitimacy. Such a favourable environment permitted to reinforce the niche network and extend its spatial scope. It also permitted the development of local learning processes - concerning both technology functionalities and the type of social structures and institutional arrangements that could support niche upscale. But this acceleration, even if partly based on territorial factors, capitalised on the spatial features of the overall niche, in particular the fact that the niche community was highly international, that activities were routinely conducted by networks of actors from different origins and that interactions and mobility between geographical locations were common. In addition, it benefited from the central position of Portuguese actors that were both involved in "local" experimental activities in various locations and engaged in "global" aggregation activities, thus playing an important role as intermediary actors.

DINÂMIA'CET - IUL, Centro de Estudos sobre a Mudança Socioeconómica e o Território

ISCTE-IUL - Av. das Forças Armadas, 1649-026 Lisboa, PORTUGAL 
From an overall niche perspective, the attempted niche upscale conducted by Portuguese actors had a strengthening effect on the niche as a whole (Spath and Rohracher, 2012). In fact, at some point Portugal was an important arena for the development of wave energy: as a setting for a variety of experimental projects that produced different learning outcomes; as a source of knowledge that circulated in the community, across projects and through actor participation in aggregation activities; and as a "showcase" and an inspiration for vision building.

However, the analysis also shows that the same type of territorial factors that contributed to accelerate niche development were responsible for its decline at country level. In what concerns policies, implementation delays and sudden withdrawal of support, by reducing the country attractiveness to mobile foreign actors and by limiting the scope of action of national actors, caused major damages (Verbong et al, 2008). In what concerns the involvement of powerful regime actors, this case evinces the risks of their excessive protagonism that leaves the niche vulnerable to their strategic shifts (Smink et al, 2013), which not only withdraw resources, but can also contribute to alienate other actors and to redirect the attention of policy makers (Geels, 2014). It also shows the impact of events taking place at the landscape level (Geels, 2002), since these effects were exacerbated by the financial crisis, which influenced the behaviour of both policy makers and regime actors, and generally reduced the resources available.

From the country standpoint, this set of events dealt a strong blow to the niche activity of Portuguese actors and effectively thwarted the country endeavour of becoming a central player in a future wave energy system. From an overall niche perspective, the downfall of the activities taking place in the Portuguese territorial space or enacted by Portuguese actors led to the shrinking of the niche space, with the reduction of the number and variety of experimental activities and the withdrawal of a component of the network (Geels and Raven, 2006). Nevertheless the continued participation of core Portuguese actors in experimental and aggregation activities - through their involvement in transnational and supra-national networks - lessened the impact of these territorial effects on the niche community and its "global level" activities. Moreover, the positioning of these actors may contribute to draw some generic lessons from this particular combination of events. On the other hand, such positioning is also important from the country standpoint, since processes taking place at global level can support niche actors' attempts to readjust the vision and expectations and to reconstruct the country level network.

Finally, it is also worth looking in greater detail into the processes that took place in the Portuguese context, since they enable us to address some important aspects in the process of niche development. At this level, the strategy that ended-up being followed, in an attempt to achieve niche upscale and break out is of particular interest. This involved attracting experimental projects that appeared to be closer to commercial application - mostly proposed by foreign companies - with a view

DINÂMIA'CET - IUL, Centro de Estudos sobre a Mudança Socioeconómica e o Território ISCTE-IUL - Av. das Forças Armadas, 1649-026 Lisboa, PORTUGAL 
to create local competence (including a supportive industry), thus profiling the country as a privileged location where these (and eventually other) promoters could establish themselves as energy producers, once the technology stabilised. Gaining access to state-of-the-art technologies wherever they were being developed and profiting from the local capacity to secure and further explore the associated technological knowledge and networks appeared to be a viable strategy for accelerating the process of technology implementation (Wieczorek et al, 2015). The industry building goal would be achieved through the participation of Portuguese companies in these experiments, supported when necessary by the extensive scientific and technological background of the research community. Thus large established companies entered in several joint ventures, mostly as capital providers, and there was also some involvement of Portuguese firms in activities along the value chain, which was expected to expand and form the basis for the emerging industry.

The country's capacity to profit from this strategy depended on the ability to turn it into an opportunity for strengthening internal niche processes. However, the strategy revealed some problems at this level. In what concerns one critical niche process - learning - the excessive focus on foreign technology developers led to a relative neglect of local technology development, preventing the creation of a stronger core of technology-intensive companies that could support more locally grounded learning processes. This was compound by the fact that, with a few exceptions (and these mainly in the early periods), the engagement of established local companies in joint-ventures was a business investment, with limited involvement in technology development or in actual learning processes. Thus, the capacity for retaining some activity when foreign actors moved away and/or for absorbing results from experiments was limited, resting almost exclusively on the scientific community or the few entrepreneurs originating from it. Even if the involvement of a small group of local companies (e.g. in shipbuilding and other sea-related activities) in experimental projects effectively permitted to start developing some competences along the value-chain and created some interest in the field, they were not sustained due to lack of continuity. Interestingly, the only project that persisted, ended-up achieving, at a local dimension, some of the effects envisaged by policy makers: the local grounding of a foreign technology developer, the formation of a core network of supportive actors spanning two different locations, and the creation of a local value chain harnessing competences from declining sectors.

In what concerns another critical niche process - network creation - the absence of a core group of local actors (besides scientists) concerned with the development and local embedding of the technology made networks fragile, since they ended-up being largely composed of highly mobile foreign actors and regime actors. The engagement of the former with the niche was based on a particular set of conditions and thus their allegiance was weak, and they could always move elsewhere, if the conditions offered were more favourable (which they effectively did). The 
engagement of the latter was circumstantial and mostly associated with a generic interest in renewable energies. Once it became evident that more stabilised competitor technologies offered better opportunities and, particularly, when landscape developments introduced economic difficulties and forced a choice, they shifted to them. The fact that, in this particular context, another renewable technology (wind energy) was regarded as a successful story (Bento and Fontes, 2015) turned it into an effective competitor in a period of lower resources (Flyn, 2015), with implications for the future balance between the various "ocean energies", at country level.

Moreover, the strong presence of these two types of actors may have favoured the formation of a hype (Van Lente et al, 2013) - i.e. the creation of high but unrealistic expectations that was visible in the mid-2000s - followed by disappointment. In fact, foreign technology developers had a vested interest in raising expectations, to improve the competitive position of their technologies (van Lente and Bakker, 2010), while regime actors had a limited knowledge of the field and thus were more vulnerable to inflated promises (Bakker and Budde, 2012). As a result, voicing of expectations become increasingly dissociated from project outcomes, creating the conditions for disappointment when results were very distant from (unrealistic) expectations (Geels and Raven, 2006). It also made "repair work" more difficult, at least in the medium-term, notwithstanding the efforts made by local niche advocates for translating generic lessons that transcended the scope of national experiences and imposing more long-term visions.

The evolution documented above thus provides a good illustration of the non-linearity of the niche trajectory (Geels and Raven, 2006). The analysis of the Portuguese case also permits to suggest that specific territorial conditions may impinge on the relationship between expectations, learning outcomes and the subsequent evolution of the niche processes. That is, they may potentially amplify the effects (positive and especially negative) in locations whose specific configurations of actors, institutions or policies render them more receptive to the voicing of positive expectations, or vulnerable to the negative outcomes that frustrate such expectations. On the other hand, it also suggests that the multi-spatial nature of the overall niche space may make it more resilient to these specific territorial effects, permitting to absorb them and eventually turn them in generic lessons to guide future developments. However, these preliminary insights need to be further explored in a wider number of cases.

DINÂMIA'CET - IUL, Centro de Estudos sobre a Mudança Socioeconómica e o Território ISCTE-IUL - Av. das Forças Armadas, 1649-026 Lisboa, PORTUGAL 


\section{CONCLUSION}

The paper proposed that technological niche formation and development is a complex and multispatial process and developed a conceptual framework to support this assertion. The framework draws on the socio-cognitive perspective to niche development and extends it by introducing an additional dimension - space. This permitted us to retain the powerful notion of a niche space that encompasses the variety generated by local projects and also transcends them through social and cognitive processes, which generate an increasingly structured "global niche level" (Geels and Raven, 2006; Raven and Geels, 2010). But it also permitted to strengthen it, by grounding these processes on the territorial and relational space(s) where niche actors act and interact, both within the niche space and across it, by linking-up with regime actors.

As a result, the technological niche is defined as constructed by the actions and interactions of a variety of actors that conduct different types of activities at and across different spatial levels. This multi-spatial dynamics effectively entails an interplay between a niche relational space constructed by niche actors along their "local" experimental and "global" aggregation activities (Geels and Raven, 2006), and the territorial effects introduced by the embeddedness of these actors and their actions in particular geographical and institutional settings (Hess, 2004). The niche trajectory is expected to be shaped by the processes taking place at these various levels.

This framework was applied to the case of the wave energy technological niche, by combining a generic analysis of the evolution of the "overall niche", with a more detailed analysis of the processes taking place in a specific country, Portugal, which were addressed from a territorial perspective and set against the development of the whole niche.

The analysis has confirmed that the early construction of an overall niche space was supported by the extensive transnational activities of an emerging community, as well as by the early creation of supra-national networks and infrastructures concerned with global aggregation activities, agenda setting and vision building. This space become increasingly structured over time, in what concerns both the size and strength of the community and the nature and impacts of the cognitive activities developed. This permitted to consolidate the niche trajectory and enabled it to withstand periods of downturn (Bakker and Budde, 2012). However, the research has also uncovered territorial effects. Key actors behind niche activities originally arose from certain locations where natural and institutional environments created more favourable conditions and where a substantial part of experimental activities was conducted (or at least coordinated) across multi-spatial networks. These actors also tended to occupy a central position in the more de-territorialised aggregation networks (Geels and Deuten, 2006) thus having a better access to key knowledge and also a greater potential for influencing the trajectory of the technology. In fact, the presence of shared goals and interests should

DINÂMIA'CET - IUL, Centro de Estudos sobre a Mudança Socioeconómica e o Território ISCTE-IUL - Av. das Forças Armadas, 1649-026 Lisboa, PORTUGAL 
not obscure the fact that actors also belong to countries/regions or organisations with specific interest in the emerging technology and thus power issues should not be excluded (Avelino and Rotmans, 2009).

But the research also revealed an effective interplay between territorial and niche level effects. On the one hand, the "favourable conditions" that emerge in some locations are partly shaped by processes taking place at the overall niche level. On the other hand, events taking place in some particular locations can influence the trajectory of the overall niche. They may contribute to accelerate it, by reinforcing expectations and strengthening the network and also providing learning opportunities that enable a greater structuring of the technology trajectory (Spath and Rohracher, 2012). Or, on the contrary, they may provide negative lessons whose impacts can equally be more far-reaching, and may even lead to a reconfiguration of overall expectations and adjustments in the niche trajectory. Thus, it is possible to conclude that the development of the technological niche is shaped by processes taking place at a multiplicity of levels which both build on and influence each other.

These results, albeit still relatively exploratory, contribute to the on-going debate on the role of space in niche development and more generally in socio-technical transitions (Coenen et al, 2012, 2010; Raven et al, 2012), permitting namely to start answering to the claim that it is necessary to address "the compatibility between a relational conceptualisation of space and the simultaneous acceptance of the local embeddedness of relations" (Hansen and Coenen, 2015: 101). These conclusions need now to be further explored on the basis of more in-depth analysis of the processes taking place at the "overall niche level", as well as a better understanding of the its interplay with the territorial dimension, namely through a comparative analysis involving other national (or regional) contexts. 


\section{REFERENCES}

AVELINO, F., Rotmans, J. 2009. Power in Transition An Interdisciplinary Framework to Study Power in Relation to Structural Change. European Journal of Social Theory 12, 543-569.

BAKKER, S., Budde, B., 2012. Technological hype and disappointment: lessons from the hydrogen and fuel cell case. Technology Analysis \& Strategic Management 24, 549-563.

BENTO, M. and Fontes, M., 2015. Spatial diffusion and the formation of a technological innovation system in the receiving country: The case of wind energy in Portugal, Environmental Innovation and Societal Transitions 15, 158-179.

BERGEK, A., Berggren, C., Magnusson, T., Hobday, M., 2013. Technological discontinuities and the challenge for incumbent firms: Destruction, disruption or creative accumulation? Research Policy 42, 1210-1224.

BERGEK, A., Jacobsson, S., Sandén, B.A., 2008. 'Legitimation' and 'development of positive externalities': two key processes in the formation phase of technological innovation systems. Technology Analysis \& Strategic Management 20, 575-592.

BERGGREN, C., Magnusson, T., Sushandoyo, D.. 2015. Transition pathways revisited: Established firms as multi-level actors in the heavy vehicle industry, research Policy 44: 1017-1028).

BINZ, C. Truffer, B., Coenen, L., 2014. Why space matters in technological innovation systems Mapping global knowledge dynamics of membrane bioreactor technology. Research Policy 43, 138155.

BINZ, C., Truffer, B. Li, L., Shi, Y., Lu, Y., 2012. Conceptualizing leapfrogging with spatially coupled innovation systems: The case of onsite wastewater treatment in China. Technological Forecasting and Social Change 79, 155-171.

BORUP, M., Brown, N., Konrad, K., Van Lente, H., 2006. The sociology of expectations in science and technology. Technology Analysis \& Strategic Management 18, 285-98.

BOSCHMA, R., 2005. Proximity and innovation: A critical assessment. Regional Studies 39, 61-74.

BRESCHI, S and Lissoni, F., 2001. Knowledge Spillovers and Local Innovation Systems: A Critical Survey. Industrial and Corporate Change 10, 975- 1005.

DINÂMIA'CET - IUL, Centro de Estudos sobre a Mudança Socioeconómica e o Território ISCTE-IUL - Av. das Forças Armadas, 1649-026 Lisboa, PORTUGAL 
BULKELEY, H., 2005. Reconfiguring environmental governance: Towards a politics of scales and networks. Political Geography 24, 875-902.

CA-OE (2009) Co-ordinated Action on Ocean Energy - Wave and Tidal Power, Final Report, http://cordis.europa.eu/documents/documentlibrary/124729491EN6.pdf.

CARATTI, G., Lewis, A.T. and Howett, D. 1993, Wave energy R\&D: Proceedings of a workshop held at Cork, 1 and 2 October 1992, Luxembourg: Comission of the European Communities.

CLÉMENT, A., McCullen, P., Falcão, A., Fiorentino, A., Gardner, F., Hammarlund, K., Lemonis, G., Lewis, T., Nielsen, K., Petroncini, S., Pontes, M.T., Schild, P., Sjostrom, B.O., Sorensen, H.C., Thorpe, T., 2002. Wave energy in Europe: current status and perspectives. Renewable and Sustainable Energy Reviews 6, 405-431.

COE, N. and Bunnell, T.G., 2003. 'Spatializing' knowledge communities: towards a conceptualization of transnational innovation networks. Global Networks 3, 437-456.

COENEN, L., Benneworth, P., Truffer, B., 2012. Towards a spatial perspective on sustainability transitions. Research Policy 41, 968-979.

COENEN, L., Raven, B., Verbong, G., 2010. Local niche experimentation in energy transitions: A theoretical and empirical exploration of proximity advantages and disadvantages. Technology in Society 32, 295-302.

CORSATEA, T.D. and Magagna, D., 2014. Overview of European innovation activities in marine energy technology. Joint Research Centre Policy Reports, Brussels: European Commission.

EC, 2015. Towards an Integrated Strategic Energy Technology (SET) Plan: Accelerating the European Energy System Transformation. Brussels, European Commission.

EC, 2014. Blue Energy - Action Needed to Deliver on the Potential of Ocean Energy In European Seas and Oceans by 2020 and Beyond. Brussels, European Commission.

ELLIOT, G. and Caratti, G., 1994. 1993 European Wave Energy Symposium, Proceedings of an International Symposium held in Edinburgh, Scotland, 21-24 July 1993. Brussels, Commision of the European Communities and NREL - Renewable Energy (Scotland, UK).

DINÂMIA'CET - IUL, Centro de Estudos sobre a Mudança Socioeconómica e o Território ISCTE-IUL - Av. das Forças Armadas, 1649-026 Lisboa, PORTUGAL 
EU-OEA, 2010. Oceans of Energy - European Ocean Energy Roadmap 2010 - 2050. Brussels, European Ocean Energy Association.

EU-OEA, 2013. Industry Vision Paper 2013. Brussels, European Ocean Energy Association [http://www.oceanenergy-europe.eu/index.php/en/communication/publications].

FALCÃO, A., 2010. Wave energy utilization: A review of the technologies. Renewable and Sustainable Energy Reviews 14, 899-918.

FLYN, B., 2015. Ecological modernisation of a 'Cinderella renewable'? The emerging politics of global ocean energy, Environmental Politics, 24:2, 249-269.

FONTES, M., Sousa, C., Pimenta, S., 2012. The commercialisation of emerging energy technologies: the strategic alliances of high-technology entrepreneurial firms, DINAMIA'CET-IUL Working Papers $\mathrm{n}^{\circ} 2012 / 05$.

FOXON, T. J., Hammond, G. P., \& Pearson, P. J., 2010. Developing transition pathways for a low carbon electricity system in the UK. Technological Forecasting and Social Change, 77(8), 1203-1213.

FREEMAN, L.C., 1979. Centrality in social networks conceptual clarification. Social Networks 1, 215-239.

GEELS, F. and Deuten, J., 2006. Aggregation activities. Local and global dynamics in technological development: a socio-cognitive perspective on knowledge flows and lessons from reinforced concrete, Science and Public Policy 33, 265-275.

GEELS, F., 2002. Technological transitions as evolutionary reconfiguration processes: a multi-level perspective and a case study. Research Policy 31, 1257-1274.

GEELS, F., 2005. Processes and patterns in transitions and system innovations: Refining the coevolutionary multi-level perspective. Technological Forecasting and Social Change 72, 681-696.

GEELS, F., Raven, R., 2006. Non-linearity and expectations in niche-development trajectories: ups and downs in Dutch biogas development (1973-2003). Technology Analysis \& Strategic Management $18,375-392$.

GEELS, F., Schot, J., 2007. Typology of sociotechnical transition pathways. Research Policy 36, 399417.

DINÂMIA'CET - IUL, Centro de Estudos sobre a Mudança Socioeconómica e o Território ISCTE-IUL - Av. das Forças Armadas, 1649-026 Lisboa, PORTUGAL 
GEELS, F.W., 2014, 'Regime resistance against low-carbon energy transitions: Introducing politics and power in the multi-level perspective', Theory, Culture \& Society, 31(5), 21-40.

GOSENS, J., Lu, Y., Coenen, L., 2015. The role of transnational dimensions in emerging economy 'Technological Innovation Systems' for clean-tech. Journal of Cleaner Production 86, 378-388.

HAAN, J., Rotmans, J., 2011. Patterns in transitions: Understanding complex chains of change. Technological Forecasting and Social Change 78: 90-102.

HAMAWI, S., Negro, S.O., 2012. Wave energy in Portugal, the paths towards a successful implementation, Proceedings of the 4th International Conference on Ocean Energy, 17-19 October 2012, Dublin, Ireland.

HANSEN, T. and Coenen, L., 2015. The geography of sustainability transitions: Review, synthesis and reflections on an emergent research field, Environmental Innovation and Societal Transitions 17: 92-109.

HEKKERT, M.P., Negro, S.O., 2009. Functions of innovation systems as a framework to understand sustainable technological change: Empirical evidence for earlier claims. Technological Forecasting and Social Change 76, 584-594.

HESS, M., 2004. 'Spatial relationships'? Towards a reconceptualization of embeddedness. Progress in Human Geography 28, 165-186.

HOOGMA, R., Kemp, R., Schot, J. \& Truffer, B., 2002. Experimenting for Sustainable Transport: The Approach of Strategic Niche Management. Spon Press, London and New York.

HOPPMANN, J., Peters, M., Schneider, M., Hoffmann, V.H., 2013. The two faces of market support-How deployment policies affect technological exploration and exploitation in the solar photovoltaic industry, Research Policy 42, 989-1003.

IRENA, 2014. Ocean Technologies - Technology readiness, patents, deployment status and outlook. International Renewable Energy Agency. [http://www.irena.org].

JACOBSSON, S., V. Lauber, 2006. The politics and policy of energy system transformation explaining the German diffusion of renewable energy technology. Energy Policy 34, 256-276.

DINÂMIA'CET - IUL, Centro de Estudos sobre a Mudança Socioeconómica e o Território ISCTE-IUL - Av. das Forças Armadas, 1649-026 Lisboa, PORTUGAL 
JEFFREY, H., Jay, B., Winskel, M., 2013. Accelerating the development of marine energy: Exploring the prospects, benefits and challenges. Technological Forecasting and Social Change 80, 1306-1316.

KEMP, R., Schot, J., Hoogma, R., 1998. Regime shifts to sustainability through processes of niche formation. The approach of strategic niche management. Technology Analysis and Strategic Management 10, 175-95.

KERN, F., Smith, A., 2008. Restructuring energy systems for sustainability? Energy transition policy in the Netherlands. Energy Policy 36, 4093-4103.

KONRAD, K., Markard, J., Ruef, A., Truffer, B., 2012. Strategic responses to fuel cell hype and disappointment. Technological Forecasting \& Social Change 79, 1084-1098.

LØVDAL, N., Neumann, F., 2011. Internationalization as a strategy to overcome industry barriers: An assessment of the marine energy industry. Energy Policy 39, 1093-1100.

MAGnANA, D., Tzimas, E., Hanmer, C., Badcock-Broe, A., MacGillivray, A., Jeffrey, H. and Raventos, A, 2014. SI-ocean strategic technology agenda for the ocean energy sector: From development to market, 11th International Conference on the European Energy Market (EEM), DOI: 10.1109/EEM.2014.6861284.

MARKARD, J. and Hekkert, M., 2013. Technological innovation systems and sectoral change: towards a TIS based transition framework. Proceedings of the International Sustainability Transitions Conference (IST), Zurich (pp. 19-21).

MARKARD, J., Truffer, B., 2008. Technological innovation systems and the multi-level perspective: towards an integrated framework. Research Policy 37, 596-615.

MAUTZ, R. (2007) The Expansion of Renewable Energies in Germany between Niche Dynamics and System Integration - Opportunities and Restraints, STI Studies 3, 113-131.

NEDEVA, M., 2013. Between the global and the national: Organising European science. Research Policy 42, 220-230.

NEMET, G.F., 2009. Demand-pull, technology-push, and government-led incentives for nonincremental technical change. Research Policy 38, 700-709.

NISSILA, H. (2015) Conferences as Sequential Arenas for Creating New Sustainable Fields. Industry and Innovation 22, 209-228.

DINÂMIA'CET - IUL, Centro de Estudos sobre a Mudança Socioeconómica e o Território ISCTE-IUL - Av. das Forças Armadas, 1649-026 Lisboa, PORTUGAL 
OES, 2002-2014. Annual Report of the Implementing Agreement on Ocean Energy Systems, Executive Committee of Ocean Energy Systems. [http://www.ocean-energy-systems.org/oes_reports/ annual_reports/].

ORECCA (2011) European Offshore Renewable Energy Roadmap, ORECCA Coordinated Action Project [http://www.orecca.eu/c/document_library/get_file?uuid=1e696618-9425-4265-aaffb15d72100862\&groupId=10129].

OTEO, 2014. Offshore Renewable Energy - Current Status and Future Perspectives for Portugal, Observatório Tecnológico para as Energias Offshore, Porto: INEGI.

QUITZOW, R., in print. Dynamics of a policy-driven market: The co-evolution of technological innovation systems for solar photovoltaics in China and Germany. Environmental Innovation and Societal Transitions. doi:10.1016/j.eist.2014.12.002.

RAVEN, R. and Geels, F., 2010. Socio-cognitive evolution in niche development: Comparative analysis of biogas development in Denmark and the Netherlands (1973-2004), Technovation 30, 8799.

RAVEN, R. Verbong, G., Schilpzand, W., Witkamp, M., 2011. Translation mechanisms in sociotechnical niches: a case study of Dutch river management. Technology Analysis \& Strategic Management 23, 1063-1078.

RAVEN, R., 2006. Towards alternative trajectories? Reconfigurations in the Dutch electricity regime. Research Policy 35, 581-595.

RAVEN, R., 2007. Niche accumulation and hybridisation strategies in transition processes: towards a sustainable energy system. Energy Policy 35, 2390-2400.

RAVEN, R., Schot, J., Berkhout, F., 2012. Space and scale in socio-technical transitions. Environmental Innovation and Societal Transitions 4, 63- 78.

REN21, 2010-2013. Renewables Global Status Report (GSR), Renewable Energy Policy Network for the $21^{\text {st }}$ Century. http://www.ren21.net/REN21Activities/GlobalStatusReport.aspx.

RICHTER, M. (2013) Business model innovation for sustainable energy: German utilities and renewable energy, Energy Polic, 62: 1226-1237.

DINÂMIA'CET - IUL, Centro de Estudos sobre a Mudança Socioeconómica e o Território ISCTE-IUL - Av. das Forças Armadas, 1649-026 Lisboa, PORTUGAL 
ROSENKOPF, L. and Almeida, P., 2003. Overcoming local search through alliances and mobility. Management Science 49, 751-766.

SANDÉN, B.A., Hillman, K.M., 2011. A framework for analysis of multi-mode interaction among technologies with examples from the history of alternative transport fuels in Sweden. Research Policy $40,403-414$.

SCHOT, J., Geels, F.W., 2007. Niches in evolutionary theories of technical change: A critical survey of the literature. Journal of Evolutionary Economics 17, 605-622.

SCHOT, J., Geels, F.W., 2008. Strategic niche management and sustainable innovation journeys: Theory, findings, research agenda, and policy. Technology Analysis \& Strategic Management 20, $537-554$.

SCHOT, J., Geels, F.W., 2008. Strategic niche management and sustainable innovation journeys: Theory, findings, research agenda, and policy. Technology Analysis \& Strategic Management 20, $537-554$.

SINE, W., David, R.J., 2003. Environmental jolts, institutional change, and the creation of entrepreneurial opportunity in the US electric power industry. Research Policy 32, 185-207.

SMINK, M., Hekkert, M., Negro, S., 2013. Keeping sustainable innovation on a leash. Exploring incumbents' institutional strategies. Business Strategy and the Environment 24, 86-101.

SMITH, A., 2007. Translating sustainabilities between green niches and socio-technical regimes. Technology Analysis \& Strategic Management 19, 427-450.

SMITH, A., Raven, B., 2012. What is protective space? Reconsidering niches in transitions to sustainability. Research Policy 41, 1025- 1036.

SMITH, A., Stirling, A., Berkhout, F., 2005. The governance of sustainable sociotechnical transitions. Research Policy 34, 1491-1510.

SOWFIA (2011) Mora-Figueria, V., Olivares, C., Holmes, B. Project Streamlining of Ocean Wave Farms Impact Assessment (SOWFIA), Deliverable D.2.1, Catalogue of Wave Energy Test Centres, http://sowfia.eu/fileadmin/sowfia_docs/documents/D2.1_Annex_Update_Sept_2012.pdf.

DINÂMIA'CET - IUL, Centro de Estudos sobre a Mudança Socioeconómica e o Território ISCTE-IUL - Av. das Forças Armadas, 1649-026 Lisboa, PORTUGAL 
SPATH, P., Rohracher, H., 2012. Local demonstrations for global transitions - Dynamics across governance levels fostering socio-technical regime change towards sustainability. European Planning Studies 20, 461-479.

TIRON, R., Mallon, F., Dias, F., Reynaud, E.G., 2015. The Challenging Life of Wave Energy Devices at Sea: A Few Points to Consider, Renewable and Sustainable Energy Reviews 43, 1263-1272.

VAN LENTE, H., Spitters, C. and Peine, A. (2013) Comparing technological hype cycles: Towards a theory, Technological Forecasting \& Social Change, 80: 1615-1628.

VAN LENTE, H., and Bakker, S., 2010. Competing expectations: The case of hydrogen storage technologies. Technology Analysis \& Strategic Management 22, 693-709.

VERBONG, G., Geels, F., 2010. Exploring sustainability transitions in the electricity sector with socio-technical pathways. Technological Forecasting \& Social Change 77, 1214-1221.

VERBONG, G., Geels, F., Raven, R., 2008. Multi-niche analysis of dynamics and policies in Dutch renewable energy innovation journeys (1970-2006). Technology Analysis \& Strategic Management 20, 555-573.

VERHEES, B., Raven, R., Veraart, F., Smith, A. and Kern, F., 2013. The development of solar PV in The Netherlands: A case of survival in unfriendly contexts. Renewable and Sustainable Energy Reviews, 19: 275-289.

WASSERMAN, S. and Faust, K., 1994. Social Network Analysis: Methods and Applications. Cambridge University Press, Cambridge.

WAVEC (2004) Potential and Strategy for the Development of Wave Energy in Portugal, Study for the Energy and Geology Directorate General, Lisboa: Wave Energy Centre.

WAVEC (2008) WAVEC'S 5 Years of Activities 2003-2008, Lisboa: Wave Energy Centre.

WIECZOREK, A.J., Raven, R., Berkhout, F., 205. Transnational linkages in sustainability experiments: A typology and the case of solar photovoltaic energy in India. Environmental Innovation and Societal Transitions. 17: 149-165.

DINÂMIA'CET - IUL, Centro de Estudos sobre a Mudança Socioeconómica e o Território ISCTE-IUL - Av. das Forças Armadas, 1649-026 Lisboa, PORTUGAL 


\section{Appendix}

\section{Appendix 1 - network analysis}

Characterisation of knowledge network in wave energy (European funded RTD projects) by period

\begin{tabular}{|c|c|c|c|c|c|c|}
\hline & $\begin{array}{c}\text { Period 2 } \\
1988-1993\end{array}$ & $\begin{array}{c}\text { Period } 3 \\
1994-1999\end{array}$ & $\begin{array}{c}\text { Period } 4 \\
2000-2005\end{array}$ & $\begin{array}{c}\text { Period } 5 \\
2006-2010\end{array}$ & $\begin{array}{c}\text { Period } 6 \\
2011-2014\end{array}$ \\
\hline \multicolumn{2}{|c|}{ Number of organisations } & 10 & 72 & 121 & 195 & 213 \\
\hline \multicolumn{2}{|c|}{ Number of ties } & 37 & 269 & 1481 & 2614 & 2435 \\
\hline \multirow{3}{*}{$\begin{array}{l}\text { Degree } \\
\text { centrality }\end{array}$} & Average & 0.206 & 1.672 & 8.817 & 16.656 & 15.106 \\
\hline & Maximum & 9 & 42 & 87 & 199 & 183 \\
\hline & Minimum & 1 & 2 & 1 & 1 & 2 \\
\hline
\end{tabular}


Oceans of energy? The non-linear trajectory of the emerging wave energy technology

APPENDIX 2 - ENERGY POLICIES WITH INFLUENCE IN THE DEVELOPMENT OF THE WAVE ENERGY NICHE

\begin{tabular}{|c|c|c|c|c|c|c|c|}
\hline & $1978-1987$ & $1988-1993$ & 1994-1999 & $2000-2005$ & 2006-2010 & 2011-2013 & 2014 onwards \\
\hline European FPs & FP1 & FP2; FP3 & FP4 & FP5; FP6 & FP7 & FP7 & $\mathrm{H} 2020$ \\
\hline $\begin{array}{l}\text { Policies target } \\
\text { wave energy }\end{array}$ & & $\begin{array}{l}1991 \text { - Included in } \\
\text { Joule Prog }\end{array}$ & & & $\begin{array}{l}2006 \text { - Promote creation European } \\
\text { association }\end{array}$ & $\begin{array}{l}2012 \text { - Programme Blue } \\
\text { Growh }\end{array}$ & $\begin{array}{l}2014 \text { - Blue Energy Action } \\
\text { Plan }\end{array}$ \\
\hline Portugal QCAs & & QCA I & QCA II & QCA III & QCA III; QREN & QREN & PT2020 \\
\hline \multirow{5}{*}{$\begin{array}{l}\text { PT Energy policies } \\
\text { for renewable } \\
\text { energies }\end{array}$} & \multirow[t]{5}{*}{$\begin{array}{l}1982 \text { - Fiscal } \\
\text { incentives to } \\
\text { RET }\end{array}$} & \multirow{5}{*}{$\begin{array}{l}\text { 1988 - Energy } \\
\text { market } \\
\text { liberalisation } \\
\text { 1988- Prog PEDIP - } \\
\text { SIURE: Incentive } \\
\text { System for Energy }\end{array}$} & \multirow[t]{5}{*}{$\begin{array}{l}1994- \\
\text { Programa } \\
\text { Operacional } \\
\text { Energia }\end{array}$} & $\begin{array}{l}2000 \text { - Prog POE; Measure for } \\
\text { Energy Infrastructures }\end{array}$ & \multirow{2}{*}{$\begin{array}{l}2006 \text { - Prog. PRIME: Measure } \\
\text { supporting renewable energy } \\
\text { production; } \\
2006 \text { - National Strategy for the } \\
\text { Sea: Includes renewable energies }\end{array}$} & $\begin{array}{l}2012 \text { - Suspension of } \\
\text { licensing for new projects } \\
\text { feeding electricity to grid }\end{array}$ & $\begin{array}{l}2014 \text { - Prog. POSEUR - } \\
\text { Support experimental } \\
\text { projects in "less exploited" } \\
\text { energy sources (inc. wave) }\end{array}$ \\
\hline & & & & $\begin{array}{l}2001 \text { - Prog POE - Measure } \\
\text { MAPE: Incentive System for } \\
\text { RET }\end{array}$ & & $\begin{array}{l}2013 \text { - Revised PNAER 2020: } \\
\text { reviews role of RET, in } \\
\text { particular "less competitive" } \\
\text { technologies as wave }\end{array}$ & $\begin{array}{l}2014 \text { - Revised National } \\
\text { Strategy for Sea \& Action } \\
\text { Plan Sea -Portugal: itly } \\
\text { includes wave energy }\end{array}$ \\
\hline & & & & $\begin{array}{l}2001 \text { - Prog E4 (Endogenous } \\
\text { Energies \& Energy Efficiency) } \\
\text { Policy objectives for RET; } \\
\text { Special tarifs; Energy targets } \\
\text { for } 2010\end{array}$ & $\begin{array}{l}2007 \text { - Regulates use public } \\
\text { maritime resources for production } \\
\text { of electricity based on wave } \\
\text { energy; }\end{array}$ & $\begin{array}{l}2013 \text { - Change tariff regime; } \\
\text { Reduce wave energy target }\end{array}$ & $\begin{array}{l}2014 \text { - National Strategy for } \\
\text { Smart Specialisation: } \\
\text { Endogenous Energy } \\
\text { Resources included in the } \\
\text { "Sea Economy" }\end{array}$ \\
\hline & & & & $\begin{array}{l}2003 \text { - Target for wave energy } \\
\text { in } 2010 \text { ( } 50 \mathrm{MW} \text { ) }\end{array}$ & $\begin{array}{l}2008 \text { - Revises wave energy target } \\
(250 \mathrm{MW}) \text {; Defines production } \\
\text { regime and sets-up feed-in tariff }\end{array}$ & $\begin{array}{l}2013 \text { - Pilot Zone extended to } \\
\text { other ocean technologies } \\
\text { (e.g. offshore wind) }\end{array}$ & $\begin{array}{l}2014 \text { - Power granting } \\
\text { tender of 50MW for } \\
\text { experimental projects of } \\
\text { ocean source (wave) or } \\
\text { location (offshore wind) }\end{array}$ \\
\hline & & & & $\begin{array}{l}2005 \text { - National Strategy for } \\
\text { Energy: reinforce RET and } \\
\text { associated industrial clusters }\end{array}$ & $\begin{array}{l}2008 \text { - Set-up and regulate Pilot } \\
\text { Zone; Concession Pilot Zone to } \\
\text { REN; (Concession formalized in } \\
\text { 2010) } \\
2010 \text { - National Strategy for Energy } \\
\text { 2020: reinforce investment in RET; } \\
\text { PNAER (National Action Plan for } \\
\text { Renewable Energies) - applies EU } \\
\text { directive } 2009 / 28 / C E\end{array}$ & & \\
\hline
\end{tabular}

FP - European Framework Programmes for Research and Technological Development.

QCA (Quadro Comunitário de Apoio) - Community Framework Programme for Portugal in which context National Support Programmes were set-up.

RET - Renewable Energy Technologies

Blue cells - Policies \& incentives with direct impact upon wave energy

DINÂMIA'CET - IUL, Centro de Estudos sobre a Mudança Socioeconómica e o Território

ISCTE-IUL - Av. das Forças Armadas, 1649-026 Lisboa, PORTUGAL

Tel. 210464031 - Extensão 293100 E-mail: dinamia@iscte.pt http://dinamiacet.iscte-iul.pt/ 